\title{
Nanoantioxidants: Pioneer Types, Advantages, Limitations, and Future Insights
}

\author{
Basma Omran ${ }^{1,2}$ and Kwang-Hyun Baek ${ }^{1, *}$ \\ 1 Department of Biotechnology, Yeungnam University, Gyeongsan 38541, Gyeongbuk, Korea; \\ obasma@ynu.ac.kr \\ 2 Department of Processes Design \& Development, Egyptian Petroleum Research Institute (EPRI), \\ Cairo 11727, Egypt \\ * Correspondence: khbaek@ynu.ac.kr; Tel.: +82-53-810-3029; Fax: +82-53-810-4769
}

check for updates

Citation: Omran, B.; Baek, K.-H. Nanoantioxidants: Pioneer Types, Advantages, Limitations, and Future Insights. Molecules 2021, 26, 7031. https://doi.org/10.3390/ molecules26227031

Academic Editor: Mariana

Emilia Ghica

Received: 6 October 2021

Accepted: 18 November 2021

Published: 21 November 2021

Publisher's Note: MDPI stays neutral with regard to jurisdictional claims in published maps and institutional affiliations.

Copyright: (C) 2021 by the authors. Licensee MDPI, Basel, Switzerland. This article is an open access article distributed under the terms and conditions of the Creative Commons Attribution (CC BY) license (https:// creativecommons.org/licenses/by/ $4.0 /)$.

\begin{abstract}
Free radicals are generated as byproducts of normal metabolic processes as well as due to exposure to several environmental pollutants. They are highly reactive species, causing cellular damage and are associated with a plethora of oxidative stress-related diseases and disorders. Antioxidants can control autoxidation by interfering with free radical propagation or inhibiting free radical formation, reducing oxidative stress, improving immune function, and increasing health longevity. Antioxidant functionalized metal nanoparticles, transition metal oxides, and nanocomposites have been identified as potent nanoantioxidants. They can be formulated in monometallic, bimetallic, and multi-metallic combinations via chemical and green synthesis techniques. The intrinsic antioxidant properties of nanomaterials are dependent on their tunable configuration, physico-chemical properties, crystallinity, surface charge, particle size, surface-to-volume ratio, and surface coating. Nanoantioxidants have several advantages over conventional antioxidants, involving increased bioavailability, controlled release, and targeted delivery to the site of action. This review emphasizes the most pioneering types of nanoantioxidants such as nanoceria, silica nanoparticles, polydopamine nanoparticles, and nanocomposite-, polysaccharide-, and protein-based nanoantioxidants. This review overviews the antioxidant potential of biologically synthesized nanomaterials, which have emerged as significant alternatives due to their biocompatibility and high stability. The promising nanoencapsulation nanosystems such as solid lipid nanoparticles, nanostructured lipid carriers, and liposome nanoparticles are highlighted. The advantages, limitations, and future insights of nanoantioxidant applications are discussed.
\end{abstract}

Keywords: oxidative stress; nanoantioxidants; nanotoxicity; nanoencapsulation

\section{Introduction}

Environmental pollution, climatic changes, and unhealthy lifestyles have increased the prevalence of serious and chronic diseases and age-related disorders [1]. Evidence from toxicological investigations on cultured cells and animal models has shown a strong and direct relationship between exposure to hazardous pollutants and generation of oxidative stress, leading to the development of a plethora of pathological diseases such as renal failure [2], atherosclerosis [3], diabetes [4], systemic inflammation [5], acute respiratory syndrome [6], asthma [7], Alzheimer's and Parkinson's disorders [8], certain types of cancer [9], and arthritis [10], etc. (Figure 1). In 1985, the concept of oxidative stress was formulated by Helmut Sies in the book entitled "Oxidative Stress" to describe the disruption of the balance between antioxidative defenses and oxidant molecules [11]. The imbalance between oxidants and the cellular defensive antioxidants triggers oxidative stress. In 1956, the term 'reactive species" was coined to refer to oxidizing radicals [12]. 
(a)
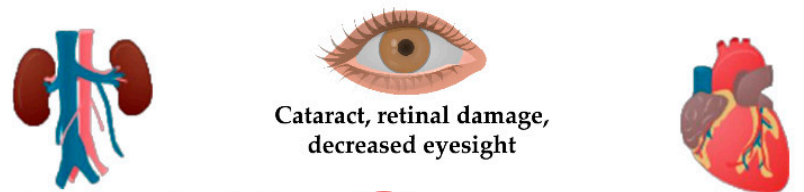

Renal dysfunction, glomerulonephritis, decreased cortisol

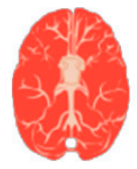

Migraine, fatigue, autism, anxiety, depression, Alzheimer's and Parkinson's diseases, trauma

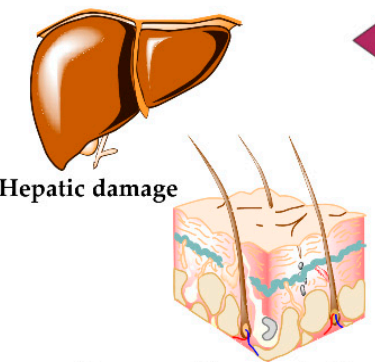

Rheumatoid and arthritis, gout dermatitis, burns, psoriasis

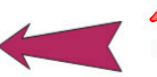

Gov
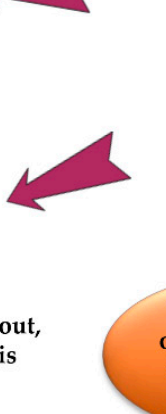
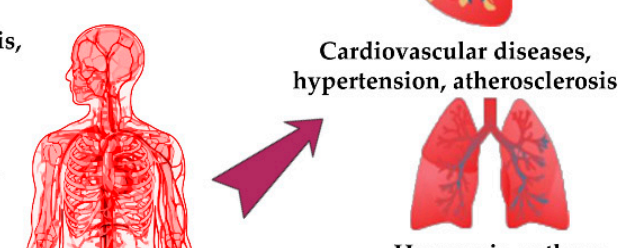

Hyperoxia, asthma, increased risk of allergy

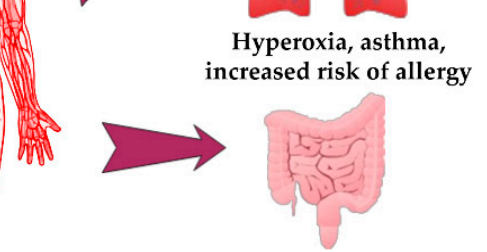

Gastric ulcers and cancer, dyspepsia,

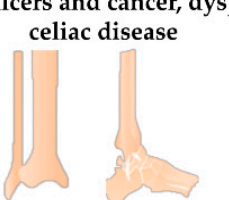

Ache in joints and muscles rheumatoid, osteoarthritis
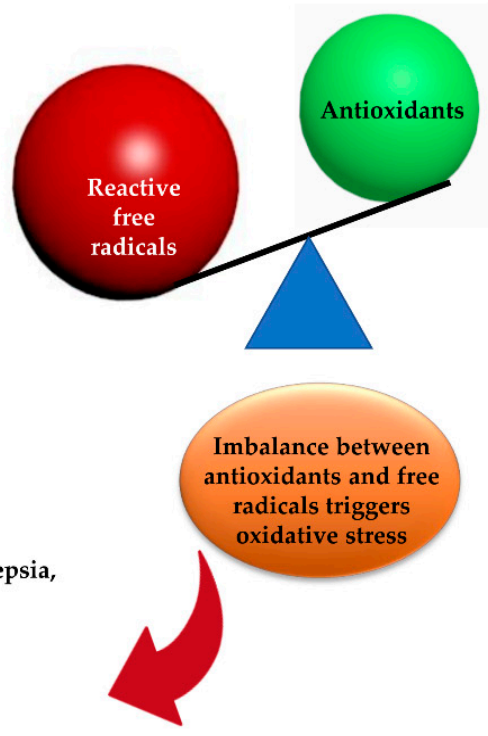

(b)

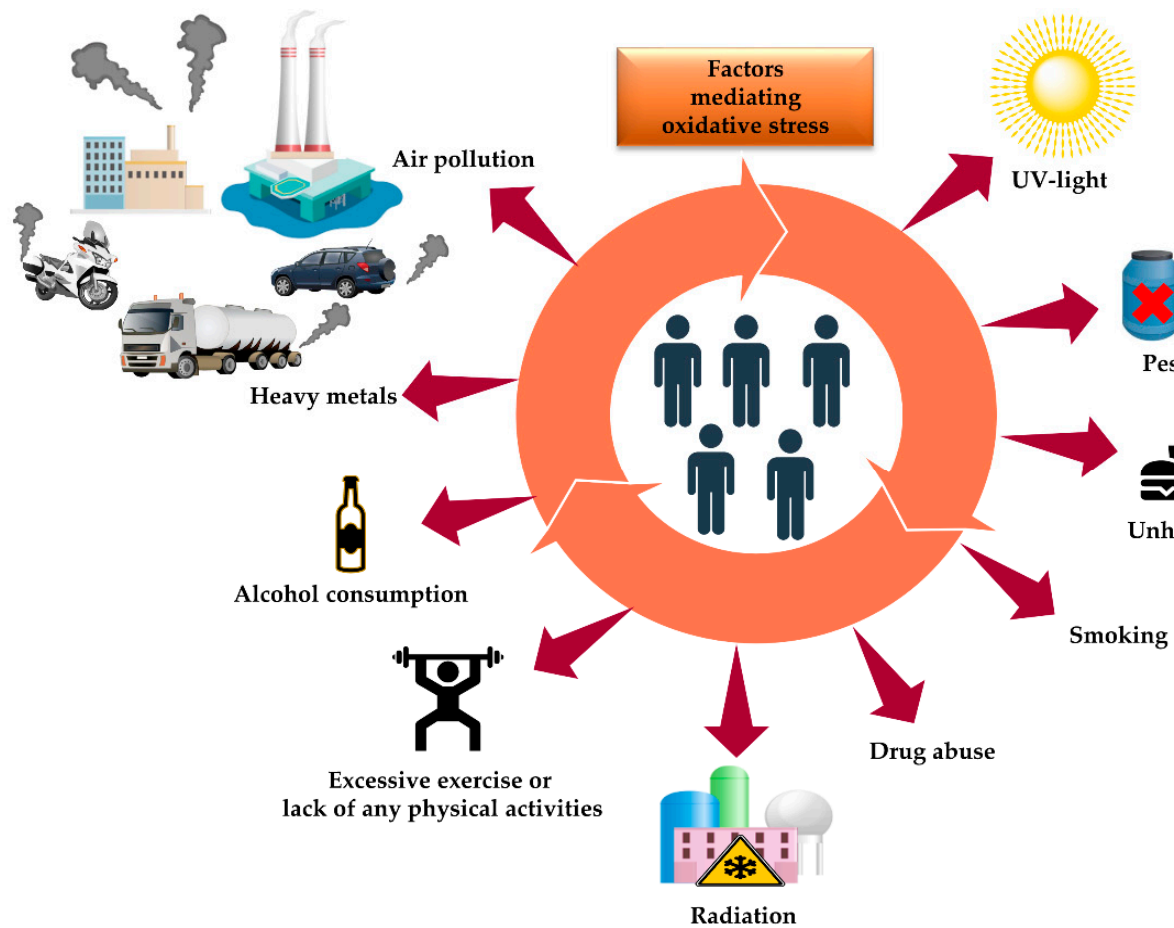

Figure 1. Exposure to different toxic chemicals triggers oxidative stress progression (a) and the incidence of oxidative stress in the human body is accompanied by a plethora of pathological diseases and disorders that cause damage to the heart, lungs, intestine, joints, muscles, skin, liver, brain, kidneys, eyes, and immune system (b).

The reaction of antioxidants with free radicals is governed by various mechanisms, involving hydrogen atom transfer (HAT), single electron transfer (SET), and proton-coupled electron transfer mechanisms [13,14]. The HAT mechanism is based on the ability of antioxidants to quench free radicals by detaching a phenolic hydrogen atom from the antioxidant via homolytic cleavage of the $\mathrm{O}-\mathrm{H}$ bond to the free radical, producing a stable product [15]. 
In this mechanism, the antioxidant is converted into a radical, which is significantly more stable than the original free radical, and as a result, inhibiting the overall oxidation processes [16]. The bond dissociation enthalpy (BDE), a numerical parameter related to HAT, is an essential parameter to evaluate the antioxidant activity in this mechanism [17]. Generally, the lower the BDE of the H-donating group of the antioxidant, the easier it is to inactivate free radicals, and thus the high is the antioxidant activity of a compound [18]. Examples of HAT-based assays are the oxygen radical absorption capacity (ORAC), total peroxyl radical trapping antioxidant parameter (TRAP), and total oxyradical scavenging capacity (TOSC) assays [19].

The SET mechanism is based on the transfer of a single electron from the antioxidant to the free radical. The antioxidant molecule is converted to an intermediate radical cation that is less reactive than the original free radical [20]. In the SET mechanism, the ionization potential (IP) of the reactive functional group of the antioxidant is the most significant parameter for determining its antioxidant activity. Examples of SET-based assays involve cupric reducing antioxidant capacity (CUPRAC), the Folin-Ciocalteu (FC), and the ferric reduction of antioxidant power (FRAP) [19]. SET can be subdivided into single-electron transfer followed by a proton transfer (SET-PT) and sequential proton loss electron transfer (SPLET) [21,22]. In the SET-PT mechanism, an electron is first transferred from the phenolic $\mathrm{OH}$ to the radical and the phenolic $\mathrm{OH}$ becomes a phenoxy radical cation $\left(\mathrm{PhOH}^{\bullet+}\right)$, which deprotonates during the second step, resulting in the formation of a phenoxy radical $\left(\mathrm{PhO}^{\bullet}\right)$ [23]. In the SET-PT mechanism, the radical transfer (i.e., first stage) is measured as the ionization potential (IP) and the deprotonation (i.e., second stage) corresponds to the proton dissociation enthalpy (PDE). The SPLET mechanism was first proposed by Litwinienko and Ingold [24-26]. This mechanism proceeds via two stages, involving (i) deprotonation of $\mathrm{PhOH}$ and formation of a phenoxide ion $\left(\mathrm{PhO}^{-}\right)$and (ii) transfer of an electron from $\mathrm{PhO}^{-}$ion to the radical, leading to the formation of $\mathrm{PhO}^{\bullet}[27,28]$. The enthalpies of the first and second stages in the SPLET mechanism are denoted as proton affinity and electron transfer enthalpy, respectively. The aforementioned mechanisms are dependent on radical and solvent properties [29].

Proton-coupled electron transfer (PCET) is a more complex mechanism by which an electron and a proton are transferred and their coupling has significant thermodynamic and kinetic impacts on the process [30]. In the PCET mechanism, the transfer of an electron and a proton can be sequential or concerted. In the PCET sequential transfer mechanism, the electron can be transferred first and this process is designated as electron transfer-proton transfer (ETPT). On the other hand, when the proton is transferred first, the process is referred to as proton transfer-electron transfer (PT-ET). In the concerted PCET mechanism, the electron and the proton are transferred simultaneously [31].

Reactive oxygen species (ROS) include radical species such as hydroxyl radical $\left({ }^{\bullet} \mathrm{OH}\right)$ and superoxide anion radical $\left(\mathrm{O}_{2}{ }^{\bullet-}\right)$, while singlet oxygen $\left({ }^{1} \mathrm{O}_{2}\right)$, hydrogen peroxide $\left(\mathrm{H}_{2} \mathrm{O}_{2}\right)$, ozone $\left(\mathrm{O}_{3}\right)$, lipid peroxide $(\mathrm{LOOH})$, and hypochlorous acid $(\mathrm{HOCl})$ represent the non-radical forms of ROS [32]. Reactive nitrogen species (RNS) include nitric oxide $\left({ }^{\bullet} \mathrm{NO}\right)$, peroxynitrite $\left(\mathrm{ONO}_{2}{ }^{-}\right)$, nitrous oxide $\left(\mathrm{N}_{2} \mathrm{O}\right)$, nitrogen dioxide $\left(\mathrm{NO}^{\bullet}{ }_{2}\right)$, peroxynitrous acid $\left(\mathrm{HNO}_{3}\right)$, and nitroxyl anion $\left(\mathrm{NO}^{-}\right)$radicals [33]. Reactive oxygen and nitrogen species (RONS) are spontaneously produced by endogenous metabolic pathways, for instance the electron transport chain (ETC) or by enzymes like xanthine oxidase and nitric oxide synthase. However, excessive exposure to some exogenous factors such as ionizing radiation, heavy metals, and UV radiation also trigger the generation of excessive levels of RONS [34]. Under homeostatic conditions, the thresholds of RONS are tightly controlled at a systemic level to fine-tune multiple physiological processes, including autophagy, immune and mitogen induction, muscle contraction, enzymatic activities, and cell signal transduction pathways [35]. Nevertheless, the sustained increase of free radical levels (e.g., ROS and/or RNS) suppresses the natural body defense mechanisms, causing significant damage to biological macromolecules, leading to aberrant protein expression, lipid peroxidation, 
oxidative DNA disruption, red blood cell degradation, enzyme inactivation, and vascular and nerve impairment, hence affecting normal cellular functions [36].

Human cells possess cellular mechanisms devoted to the establishment of redox homeostasis. The disruption of this homeostasis has substantial pathophysiological implications [37]. In human cells, endogenous enzymatic and non-enzymatic defense mechanisms counteract the disruption triggered by oxidative stress and help maintain appropriate levels of RONS [38]. The enzymatic defenses involve catalases (CAT), superoxide dismutases (SOD), and glutathione peroxidases (GSH-Px), whereas the non-enzymatic defenses involve glutathione, uric and lipoic acids, thioredoxin, bilirubin, and ubiquinone [39]. These enzymatic and non-enzymatic molecules have a crucial role in maintaining adequate levels of RONS. Generally, the activity of antioxidants takes place via two basic pathways, either by scavenging RONS or by inhibiting the synthesis of RONS. In certain cases, antioxidants particularly, enzymatic compounds, exhibit antioxidant capacity via the simple degradation of RONS to less damaging intermediates [40]. Exogenous natural antioxidants such as vitamins, carotenoids, polyphenolic compounds, curcumin, and metabolic sensitizers, which are derived from fruits, vegetables, and their byproducts have displayed a high potential to scavenge and combat the exacerbated levels of free radicals [41]. However, natural antioxidants can be degraded prior to delivery to target sites and their biodistribution is restricted by low absorption [42]. Some synthetic antioxidants such as butylated hydroxyanisole, hydroxytoluene, and gallic acid esters have exhibited antioxidant potency; however, adverse health effects limit their use [41].

Nanotechnology has opened up new horizons to explore creative solutions for the treatment of oxidative stress-related disorders. Progress in nanotechnology has revolutionized the potential use of a number of nanomaterials as effective nanoantioxidants [43-46]. Nevertheless, the antioxidant capacity of these nanostructures varies according to their chemical configuration, nature, surface charge, crystallinity, particle size, and surface coating [47]. Recently, engineered nanoparticles (NPs) and nanocomposites have been considered as nouveau tools for the development of innovative nanoantioxidants with enhanced properties for health longevity. The integration of nanoscience with biomedicine for the development of nanoantioxidant therapy has witnessed a significant breakthrough, leading to major progress in the pharmaceutical and biotechnological industries [48]. Indeed, nanoscience has provided promising solutions to address the challenges associated with conventional antioxidant compounds and to enable the development of pioneering classes of nanoantioxidants [49]. More interestingly, many categories of nanoantioxidants have potent radical scavenging and quenching capacities that have shown greater antioxidative sturdiness and more resistance to severe microenvironments than natural antioxidants. Nanoantioxidants improve the pharmacokinetics of natural antioxidant molecules by preventing their rapid degradation under stress conditions either through nanoencapsulation or nanodelivery [50]. Although antioxidant-functionalized nanostructures have displayed tremendous potential in animal experiments, clinical studies in humans remain elusive.

Reviews describing nanoantioxidant types and diverse applications can be found in the recent scientific literature [51-55]. The presented 3D pie chart illustrates the number of published original scientific literature under the keywords "nanoantioxidants", "antioxidant nanomaterials", and "nanomaterials and antioxidant activity" in the last ten years (Figure 2). This review covers the literature published over the last ten years by providing a discussion of the most pioneering nanoantioxidant types, such as ceria NPs, silica NPs, polydopamine NPs, carbohydrate-and protein-based NPs, and nanocomposite-based nanoantioxidants. The promising antioxidant role of biologically synthesized nanomaterials as alternative candidates is also overviewed. Solid lipid NPs, nanostructured lipid carriers, and liposome NPs are overviewed as efficient nanoencapsulation nanosystems. The toxicity concerns of nanoantioxidant applications are emphasized. The advantages, limitations, and future perspectives of nanoantioxidant applications are proposed. 


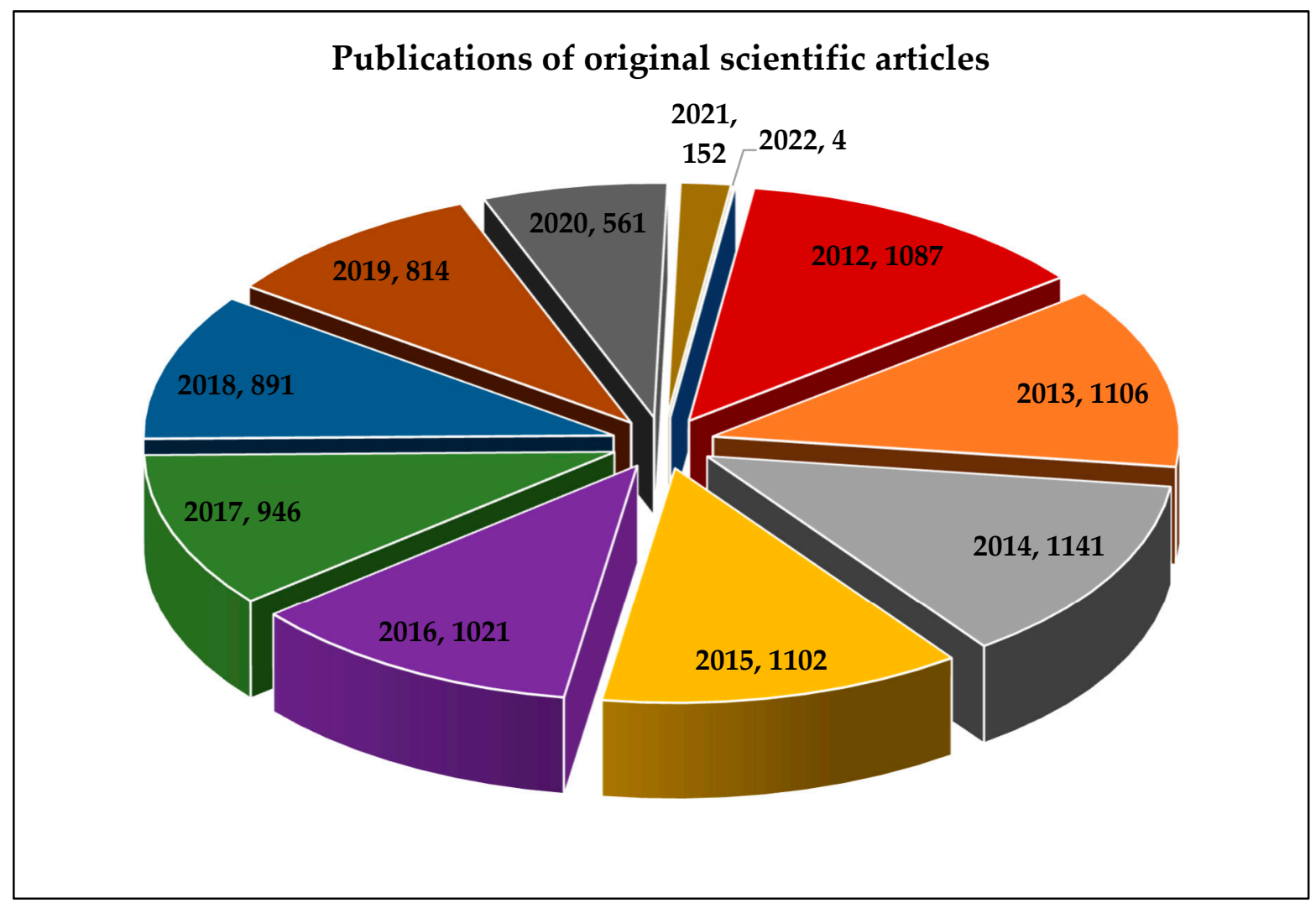

Figure 2. Published original scientific articles under the keywords "nanoantioxidants", "antioxidant nanomaterials", and "nanomaterials and antioxidant activity" (based on a SciFinder search; duplicates removed, November 2021).

\section{Pioneer Types of Nanoantioxidants}

Antioxidants are molecules that can counteract the action of reactive species and inhibit the subsequent chain reactions before essential biological macromolecules are damaged and cellular processes are disrupted. For a compound to be an antioxidant, it should be capable of forming new intermediates that are non-reactive and quite stable when exposed to further oxidation [56]. Antioxidants are divided into two main classes, including (i) radical-trapping antioxidants, also referred to as chain-breaking antioxidants, which capture chain-carrying radicals and hence cause the breaking of the oxidation chain and (ii) preventive antioxidants, which reduce the rate of radical chains [57]. The antioxidant mode of action involves (i) combating reactive radicals that induce peroxidation, (ii) preventing the generation of reactive radicals and decomposition of peroxides by metal ion chelation, (iii) scavenging $\mathrm{O}_{2}{ }^{\bullet-}$ to inhibit peroxide production, (iv) interrupting autooxidative reactions, and/or (v) minimizing localized $\mathrm{O}_{2}$ concentrations [58].

Currently, nanotechnology is growing rapidly in all scientific disciplines. The convergence of nanotechnology with other scientific fields such as biomaterial science, molecular biology, and medicine has contributed to the expansion and progress of nanomedicine. Nanotechnology enables the synthesis and manipulation of nanometer-scale materials, resulting in the development of novel nanomaterials for therapeutic and diagnostic applications in biological systems. NPs are the building blocks of nanoscience and have outstanding properties such as a high surface-area-to-volume ratio [59]. The high crystalline surface area provides NPs with superb mechanical, optical, magnetic, catalytic, and optical properties, thus increasing their potential pharmacological and biomedical applications [60]. Nanoantioxidants are nanomaterials that can slow the overall rate of autoxidation by trapping chain-carrying radicals or reducing initiation processes [61]. The term nanoantioxidant (artificial antioxidants) was proposed by Sharpe et al. [40]. These artificial antioxidants can be engineered at the nanoscale level, depending on the chemical 
composition, surface charge, surface-to-volume ratio, and surface coating of the NPs [40]. Antioxidants were defined by Halliwell as "any substance that can significantly delay or prevent oxidation of an oxidizable substrate, when present at low concentrations compared to those of that substrate" [56]. Numerous approaches have been established for the synthesis of nanoantioxidants. The most common techniques applied for the preparation of nanoantioxidants are summarized in Table 1 . The antioxidant potential of nanoantioxidants can be ascribed to their tunable catalytic and redox properties and the capacity to oscillate between different oxidation states [51] (Figure 3).

Table 1. The most common methods applied for the preparation of nanoantioxidants.

\begin{tabular}{cccc}
\hline Preparation Techniques & Suitable Materials & Advantages & References \\
\hline Templating & Mesoporous materials & $\begin{array}{c}\text { Easy operation, precise control over } \\
\text { particle size, shape, and structure, less } \\
\text { sensitive to operating conditions }\end{array}$ & Mild operating conditions \\
\hline Supercritical fluid & $\begin{array}{c}\text { Temperature-sensitive } \\
\text { materials }\end{array}$ & $\begin{array}{c}\text { Rapid, mild operating conditions, } \\
\text { economical, no toxic solvents }\end{array}$ \\
\hline $\begin{array}{c}\text { Emulsion/solvent } \\
\text { evaporation }\end{array}$ & Polymeric materials & $\begin{array}{c}\text { Lipophilic, polymeric, and } \\
\text { bioactive materials } \\
\text { polvent displacement } \\
\text { (Nanoprecipitation) }\end{array}$ & $\begin{array}{c}\text { Folymeric NPs, nanospheres, and } \\
\text { nanocapsules }\end{array}$ \\
\hline [54]
\end{tabular}

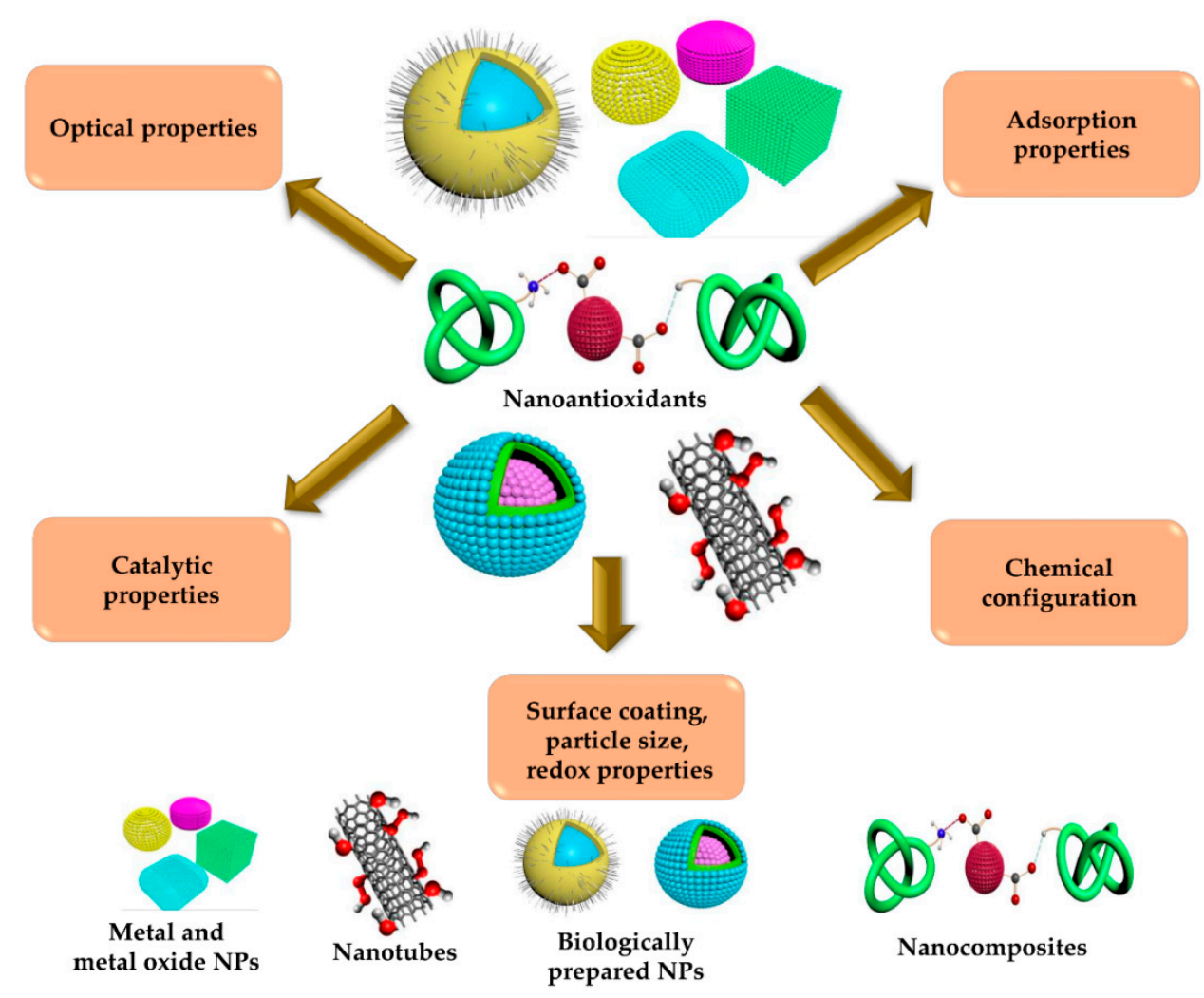

Figure 3. Antioxidant activity of nanomaterials is dependent on their unique properties.

Nanoantioxidant biomedical applications have significantly advanced the biotechnological and pharmaceutical industries, with remarkable progress in the field of antioxidant therapy [64]. Nanoantioxidants have shown promising results to address the challenges associated with conventional antioxidants and have enabled the development of an innovative class of antioxidants [49]. They exhibit high antioxidative potential and high tolerance 
to harsh microenvironments. The potential use of nanoantioxidants has been reported for several biomedical applications, such as treatment of autoimmune and metabolic diseases [65,66], wound healing [67], tumor therapy [48], drug delivery [68], gene delivery [69], theranostics [70] (Figure 4). The subsections that follow describe the most common and pioneer types of nanoantioxidants based on the previously published literature.

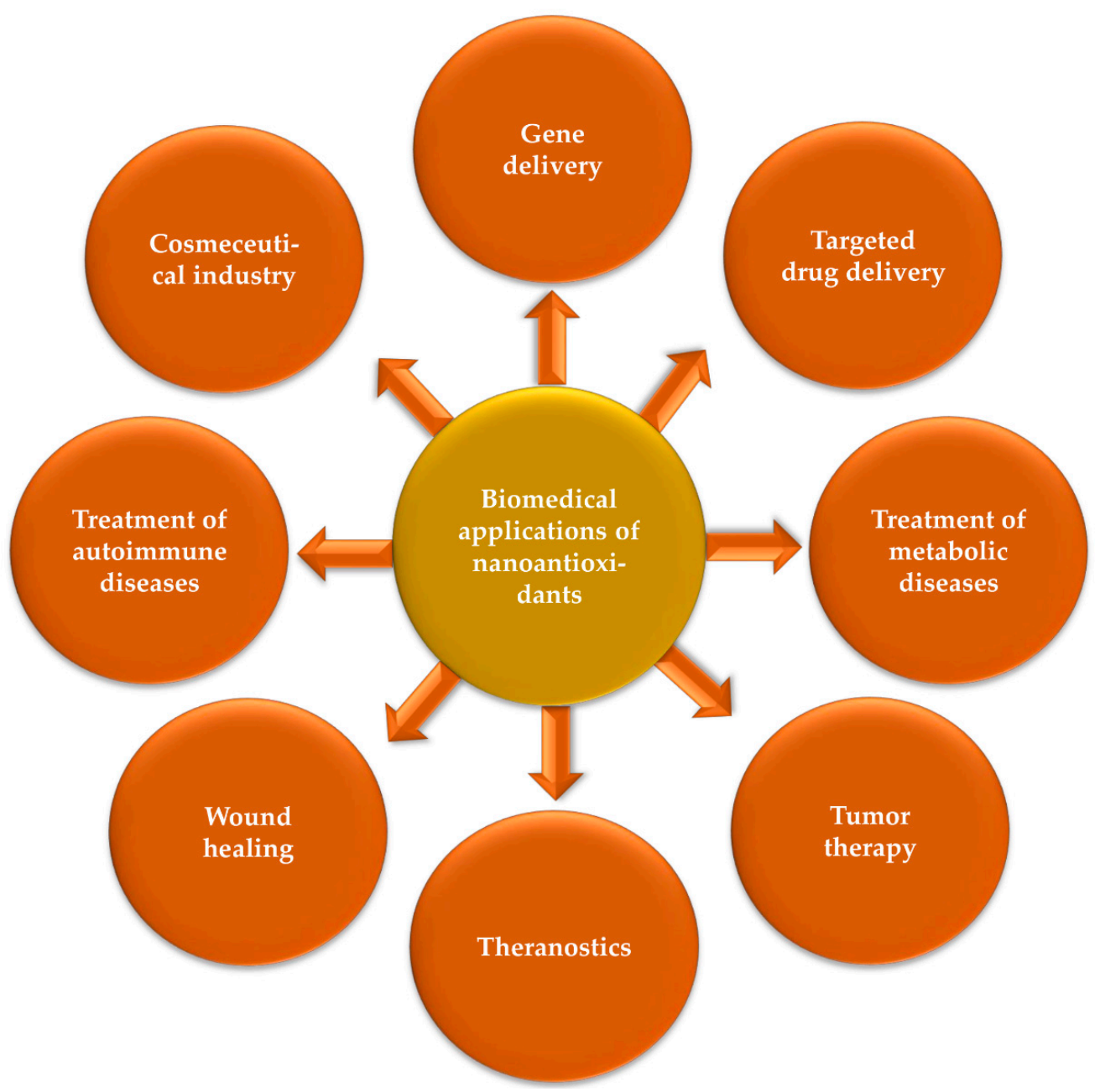

Figure 4. A schematic representation of some of the biomedical applications of nanoantioxidants.

\subsection{Metal Oxide-Based Nanoantioxidants}

Metal oxide NPs are highly reactive particles due to the presence of atoms with unpaired valence electrons located on the NP surface [71]. As a result of the unique characteristics of NPs, their clinical application has significant advantages as compared to conventional treatment therapies, which have several side effects and reduced efficiency at target sites. Metal oxide NPs have been studied for a variety of biomedical applications, involving antioxidant and antimicrobial applications, bioimaging, drug delivery, and biosensing [72].

\subsubsection{Nanoceria or Cerium Oxide-Based Nanoantioxidants}

Several synthesis techniques have been reported for the chemical fabrication of cerium oxide NPs $\left(\mathrm{CeO}_{2} \mathrm{NPs}\right)$ or nanoceria including chemical precipitation [71], coprecipitation [73], sonochemical [74], sol-gel [75], microwave [76], hydrothermal [77], and microwave-assisted hydrothermal [78] techniques. $\mathrm{CeO}_{2} \mathrm{NPs}$ are one of the most intriguing metal oxide NPs, which have been widely employed for nanomedical and nano pharmaceutical research fields. Numerous studies have shown that $\mathrm{CeO}_{2} \mathrm{NPs}_{\text {s }}$ ave the potential to suppress oxidative stress-related diseases such as Alzheimer's disease [79,80], cardiomy- 
opathy [81], and cancer [82]. Free radicals play a dual role in living cells, having either beneficial or toxic effects. At low/moderate levels, free radicals have several physiological activities, involving immune function, cellular signaling pathways, mitogenic responses, redox signaling, and growth regulation [83]. However, high levels of ROS/RNS can cause oxidative stress and nitrosative stress, respectively, causing significant damage to cellular biomolecules [84]. The ability of $\mathrm{CeO}_{2} \mathrm{NPs}$ to scavenge free radicals is attributed to their superior optical and catalytic properties and their potential to switch the oxidation states (e.g., $\mathrm{Ce}^{3+}$ and $\mathrm{Ce}^{4+}$ ) [85] (Equations (1)-(3)) (Figure 5).

$$
\begin{gathered}
\text { SOD mimic activity } \mathrm{Ce}^{4+}+\mathrm{O}_{2}^{\bullet-} \rightarrow \mathrm{Ce}^{3+}+\mathrm{O}_{2} \\
\mathrm{Ce}^{3+}+\mathrm{O}_{2}^{\bullet-}+2 \mathrm{H}^{+} \rightarrow \mathrm{Ce}^{4+}+\mathrm{H}_{2} \mathrm{O}_{2} \\
\text { CAT mimic activity } \mathrm{H}_{2} \mathrm{O}_{2} \rightarrow \mathrm{Ce}^{3+}+2 \mathrm{H}^{+} \rightarrow \mathrm{Ce}^{4+}+2 \mathrm{H}_{2} \mathrm{O}
\end{gathered}
$$

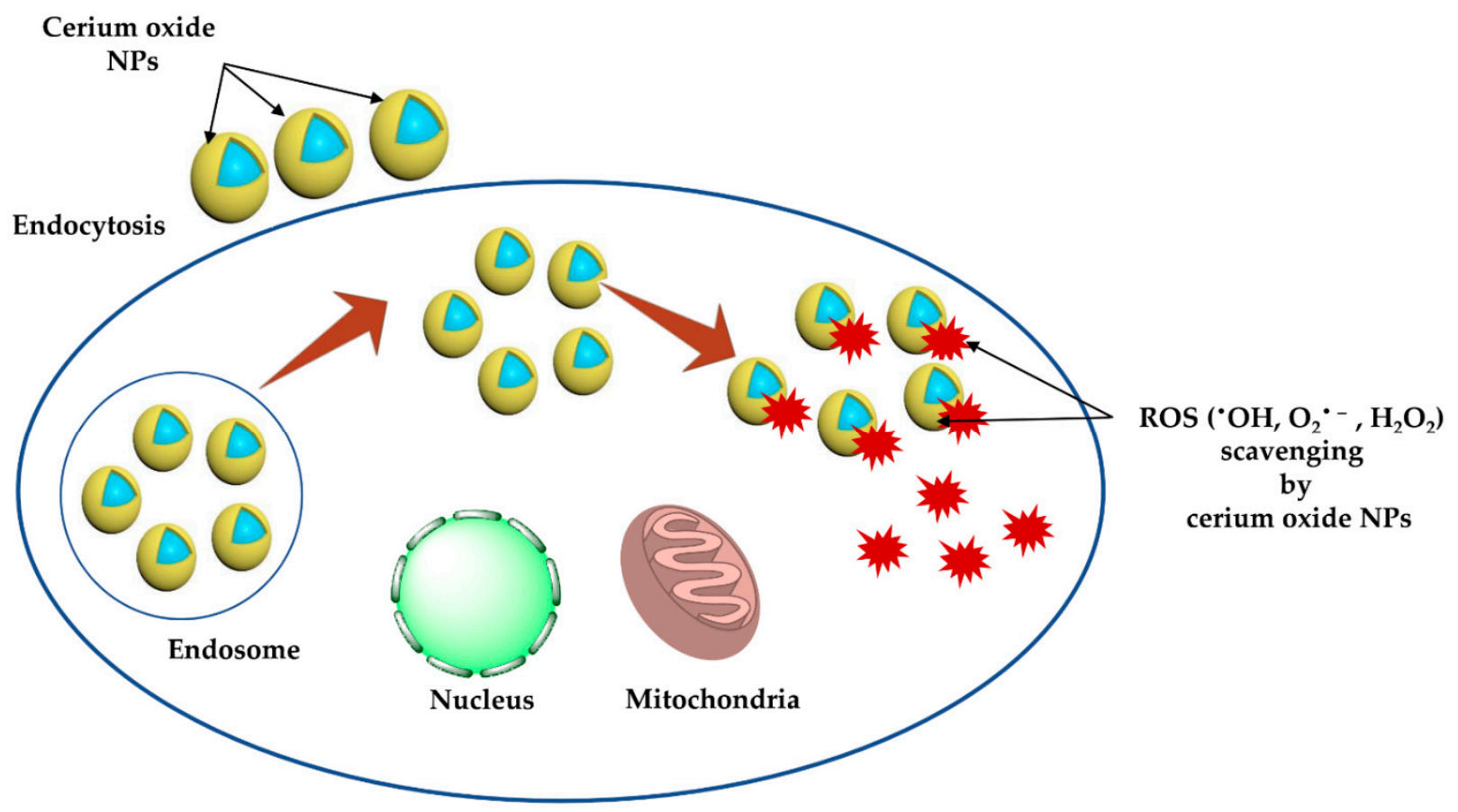

Normal cell

Figure 5. Antioxidant effect of cerium oxide NPs in normal cell under physiological $\mathrm{pH}$ via endocytosis and then scavenging ROS, such as ${ }^{\bullet} \mathrm{OH}, \mathrm{O}_{2}{ }^{\bullet-}$, and $\mathrm{H}_{2} \mathrm{O}_{2}$ as a result of SOD mimetic activity, by which $\mathrm{O}_{2}{ }^{\bullet-}$ is reduced to $\mathrm{H}_{2} \mathrm{O}_{2}$ and CAT activity by which $\mathrm{H}_{2} \mathrm{O}_{2}$ is further degraded into $\mathrm{H}_{2} \mathrm{O}$, and hence providing protection to normal cells.

However, $\mathrm{CeO}_{2} \mathrm{NPs}$ are poorly soluble in water, posing several challenges when it comes to biological applications. As a result, several studies reported that $\mathrm{CeO}_{2} \mathrm{NPs}$ could be well-dispersed in aqueous solutions when coated with dextran [86], polyethylene glycol (PEG) [87], and polyacrylic acid [88] to improve their stability, biocompatibility, and water solubility. Impregnation of nanoceria in polymeric matrices such as three dimensional (3D) scaffolds or polymer coatings is a promising option for increasing biocompatibility, but it may result in a reduction in therapeutic effects [89]. For instance, fructans are poly-fructose molecules that are made up of fructose-linked polymers, involving levan and inulin. Levan is a $\beta-2,6$-conjugated fructose polymer. By applying a one-pot co-precipitation technique, $\mathrm{CeO}_{2} \mathrm{NPs}$ were conjugated with levan that acted as a reductant and a stabilizing agent [90]. Coating $\mathrm{CeO}_{2} \mathrm{NPs}$ with levan boosted its antioxidant potential. Additionally, ROS levels were reduced in $\mathrm{H}_{2} \mathrm{O}_{2}$-induced NIH3T3 cells after treatment with levan-coated $\mathrm{CeO}_{2} \mathrm{NPs}$, which could be useful in the treatment of ROS-mediated diseases. Using 3D printing strategies may also be advantageous for the proper design of structures containing 
nanoceria to fine-tune their release for better therapeutic effects [89]. Entrapment within an encapsulation hydrogel was reported as a strategy to reduce the cytotoxicity of $\mathrm{CeO}_{2}$ NPs. This delivery strategy allows particles to be targeted at the site of interest, reducing phagocytosis while retaining their catalytic potential. A nanocomposite was engineered by the incorporation of $\mathrm{CeO}_{2} \mathrm{NPs}$ within an encapsulating alginate microbead hydrogel [91]. The as-prepared nanocomposite provided high antioxidant potential and cryoprotection to beta cells against $\mathrm{O}_{2}{ }^{\bullet-}$ attacks without cytotoxic effects up to $10 \mathrm{mM}$ of encapsulated $\mathrm{CeO}_{2}$ NPs. In contrast, phagocytosis of beta cells occurred even at concentrations as low as $1 \mathrm{mM}$ of non-encapsulated $\mathrm{CeO}_{2} \mathrm{NPs}$.

Several factors affect the antioxidant potential of nanoantioxidants, such as size, shape, surface charge, agglomeration, coating, and dissolution [92]. The effect of shape and agglomeration on the antioxidant activity of $\mathrm{CeO}_{2}$ NPs-modified with AuNPs was studied [93]. $\mathrm{Au} / \mathrm{CeO}_{2} \mathrm{NPs}$ were prepared by hydrothermal technique and three morphological structures of $\mathrm{Au} / \mathrm{CeO}_{2} \mathrm{NPs}$ were obtained (i.e., NPs, nanocubes, and nanorods). At low concentrations, the antioxidant capacity of $\mathrm{Au} / \mathrm{CeO}_{2}$ nanorods and NPs was enhanced, while that of $\mathrm{Au} / \mathrm{CeO}_{2}$ nanocubes was reduced. On the other hand, at high concentrations, a reduction in the antioxidant activity of $\mathrm{Au} / \mathrm{CeO}_{2}$ nanorods and NPs was observed, while that of $\mathrm{Au} / \mathrm{CeO}_{2}$ nanocubes was improved. This could be attributed to the severe agglomeration of $\mathrm{Au} / \mathrm{CeO}_{2}$ nanorods and NPs at high concentrations, which covered the active sites and reduced the antioxidant activity when compared to $\mathrm{Au} / \mathrm{CeO}_{2}$ nanocubes, which exhibited less aggregation. The behavior of nanocubes was contradictory to that of the NPs and nanorods, which could be attributed to the $\left(\begin{array}{lll}1 & 0 & 0\end{array}\right)$ crystal planes, which might have had an impact on the transfer of electrons at the interface.

\subsubsection{Other Metal Oxide-Based Nanoantioxidants}

Coating or surface functionalization of iron oxide (IO) NPs boosts their antioxidant potential [54]. Gallic acid-functionalized $\mathrm{Fe}_{3} \mathrm{O}_{4} \mathrm{NPs}$ with average sizes of 5 and $8 \mathrm{~nm}$ had 2- to 4-folds lower half maximal inhibitory concentration $\left(\mathrm{IC}_{50}\right)$ values than the nonfunctionalized $\mathrm{Fe}_{3} \mathrm{O}_{4} \mathrm{NPs}$ using the 1, 1-diphenyl-1-picrylhydrazyl (DPPH) scavenging assay [47]. The free radical scavenging activity was due to the reaction of gallic acid with DPPH-radicals. FTIR clearly demonstrated the disappearance of the hydroxyl groups of gallic acid. In another study, under physiological conditions, monocrystalline and orthorhombic forms of vanadia $\left(\mathrm{V}_{2} \mathrm{O}_{5}\right)$ nanowires with a size of $\sim 100 \mathrm{~nm}$ exhibited significant antioxidant potential by mimicking the antioxidant behavior of the antioxidant enzyme GPx [94]. Although the bulk form of $\mathrm{V}_{2} \mathrm{O}_{5}$ is known for its cellular toxicity, this can be dramatically altered when it is reduced to the nanoscale dimensions. Furthermore, the biocompatibility of $\mathrm{V}_{2} \mathrm{O}_{5}$ nanowires may inspire its therapeutic potential for the prevention of oxidative stress-related diseases. Another study showed that $20 \mathrm{~nm}$-sized molybdenum trioxide $\left(\mathrm{MoO}_{3}\right) \mathrm{NPs}$ had an intrinsic biomimetic sulfite oxidase potential, allowing for the conversion of sulfite to sulfate and thus had a significant role in the detoxification processes [95]. $\mathrm{MoO}_{3}$ NPs were surface-functionalized with dopamine as an anchor group and triphenylphosphonium ion as a targeting agent. Lutetium oxide NPs $\left(\mathrm{Lu}_{2} \mathrm{O}_{3} \mathrm{NPs}\right)$ were synthesized via the sol-gel technique and doped with europium $\left(\mathrm{Eu}^{3+}\right)$ [96]. The antiradical activity of $\mathrm{Lu}_{2} \mathrm{O}_{3} \mathrm{NPs}$-doped with $\mathrm{Eu}^{3+}$ ions remarkably reached $86 \%$ as determined by the 2, 2'-azino-bis-3-ethylbenzothiazoline-6-sulfonic acid (ABTS) assay. In another report, copper oxide NPs (CuO NPs) were synthesized using the co-precipitation technique and were coated with PEG and polyvinyl-pyrrolidone (PVP) by simple adsorption [97]. Interestingly, the antioxidant potential of the coated $\mathrm{CuO}$ NPs (i.e., CuO-PEG and CuO-PVP NPs) was higher than that of the uncoated particles. Similar behavior was noticed with that of $\mathrm{ZnO}$ NPs that were capped with PEG and PVP [98]. The high antioxidant potency could be attributed to the presence of ester linkages and carbonyl groups in both PEG and PVP [99]. 


\subsection{Mesoporous Silica or Silicon Dioxide-Based Nanoantioxidants}

According to the Woodrow Wilson International Center for Scholars, silica NPs (SNPs) are one of the five most commonly used nanomaterials in consumer products [100]. The US Food and Drug Administration (FDA) approved the use of Cornell Dots (C-Dots) and silicaintegrated NPs for clinical trials on humans [101]. SNPs are perfect candidates to overcome a variety of medical problems, including rapid hydrolysis, enzymatic degradation, mass transport complications, difficulties of suspension formulation, and toxicity [102]. SNPs have distinct properties, involving tunable mesoporous structures with versatile morphological structures depending on the synthesis techniques. SNPs are distinguished by their biocompatibility and ease of fabrication, which allow for tunable surface modification [103]. The amorphous structure, size, stability, porosity, and surface modification are dependent on the reaction parameters [104]. For the preparation of gel-type SNPs, the sol-gel technique is usually applied, in which temperature, catalyst concentration, reagent ratio, and pressure are important criteria that can alter the properties of SNPs. Mesoporous SNPs are excellent nano vehicle candidates for smart drug delivery because of their porous structure, which can encapsulate therapeutic agents [105]. Furthermore, altering the surface of the SNPs or incorporating magnetic NPs to their cores can allow in vivo targeting to specific sites [106].

Novel mesoporous silica organic-based nanocomposites have been extensively investigated because of their large surface area and pore size, excellent thermal stability, size control potential, monodispersity, and tunable functionalities [107]. The antiradical properties of silicon dioxide $\left(\mathrm{SiO}_{2}\right) \mathrm{NPs}$ were assessed via the DPPH assay using UV/Vis and electron paramagnetic resonance (EPR) spectrophotometers [108]. The $\mathrm{SiO}_{2} \mathrm{NPs}$ were covalently grafted and functionalized with gallic acid $\left(\mathrm{SiO}_{2}-\mathrm{GA} \mathrm{NPs}\right)$. The DPPH solution exhibited a rapid decolorization of the initial characteristic purple color upon reaction with the $\mathrm{SiO}_{2}-\mathrm{GA}$ NPs. The key advantage of this preparation was the possibility of gallic acid regeneration. DLS data indicated that $\mathrm{SiO}_{2}-\mathrm{GA}$ NPs exhibited a dramatic agglomeration after their interaction with DPPH-radicals, resulting in an approximately six-fold increase in the size of the $\mathrm{SiO}_{2}$-GA NPs compared to their original size $(180 \mathrm{~nm})$ before the interaction with the DPPH-radicals. In another study, a silica-based nanocomposite was fabricated using the modified Stöber technique via the incorporation of mesoporous poly-(tannic acid) with SNPs (p(TA)- SNPs) [109]. SEM images showed the formation of $300 \mathrm{~nm}$-sized spherical-shaped p(TA)- SNPs. The Folin-Ciocalteu and Trolox equivalent antioxidant capacity assays were used to assess the antiradical potential of $\mathrm{p}$ (TA)-SNPs against gallic acid and Trolox standards, respectively. The antiradical potency of $p(T A)-$ SNPs was $140.3 \mathrm{~g} / \mathrm{mL}$ total phenol content in terms of gallic acid equivalency and $686 \mathrm{mM}$ trolox equivalent/g.

Two biopolymer silica-based nanocomposites, chitosan- $\mathrm{SiO}_{2}$ and carboxy methyl cellulose- $\mathrm{SiO}_{2}\left(\mathrm{Chi}-\mathrm{CMC}-\mathrm{SiO}_{2}\right)$ were fabricated and loaded with an aqueous extract of Larrea divaricata [110]. SEM micrographs demonstrated the uniform and porous structure of the prepared silica-based nanocomposites. The antiradical activity was assessed using the DPPH scavenging assay and by evaluating the SOD activity. Chi-CMC-SiO ${ }_{2}$ nanocomposite exhibited 3.5-folds higher antiradical capacity when compared with $\mathrm{Chi}_{2} \mathrm{SiO}_{2}$ nanocomposite. In another report, a synthetic antioxidant fluorescent flavone was anchored onto APTES-modified SNPs via sulfonamide linkage (FMES) [111]. The polydispersed index of FMFS NPs was $443.7 \mathrm{~nm}$ and the zeta potential value was $10.2 \mathrm{mV}$. FMFS NPs displayed a ferric reducing antiradical value of $55.6 \pm 0.06 \mathrm{mM}$ of gallic acid equivalent/g, which was almost similar to quercetin [112]. Uniform spherical-shaped quercetin-loaded SNPs (70-140 $\mathrm{nm}$ ) were prepared by an oil-in-water microemulsion method [113]. The variations in the sizes of the prepared particles were attributed to the increased concentrations of quercetin. Nitroblue tetrazolium reduction method was used to quantify the generated $\mathrm{O}_{2}{ }^{\bullet-}$ by xanthine/xanthine oxidase $(\mathrm{XO})$. Quercetin-loaded SNPs displayed a scavenging activity of $73 \%$ towards $\mathrm{O}_{2}{ }^{\bullet-}$, which could be attributable to the highly porous structure of SNPs that provided a favorable platform for increasing the biological activities of the embedded components. 


\subsection{Nanocomposite-Based Nanoantioxidants}

Nanocomposites are innovative nanostructures consisting of organic and inorganic components, which act as nanofillers dispersed in ceramic, metal, or polymeric matrices [114]. Nanocomposite configuration depends on the integration of specific matrices with nanofillers such as NPs, nanofibers, or nanofragments that bind together and surround the matrix. Nanocomposites have several phases and at least one, two, or three phases are within the nano dimensional range [115]. The fabrication of nanocomposites has been extensively investigated owing to their distinctive features, novel design, cost-effectiveness, and ease of preparation. The combination of a nanofiller with specific matrices boosts the unique features of the nanocomposite, such as high mechanical stability (i.e., toughness, strength, flexibility), good optical characteristics, low water and gas permeability, and high electrical and thermal conductivity [116]. The properties of nanocomposites are highly dependent on the strength of the matrix and the reinforcing properties of the fillers. The type, size, concentration, and shape of the embedded fillers within the matrix impart unique properties to each nanocomposite [117]. The radical scavenging potential of nanocompositebased nanoantioxidants is dependent on several criteria such as methods of preparation, used solvents, and nanocomposite size [118]. The primary goal of hybrid nanocompositebased nanoantioxidants is to introduce innovative nanoantioxidants with multi-functional and innovative properties that are distinct from their individual components.

A nanocomposite-based nanoantioxidant consisting of $\mathrm{V}_{2} \mathrm{O}_{5}$ nanowires and $\mathrm{MnO}_{2}$ NPs acted as a platform to mimic the endogenous antioxidant enzyme-based defense reactions [119]. $\mathrm{V}_{2} \mathrm{O}_{5}$ nanowires mimicked the activity of GPx, whereas $\mathrm{MnO}_{2} \mathrm{NPs}$ mimicked the activities of SOD and CAT. Dopamine was employed as a crosslinker to combine and assemble the two nanomaterials into a nanocomposite form. The prepared $\mathrm{V}_{2} \mathrm{O}_{5} @ \mathrm{PDA} @ \mathrm{MnO}_{2}$ nanocomposite functioned as a multi-nanozyme model to mimic the intracellular antioxidant enzymes. Both in vitro and in vivo experiments revealed the biocompatibility of the synthesized nanocomposite with superior intracellular ROS scavenging potency, indicating its potential use in inflammation therapies. In another study, a nanocomposite $\left(\mathrm{MoS}_{2} @ \mathrm{TiO}_{2}\right)$ containing $\mathrm{TiO}_{2}$ nano-belts and decorated with $\mathrm{MoS}_{2} \mathrm{NPs}$ was synthesized [120]. The prepared $\mathrm{MoS}_{2} @ \mathrm{TiO}_{2}$ nanocomposite had the highest CAT and SOD activities under physiologically relevant conditions. Notably, the nanocomposite activity surpassed the single components in terms of dispersibility and catalytic behavior. This could be attributed to the high surface area and the exposure of more reactive sites. The $\mathrm{MoS}_{2} @ \mathrm{TiO}_{2}$ nanocomposite exhibited good in vitro and in vivo biocompatibility as well as efficient elimination and restoration of endogenous ROS to the normal levels using fibroblast cell (L929) line as a testing model. In another study, the ROS-scavenging potency of the $\mathrm{CDs}-\mathrm{CeO}_{2}$ nanocomposite was assessed using $2^{\prime}, 7^{\prime}$-dichlorofluorescin diacetate dye-based assay (DCFHDA). CDs- $\mathrm{CeO}_{2}$ nanocomposite had the potential to scavenge $\mathrm{ROS}$ and prevent $\mathrm{H}_{2} \mathrm{O}_{2}$-mediated oxidative stress in NIH3T3 fibroblast cells [121]. The initiation of radical adducts is largely dependent on the $\mathrm{sp}^{2}$ carbon content. However, $\mathrm{CDs}$ with very little $\mathrm{sp}^{2}$ carbon content can display scavenging potency [122].

The stability and dispersibility of IO NPs in aqueous media represent the two main barriers to their biomedical applications. IO NPs have a high tendency for agglomeration due to interactions with the NPs themselves or with other biological molecules, leading to subsequent precipitation out of the colloidal system [123]. Effective approaches have been investigated to enhance the stability of IO NPs either by grafting with polymers or surfactants or by encapsulation with inorganic coating materials, such as metals, nonmetals, metal oxides, and/or metal sulfides [124]. It is worth mentioning that surface coating not only prevents IO NPs from being aggregated but also provides them with more functionality. The antiradical potential of a rod-shaped chitosan-coated iron oxide nanocomposite (CS-FeO) (20-90 nm) was evaluated using the DPPH and $\mathrm{H}_{2} \mathrm{O}_{2}$ assays [125]. The scavenging potency was concentration-dependent as it increased with the increase in the nanocomposite concentration. Interestingly, CS-FeO nanocomposites showed higher scavenging activity compared to the uncoated FeO NPs. The free radical scavenging 
efficiency of CS-FeO nanocomposites might be due to the presence of phenolic molecules that had the ability to release the hydrogen atoms located in their hydroxyl groups. In another report, reduced graphene oxide/zinc oxide nanocomposite-decorated with PdNPs (Pd-RGO-ZnO) was synthesized via a one-pot hydrothermal method [126]. The size of the Pd-RGO-ZnO nanocomposite ranged from 20 to $50 \mathrm{~nm}$. The scavenging activity was concentration-dependent and the highest radical scavenging potential was $48.6 \%$ using $200 \mu \mathrm{g} / \mathrm{mL}$ of Pd-RGO-ZnO.

Interestingly, the progress of advanced technologies such as microfluidics enables the development of large-scale production of nanocomposites with desirable characteristics. Microfluidic reactors provide a facility for the reaction of small reagent volumes, precise monitoring of fluid blending, effective mass transport, better heat transfer, safe and lowcost operations, and ease of automation in a short period [127]. They are extremely useful in a variety of applications, including chemical, biological, material, and pharmaceutical industries [128].

\subsection{PDA-Based Nanoantioxidants}

PDA has recently been studied as a novel biomaterial with numerous biomedical applications such as drug carriers [129]. In 2007, Lee et al. [130] proposed the groundbreaking pathways for PDA polymerization inspired by the exceptional adhesive properties of mussel proteins and their ability to bind to almost any type of surface. The two proposed pathways are the covalent bonding oxidative polymerization as well as physical self-assembly (Figure 6). The adhesive power was attributed to the amino acid, lysine and 3,4-dihydroxy-L-phenylalanine (DOPA) [131]. Dopamine, a DOPA derivative, is a catecholamine that has a significant role in mussel strong adhesion to a variety of substrates via covalent and non-covalent linkages. PDA, a dopamine polymerized product, can adhere to almost any material, such as metal-, ceramic-, and semiconductor-based polymers [132]. PDA is distinguished by its ease of synthesis without the need for organic solvents. Furthermore, adjusting synthesis parameters, such as temperature, $\mathrm{pH}$, reaction time, and oxidant and dopamine concentrations aids in controlling the thickness of PDA films [133]. NPs can be significantly loaded onto PDA via physical or chemical bonds as a result of the abundance of catechol/quinone moieties [134]. The unique properties of PDA can enhance the hydrophilicity of the NPs, provide excellent biocompatibility and ROS scavenging potency, and exhibit appropriate biodegradability. PDA has been extensively used for coating organic and inorganic NPs due to its outstanding adhesive and biochemical properties. PDA-based NPs have sparked the interest of researchers for cancer treatment, tissue repair, antibacterial, antioxidant, and anti-inflammatory applications [135].

PDA core-shell NPs were synthesized by a simple stirring of dopamine hydrochloride in a Tris- $\mathrm{HCl}$ buffer saline solution at $\mathrm{pH}$ 8.5. Using Schiff base chemical bonding, reduced PDA NPs (rPDA NPs) were integrated into oxidized dextran/chitosan hybrid hydrogel [136]. The rPDA NPs were spherical in shape with a particle size of $240 \pm 36 \mathrm{~nm}$. The prepared hydrogel exhibited a wound-healing effect due to its outstanding antioxidant and antibacterial properties. The rPDA NPs were biocompatible and provided protection against oxidative damage. In another study, lipid-coated PDA NPs (L-PDA NPs) were prepared using Stöber method [137]. Transmission electron microscope (TEM) and scanning electron microscope (SEM) revealed the uniform rounded shape of L-PDA NPs with an average size of $170 \pm 30 \mathrm{~nm}$. The as-prepared L-PDA NPs had both antioxidant and neuroprotective activities and provided a photothermal conversion platform, hence enhancing the neuronal activity. L-PDA NPs suppressed the accumulation of ROS in different SHSY5Y, which were prone to pro-oxidative stimulation exerted by tert-butyl hydroperoxide. Moreover, L-PDA NPs suppressed mitochondrial ROS-induced dysfunction and enhanced neurite outgrowth. 


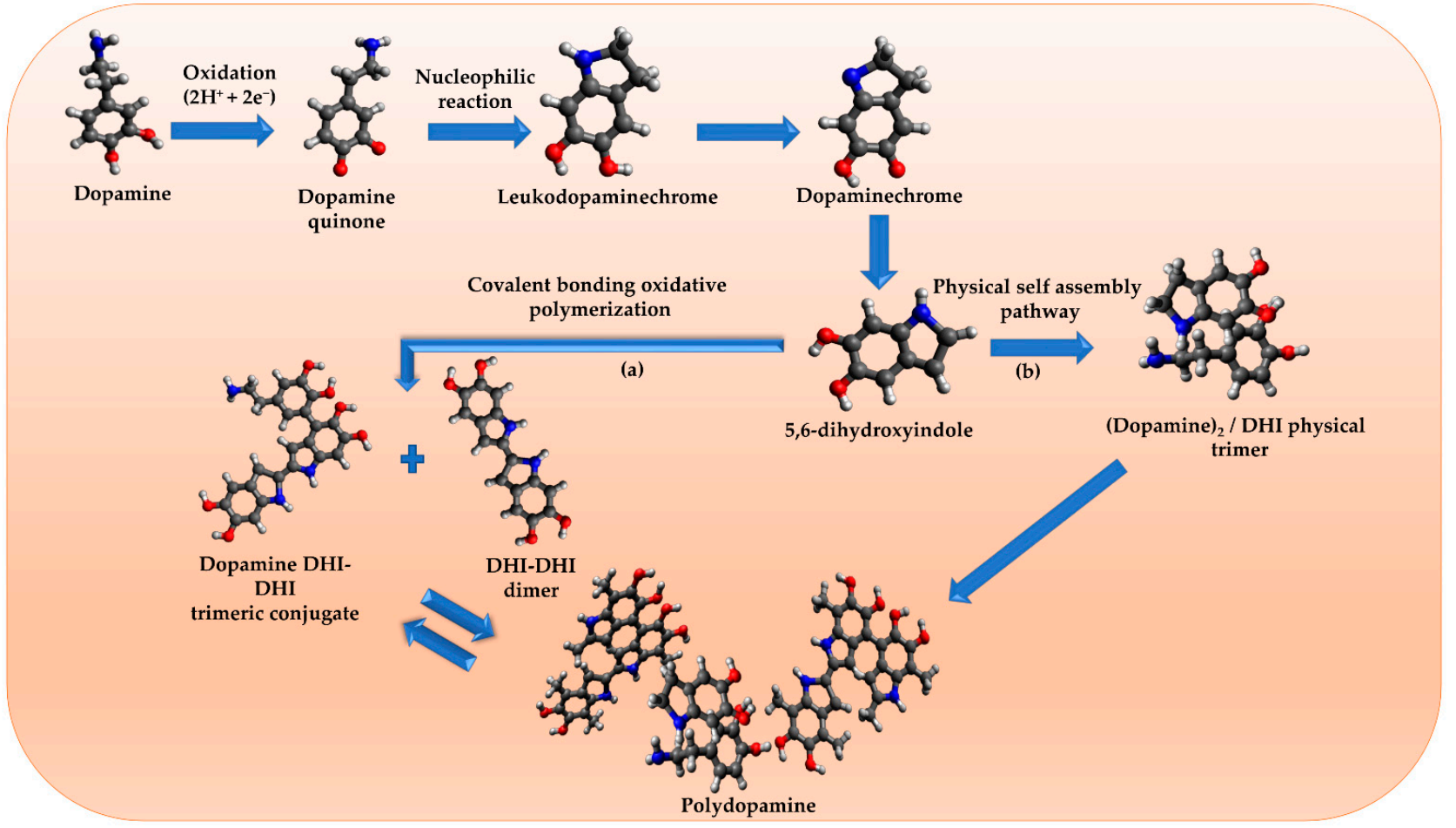

Figure 6. The two pathways applied for polydopamine polymerization, (a) covalent bonding oxidative polymerization and (b) physical self-assembly.

$\mathrm{CuCl}_{2}$ was successfully anchored on PDA-coated magnetic NPs $\left(\mathrm{Fe}_{3} \mathrm{O}_{4} @ \mathrm{PDA}-\mathrm{CuCl}_{2}\right)$, which displayed a uniform and well-dispersed quasi-spherical shape with a mean diameter of 10-20 $\pm 5 \mathrm{~nm}$ [138]. Successful coordination of $\mathrm{Cu}$ species on $\mathrm{Fe}_{3} \mathrm{O}_{4} @ P D A$ surface was confirmed using energy-dispersive X-ray (EDX)-coupled with FESEM, which revealed the presence of elemental peaks of $\mathrm{Fe}, \mathrm{C}, \mathrm{N}, \mathrm{O}$, and $\mathrm{Cu}$. Additionally, TEM images showed the successful coating of dark $\mathrm{Fe}_{3} \mathrm{O}_{4}$ cores with the grey PDA $/ \mathrm{CuCl}_{2}$ shells. The DPPH radical scavenging activity of the prepared PDA-based nanocomposite was close to that of butylated hydroxytoluene. The development of osteoarthritis has been related to excessive ROS production as a result of mitochondrial dysfunction [139]. In another study, uniform and non-agglomerated PDA nanospheres $(117.7 \mathrm{~nm})$ acted as dual-task platforms for the treatment of osteoarthritis by scavenging ROS and regulating cellular powerhouses (Figure 7) [140]. Zeta potential measurements revealed that the NPs were negatively charged $(-39.8 \mathrm{mV})$, which could be ascribed to the abundance of catechol functional groups on the surface of PDA NPs. ROS scavenging activity of PDA NPs was assessed against ${ }^{1} \mathrm{O}_{2},{ }^{\bullet} \mathrm{OH}, \mathrm{H}_{2} \mathrm{O}_{2}$, and $\mathrm{O}_{2}{ }^{\bullet}$. A dramatic reduction in ROS levels occurred in presence of different concentrations of PDA NPs. The ${ }^{1} \mathrm{O}_{2}, \bullet \mathrm{OH}, \mathrm{H}_{2} \mathrm{O}_{2}$, and $\mathrm{O}_{2}{ }^{\bullet-}$ were eliminated using $200 \mu \mathrm{g} / \mathrm{mL}$ of $\mathrm{Fe}_{3} \mathrm{O}_{4} @ \mathrm{PDA}-\mathrm{CuCl}_{2}$ with percentages of $66.6 \%$, $71.1 \%, 76.1 \%$, and $83.9 \%$, respectively, indicating the remarkable scavenging potential and the efficient removal of ROS in aqueous solutions. Furthermore, the intracellular ROS-scavenging potential of PDA NPs was further assessed using DCFHDA and MitoSOX (i.e., mitochondria-specific ROS probe). After incubation with PDA NPs for $24 \mathrm{~h}$, the ROS levels significantly decreased in a PDA concentration-dependent manner. Generally, nutritional molecules are converted to ATP in mitochondria via mitochondrial oxidative phosphorylation (OXPHOS). Mitochondria, cellular powerhouses, are considered significant cellular compartments for ROS production [141]. ROS are generated through the ETC as byproducts of oxidative metabolism. ETC is found in the inner mitochondrial membrane and is comprised of four protein complexes (i.e., Complex I, II, III, and IV) that mediate electron transport and ATP synthesis. To investigate the effect of PDA NPs on mitochondrial functionality, ATP levels were measured in LPS-treated chondrocytes in 
the presence and absence of PDA NPs. A significant increase in ATP levels was noticed in chondrocytes incubated with LPS-PDA NPs. PDA NPs reversed the decrease in OXPHOS efficiency by boosting the efficiency of Complexes II, III, and IV in the ETC, hence improving mitochondrial function and decreasing mitochondrial ROS production [140].

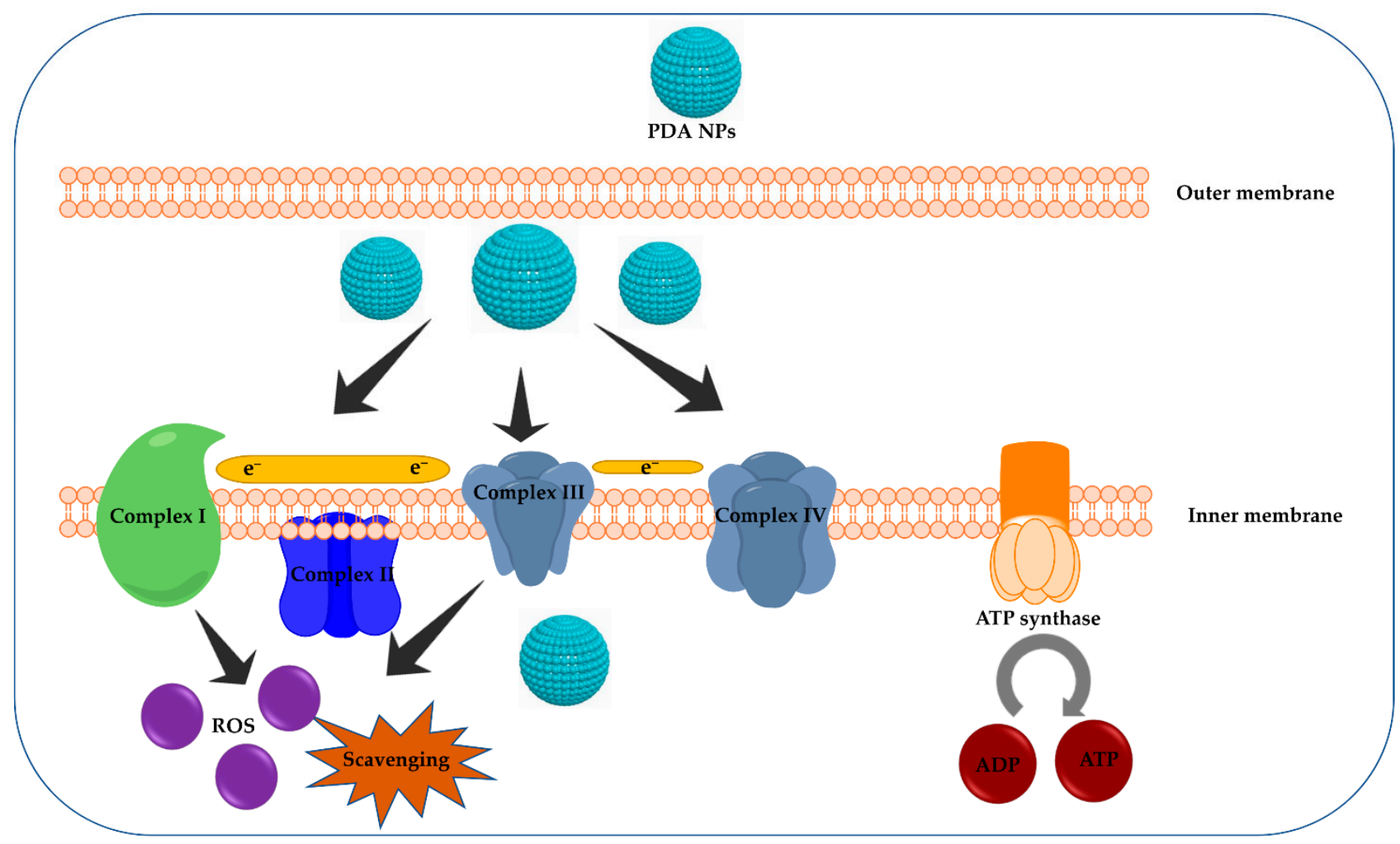

Figure 7. Illustration of PDA NPs as ROS scavengers and as regulators of cellular powerhouses (mitochondria) to reduce osteochondral inflammation.

\subsection{Polysaccharide-and Protein-Based Nanoantioxidants}

Polysaccharide NPs have been extensively studied in a variety of basic and applied science fields, ranging from polymer chemistry to material research to advanced pharmaceutical and biomedical applications [142]. Pharmaceutical applications of polysaccharide NPs involve targeted drug release [143], in vivo drug delivery [144], and stabilizing cosmetic ingredients (e.g., skin and hair care) [145], gene delivery [146], and vaccine delivery [147] as a result of their biodegradability, biocompatibility, muco-adhesive properties, and cellular uptake $[148,149]$. Cell viability tests have revealed their non-cytotoxicity $[150,151]$, whereas biomedical applications of the polysaccharide NPs involve their use as sensors for the detection of viruses and bacteria [142], tissue engineering [152], wound healing [153], tumor therapy, and delivery of anticancer agents [154].

Chitosan and sodium alginate has been extensively investigated as carrier molecules to encapsulate micro-and nano-particulate drugs under mild conditions [155]. Chitosan (cationic biopolymer) and sodium alginate (anionic biopolymer) have the potential to encapsulate active macromolecular and low molecular weight molecules [156]. Chitosan is a biodegradable and naturally occurring bio-based marine polysaccharide derived from the fractional N-deacetylation of crustacean shell chitin [157]. The poor water solubility of chitosan limits its diverse applications; however, it can be resolved via the preparation of chitosan nanoformulations, which have distinct properties such as antimicrobial and antioxidant activities. In one study, tripolyphosphate acted as a cross-linker for the synthesis of naringenin-encapsulated chitosan NPs (CS-NPs/NAR) via ionic gelation [158]. The free radical scavenging activity of CS-NPs/NAR was evaluated at two concentrations 
(e.g., $0.3 \mathrm{mg} / \mathrm{mL}$ and $0.5 \mathrm{mg} / \mathrm{mL}$ ). The $\mathrm{DPPH}$ and $\bullet{ }^{\bullet} \mathrm{OH}$ radical scavenging activities were $84 \%$ and $75 \%$, respectively using $0.5 \mathrm{mg} / \mathrm{mL}$ of CS-NPs/NAR. A significant reduction in nitrate rate $(0.16 \mu \mathrm{M}$ and $0.12 \mu \mathrm{M})$ was noticed using $0.3 \mathrm{mg} / \mathrm{mL}$ and $0.5 \mathrm{mg} / \mathrm{mL}$ of CS-NPs/NAR, respectively. NAR is a potential scavenger of ${ }^{\bullet} \mathrm{NO}$ and it reacts with $\bullet^{\mathrm{NO}}$ by competing with oxygen, hence aiding in the inhibition of nitrite production. Additionally, NAR released from CS-NPs/NAR had the potential to convert DPPH radicals to non-radical forms, which are inactive. In another report, catechin-loaded NPs were formulated by ionic gelation via the dropwise addition of tripolyphosphate in chitosan cationic solution [159]. Catechin-loaded NPs displayed higher DPPH-radical scavenging activity than pure catechin, exhibiting scavenging activities of $67.01 \pm 0.15 \%$ and $65.69 \pm 0.34 \%$, respectively. Additionally, catechin-loaded NPs exhibited ${ }^{\bullet} \mathrm{NO}$ and $\mathrm{H}_{2} \mathrm{O}_{2}$ scavenging activities of $46.12 \pm 0.11 \%$ and $36.31 \pm 0.31 \%$, respectively, which were higher than those of pure catechin, which exhibited scavenging activities of $42.31 \pm 0.14 \%$ and $38.12 \pm 0.11 \%$, respectively. This could be ascribed to the presence of a matrix structure containing ionic polymers. A similar interpretation for the high scavenging activity was proposed in the study of Nallamuthu et al. [160], in which chlorogenic acid, a phenolic compound, was encapsulated into chitosan NPs by ionic gelation method.

Alginate is a naturally occurring biopolymer that is derived from algae, seaweeds, and bacteria [161,162]. It is charcaterized by its high biocompatibility and biodegradability as well as its water-forming gel characteristics. Because of its availability, cost-effectiveness, and ease of formulation, alginate became one of the most commonly used polymers in formulation studies [54]. Alginate nanohydrogels have been used to deliver antioxidants, primarily by combining a multi-functional cross-linker with other polymers to boost the mechanical properties and bioactive release profiles. In one study, AuNPs were synthesized and impregnated with a highly conducting colloidal nanocomposite, polyaniline boronic acid/sodium alginate (PABA-SAL) [163]. The nanocomposite exhibited a moderate antioxidant potential. The highest tested concentration of PABA-SAL@AuNPs nanocomposite (i.e., $6 \mu \mathrm{g} / \mathrm{mL}$ ) exhibited a low radical scavenging activity of $15.6 \%$. The results obtained were lower than that of ascorbic acid, a potent antioxidant. Findings obtained from the FRAP assay revealed that both PABA-SAL@AuNPs and ascorbic acid showed the same reduction power.

Proteins are biodegradable, biocompatible, and readily available molecules for NP preparation [164]. Protein-based NPs have been employed for the targeted delivery of bioactive drugs due to their potential to interact with both hydrophilic and hydrophobic moieties [165]. They can act as delivery nano vehicles for DNA, RNA, anticancer drugs, hormones, and growth factors. When compared with other colloidal nanocarriers, proteinbased NPs are highly stable and can be easily manufactured using various methods. The most common techniques are desolvation, complex coacervation and nanospray; however, nanospray drying is still in its infancy with some drawbacks, involving decreased flow rates and purity [166]. As a result, more studies are required to resolve these disadvantages. Polycaprolactone-gelatin nanofiber (PGNPNF) mesh-functionalized with $\mathrm{CeO}_{2} \mathrm{NPs}$ was synthesized by electrospinning and was evaluated for its antioxidative activities in wound healing applications [167]. The synthesized $\mathrm{CeO}_{2} \mathrm{NPs}$ were $\sim 42 \mathrm{~nm}$ in size with a zeta potential value of $30.8 \mathrm{mV}$. The bioactive PGNPNF nanocomposite maintained the fibrous morphological structure for 14 days. The incorporation of $\mathrm{CeO}_{2} \mathrm{NPs}$ in the PGNPNF mesh exhibited a SOD mimetic potential. The PGNPNF mesh reduced oxidative stress by ROS scavenging as revealed by relative dichlorofluorescein intensity and fluorescence microscope.

\subsection{Biologically Fabricated Nanoantioxidants}

The "Green Chemistry" approach first proposed in 1991 was pursued to reduce human and environmental exposure to toxic chemicals as well as decrease or eliminate the use of toxic constituents [168]. In 1998, John C. Warner and Paul Anastas published their pioneer book "Green Chemistry: Theory and Practice" [169]. The twelve key principles of 
green chemistry included in this book paved the way for inspiring academic scientists and industrial personnel at that time and they continue to influence the advancement of the green chemistry approach to the present day. These fundamental principles affirmed the importance of reducing or eliminating the use of hazardous solvents in chemical reactions. Furthermore, an emphasis was directed towards the urgent need to avoid the release of any toxic waste products or discharges from chemical procedures [170]. The principles shed the light on the importance of using environmentally friendly guidelines during the fabrication, manipulation, and analysis of chemical products. The primary goal of these principles was to decrease any inherent occupational or environmental hazards that may exist while operating industrial activities [171]. Nanobiotechnology has emerged as a significant biological route for NP fabrication that can employ sustainable strategies by following the basic principles of green chemistry [172]. Table 2 shows a list of some of the biologically fabricated monometallic, bimetallic, and metal oxide NPs exhibiting antioxidant/antiradical activity. A schematic representation showing the biological fabrication of nanoantioxidants using different biological entities is illustrated in Figure 8.

Table 2. List of biologically fabricated monometallic, bimetallic, and metal oxide NPs endowing antioxidant potential.

\begin{tabular}{|c|c|c|c|c|c|c|c|}
\hline Type of NPs & $\begin{array}{l}\text { Biological } \\
\text { Extract }\end{array}$ & $\begin{array}{l}\text { Size }(\mathrm{nm}) \\
\text { Shape }\end{array}$ & $\begin{array}{l}\text { Characterization } \\
\text { Techniques }\end{array}$ & $\begin{array}{l}\text { Evaluation } \\
\text { Assays }\end{array}$ & $\begin{array}{c}\text { IC }_{50} \text { Value } \\
(\mu \mathrm{g} / \mathrm{mL})\end{array}$ & $\begin{array}{l}\text { Antiradical/ } \\
\text { Antioxidant } \\
\text { Activity (\%) }\end{array}$ & References \\
\hline \multicolumn{8}{|c|}{ Monometallic-Based Nanoantioxidants } \\
\hline $\mathrm{Ag}$ & Malus domestica & $\begin{array}{c}100, \\
\text { spherical }\end{array}$ & $\begin{array}{l}\text { UV/Vis spectroscopy, SEM, } \\
\text { Zeta potential }\end{array}$ & $\mathrm{DPPH}$ & - & 75.16 & [173] \\
\hline $\mathrm{Ag}$ & $\begin{array}{l}\text { Asphodelus } \\
\text { aestivus }\end{array}$ & $\begin{array}{c}50, \\
\text { spherical }\end{array}$ & $\begin{array}{l}\text { UV/Vis spectroscopy, NTA, } \\
\text { XRD, TEM, FTIR }\end{array}$ & $\begin{array}{c}\mathrm{DPPH}, \\
\mathrm{ABTS}^{\bullet+} \\
\mathrm{H}_{2} \mathrm{O}_{2}\end{array}$ & - & $\begin{array}{l}67.54 \\
79.94 \\
31.67\end{array}$ & [174] \\
\hline $\mathrm{Ag}$ & $\begin{array}{l}\text { Lippia } \\
\text { nodiflora }\end{array}$ & $\begin{array}{c}\text { 30-60, } \\
\text { spherical }\end{array}$ & $\begin{array}{l}\text { UV/Vis spectroscopy, FTIR, } \\
\text { XRD, SE-EDX, TEM, Zeta } \\
\text { potential }\end{array}$ & $\begin{array}{l}\mathrm{DPPH} \\
\mathrm{O}_{2}^{\bullet-} \\
\mathrm{H}_{2} \mathrm{O}_{2} \\
\bullet \mathrm{OH}\end{array}$ & - & $\begin{array}{c}67 \\
70 \\
71.1 \\
69\end{array}$ & {$[175]$} \\
\hline $\mathrm{Ag}$ & $\begin{array}{l}\text { Memecylon } \\
\text { umbellatum }\end{array}$ & $\begin{array}{c}\text { 7-22, } \\
\text { spherical }\end{array}$ & $\begin{array}{c}\text { UV/Vis spectroscopy, FTIR, } \\
\text { HRTEM, XRD, } \\
\text { Zeta potential }\end{array}$ & $\mathrm{DPPH}$ & 53.46 & 81.57 & {$[176]$} \\
\hline $\mathrm{Ag}$ & $\begin{array}{l}\text { Calophyllum } \\
\text { tomentosum }\end{array}$ & $\begin{array}{c}24, \\
\text { spherical }\end{array}$ & $\begin{array}{l}\text { UV/Vis spectroscopy, FTIR, } \\
\text { XRD, EDX, SEM }\end{array}$ & $\begin{array}{l}\mathrm{DPPH} \\
\mathrm{H}_{2} \mathrm{O}_{2} \\
\bullet \mathrm{NO}\end{array}$ & - & $\begin{array}{c}90 \\
83.94 \\
78.46\end{array}$ & {$[177]$} \\
\hline $\mathrm{Ag}$ & Morus alba & $\begin{array}{c}\text { 12-39, } \\
\text { spherical }\end{array}$ & $\begin{array}{c}\text { UV/Vis spectroscopy, FTIR, } \\
\text { HRTEM, XRD, } \\
\text { FESEM, EDX }\end{array}$ & $\begin{array}{l}\mathrm{ABTS}^{\bullet+}, \\
\mathrm{DPPH}, \\
\mathrm{O}_{2}^{\bullet-}, \\
\bullet \mathrm{NO}\end{array}$ & $\begin{array}{l}25.929 \\
97.273 \\
37.097 \\
70.992\end{array}$ & $\begin{array}{l}95.08 \\
47.81 \\
81.92 \\
64.04\end{array}$ & {$[178]$} \\
\hline $\mathrm{Ag}$ & Piper longum & $\begin{array}{c}28.8, \\
\text { spherical }\end{array}$ & $\begin{array}{l}\text { UV/Vis spectroscopy, } \\
\text { FESEM, } \\
\text { XRD, FTIR, HRTEM }\end{array}$ & $\mathrm{DPPH}$ & - & 78.64 & {$[179]$} \\
\hline $\mathrm{Ag}$ & Rosa canina & $\begin{array}{c}19.75 \\
\text { spherical }\end{array}$ & $\begin{array}{c}\text { UV/Vis spectroscopy, TEM, } \\
\text { XPS, XRD }\end{array}$ & $\mathrm{DPPH}$ & - & 86.4 & {$[180]$} \\
\hline $\mathrm{Ag}$ & Clove bud & $\begin{array}{c}17.94 \\
\text { spherical }\end{array}$ & $\begin{array}{l}\text { UV/Vis spectroscopy, EDX, } \\
\text { XRD, FTIR, Zeta potential, } \\
\text { cyclic voltammetry }\end{array}$ & $\begin{array}{l}\mathrm{ABTS}^{\bullet+}, \\
\bullet \mathrm{OH}\end{array}$ & $\begin{array}{l}33.03 \\
47.37\end{array}$ & - & {$[181]$} \\
\hline $\mathrm{Ag}$ & Cleome viscosa & $\begin{array}{l}50, \\
\text { Rod/spherical/ } \\
\text { triangular }\end{array}$ & $\begin{array}{c}\text { UV/Vis spectroscopy, FTIR, } \\
\text { XERD, SEM, } \\
\text { TEM }\end{array}$ & $\begin{array}{l}\text { DPPH, } \\
\text { ABTS }^{\bullet+}\end{array}$ & $\begin{array}{c}20.32 \\
48.5\end{array}$ & $\begin{array}{l}92.8 \\
77.63\end{array}$ & [182] \\
\hline $\mathrm{Ag}$ & $\begin{array}{l}\text { Allium } \\
\text { ampeloprasum }\end{array}$ & $\begin{array}{c}35, \\
\text { spherical/quasi } \\
\text { spherical/ } \\
\text { ellipsoidal/ } \\
\text { triangu- } \\
\text { lar/hexagonal }\end{array}$ & $\begin{array}{l}\text { UV/Vis spectroscopy, FTIR, } \\
\text { XRD, TEM }\end{array}$ & $\begin{array}{c}\text { DPPH, } \\
\mathrm{ABTS}^{\bullet+}, \\
\mathrm{H}_{2} \mathrm{O}_{2} \\
\bullet \mathrm{NO} \\
\mathrm{O}_{2}^{\bullet-}\end{array}$ & $\begin{array}{l}8.93 \\
18.31 \\
11.25 \\
16.51 \\
23.22\end{array}$ & - & [183] \\
\hline
\end{tabular}


Table 2. Cont.

\begin{tabular}{|c|c|c|c|c|c|c|c|}
\hline Type of NPs & $\begin{array}{l}\text { Biological } \\
\text { Extract }\end{array}$ & $\begin{array}{l}\text { Size }(\mathrm{nm}) \\
\text { Shape }\end{array}$ & $\begin{array}{l}\text { Characterization } \\
\text { Techniques }\end{array}$ & $\begin{array}{c}\text { Evaluation } \\
\text { Assays }\end{array}$ & $\begin{array}{l}\mathrm{IC}_{50} \text { Value } \\
(\mu \mathrm{g} / \mathrm{mL})\end{array}$ & $\begin{array}{l}\text { Antiradical/ } \\
\text { Antioxidant } \\
\text { Activity (\%) }\end{array}$ & References \\
\hline $\mathrm{Ag}$ & $\begin{array}{c}\text { Aesculus } \\
\text { hippocastanum }\end{array}$ & $\begin{array}{c}50 \pm 5 \\
\text { spherical }\end{array}$ & $\begin{array}{l}\text { UV/Vis spectroscopy, FTIR, } \\
\text { XRD, SEM, Zeta potential }\end{array}$ & $\begin{array}{l}\mathrm{DPPH}, \\
\mathrm{O}_{2}^{\bullet-}\end{array}$ & - & $\begin{array}{c}93.48 \\
62.9\end{array}$ & [184] \\
\hline $\mathrm{Ag}$ & $\begin{array}{l}\text { Lactobacillus } \\
\quad \text { brevis }\end{array}$ & $\begin{array}{c}45 \\
\text { spherical }\end{array}$ & $\begin{array}{l}\text { FTIR, XRD, SEM, TEM, } \\
\text { elemental analyzer }\end{array}$ & $\begin{array}{l}\mathrm{DPPH} \\
\mathrm{H}_{2} \mathrm{O}_{2} \\
\bullet \mathrm{NO}\end{array}$ & - & $\begin{array}{l}81.4 \\
70.1 \\
75.06\end{array}$ & [185] \\
\hline $\mathrm{Ag}$ & $\begin{array}{l}\text { Achillea } \\
\text { millefolium }\end{array}$ & $\begin{array}{c}20.77 \\
\text { (spherical), } \\
18.53 \\
\text { (triangular), } \\
14.27 \text { (cubic) }\end{array}$ & $\begin{array}{c}\text { UV/Vis spectroscopy, FTIR, } \\
\text { SEM, XRD }\end{array}$ & DPPH & 7.03 & - & [186] \\
\hline $\mathrm{Ag}$ & Cannabis sativa & $\begin{array}{c}11.5, \\
\text { spherical }\end{array}$ & $\begin{array}{l}\text { UV/Vis spectroscopy, FTIR, } \\
\text { FESEM, TEM }\end{array}$ & $\mathrm{DPPH}$ & 218 & - & [187] \\
\hline $\mathrm{Au}$ & $\begin{array}{c}\text { Lotus } \\
\text { leguminosae }\end{array}$ & $\begin{array}{c}37, \\
\text { spherical }\end{array}$ & UV/Vis, IR, TEM, TGA & $\mathrm{DPPH}$ & 30.54 & - & [188] \\
\hline $\mathrm{Au}$ & Clove bud & $\begin{array}{c}27.12, \\
\text { hexagonal/ } \\
\text { polyhedral }\end{array}$ & $\begin{array}{l}\text { UV/Vis spectroscopy, EDX, } \\
\text { XRD, FTIR, Zeta potential, } \\
\text { cyclic voltammetry }\end{array}$ & $\begin{array}{l}\mathrm{ABTS}^{\bullet+} \\
\bullet \mathrm{OH}\end{array}$ & $\begin{array}{l}36.76 \\
50.32\end{array}$ & - & [181] \\
\hline $\mathrm{Au}$ & $\begin{array}{c}\text { Curcuma } \\
\text { pseudomontana }\end{array}$ & $\begin{array}{c}20, \\
\text { spherical }\end{array}$ & $\begin{array}{l}\text { UV/Vis spectroscopy, SEM, } \\
\text { HRTEM, FTIR }\end{array}$ & $\begin{array}{c}\mathrm{DPPH}, \\
\mathrm{H}_{2} \mathrm{O}_{2}, \\
\bullet \mathrm{NO}, \\
\text { reducing } \\
\text { power, } \\
\text { CUPRAC }\end{array}$ & - & $\begin{array}{l}85.2, \\
83.2, \\
84.5, \\
87.9, \\
85.6\end{array}$ & [189] \\
\hline $\begin{array}{l}\mathrm{Ag}, \\
\mathrm{Au}\end{array}$ & $\begin{array}{l}\text { Plumbago } \\
\text { zeylanica }\end{array}$ & $\begin{array}{c}28.47 \\
\text { (spherical), } \\
16.89 \\
\text { (spherical) }\end{array}$ & $\begin{array}{l}\text { UV/Vis spectroscopy, FTIR, } \\
\text { TEM, XRD, EDX }\end{array}$ & $\mathrm{DPPH}$ & $\begin{array}{l}56.98(\mathrm{Ag}) \\
68.53(\mathrm{Au})\end{array}$ & $\begin{array}{l}78.17 \\
87.34\end{array}$ & [190] \\
\hline $\mathrm{Pt}$ & $\begin{array}{c}\text { Tragia } \\
\text { involucrata }\end{array}$ & $\begin{array}{c}10 \\
\text { spherical }\end{array}$ & $\begin{array}{c}\text { UV/Vis spectroscopy, XRD, } \\
\text { FTIR, FESEM, } \\
\text { HRTEM }\end{array}$ & DPPH & - & $64 \pm 0.43$ & [191] \\
\hline $\mathrm{Cu}$ & $\begin{array}{l}\text { Falcaria } \\
\text { vulgaris }\end{array}$ & $\begin{array}{c}20-25 \\
\text { spherical }\end{array}$ & $\begin{array}{l}\text { UV/Vis spectroscopy, XRD, } \\
\text { HRTEM, FESEM, FTIR }\end{array}$ & $\mathrm{DPPH}$ & 190 & - & [192] \\
\hline $\mathrm{Cu}$ & $\begin{array}{l}\text { Borreria } \\
\text { hispida }\end{array}$ & $\begin{array}{c}121 \pm 37 \\
\text { quasi } \\
\text { spherical }\end{array}$ & $\begin{array}{l}\text { UV/Vis spectroscopy, XRD, } \\
\text { SEM, EDX, FTIR }\end{array}$ & DPPH & 0.6 & - & [193] \\
\hline \multicolumn{8}{|c|}{ Bimetallic-Based Nanoantioxidants } \\
\hline $\mathrm{Ag} / \mathrm{Cu}$ & $\begin{array}{l}\text { Borassus } \\
\text { flabellifer }\end{array}$ & $\begin{array}{l}80, \\
-\end{array}$ & $\begin{array}{l}\text { UV/Vis spectroscopy, FTIR, } \\
\text { SEM }\end{array}$ & $\begin{array}{l}\text { DPPH, } \\
\bullet \mathrm{OH}, \\
\mathrm{H}_{2} \mathrm{O}_{2} \\
\end{array}$ & - & $\begin{array}{l}58 \\
48 \\
42 \\
\end{array}$ & [194] \\
\hline $\mathrm{Cu} / \mathrm{Zn}$ & $\begin{array}{l}\text { Borassus } \\
\text { flabellifer }\end{array}$ & $\begin{array}{c}100 \\
-\end{array}$ & $\begin{array}{l}\text { UV/Vis spectroscopy, FTIR, } \\
\text { SEM }\end{array}$ & $\begin{array}{l}\text { DPPH, } \\
\bullet \mathrm{OH}, \\
\mathrm{H}_{2} \mathrm{O}_{2} \\
\end{array}$ & - & $\begin{array}{l}40 \\
38 \\
28\end{array}$ & [194] \\
\hline $\mathrm{Ag} / \mathrm{Pt}$ & $\begin{array}{l}\text { Vernonia } \\
\text { Mespilifolia }\end{array}$ & $\begin{array}{l}35.5 \pm 0.8 \\
\text { spherical }\end{array}$ & $\begin{array}{l}\text { UV/Vis spectroscopy, TEM, } \\
\text { EDX, FTIR }\end{array}$ & $\begin{array}{l}\text { DPPH, } \\
\text { ABTS }^{\bullet+}, \\
\text { FRAP }\end{array}$ & $\begin{array}{l}19.5 \\
21.6 \\
44.1\end{array}$ & - & [195] \\
\hline $\mathrm{Au} / \mathrm{Ag}$ & Clove bud & $\begin{array}{c}\text { 16.04, } \\
\text { spherical }\end{array}$ & $\begin{array}{l}\text { UV/Vis spectroscopy, EDX, } \\
\text { XRD, FTIR, Zeta potential, } \\
\text { cyclic voltammetry }\end{array}$ & $\begin{array}{c}\bullet \mathrm{OH}, \\
\mathrm{ABTS}^{\bullet+}\end{array}$ & $\begin{array}{l}30.59 \\
18.27\end{array}$ & - & [181] \\
\hline \multicolumn{8}{|c|}{ Metal Oxide-Based Nanoantioxidants } \\
\hline $\mathrm{CuO}$ & Cucurbita sp. & $\begin{array}{c}45-65, \\
\text { rod/ } \\
\text { rectangular/ } \\
\text { hexagonal }\end{array}$ & $\begin{array}{l}\text { UV / Vis spectroscopy, XRD, } \\
\text { SEM, EDX, HRTEM }\end{array}$ & $\mathrm{DPPH}$ & 40.81 & 91.37 & [196] \\
\hline $\mathrm{MgO}$ & Pisonia alba & $\begin{array}{c}<100, \\
\text { spherical }\end{array}$ & $\begin{array}{l}\text { UV/Vis spectroscopy, TEM, } \\
\text { EDX, XRD, FTIR }\end{array}$ & $\begin{array}{l}\text { DPPH, } \\
\text { FRAP }\end{array}$ & - & $\begin{array}{l}65 \\
69.3\end{array}$ & [197] \\
\hline
\end{tabular}


Table 2. Cont.

\begin{tabular}{|c|c|c|c|c|c|c|c|}
\hline Type of NPs & $\begin{array}{l}\text { Biological } \\
\text { Extract }\end{array}$ & $\begin{array}{l}\text { Size }(\mathrm{nm}), \\
\text { Shape }\end{array}$ & $\begin{array}{l}\text { Characterization } \\
\text { Techniques }\end{array}$ & $\begin{array}{c}\text { Evaluation } \\
\text { Assays }\end{array}$ & $\begin{array}{l}\mathrm{IC}_{50} \text { Value } \\
(\mu \mathrm{g} / \mathrm{mL})\end{array}$ & $\begin{array}{l}\text { Antiradical/ } \\
\text { Antioxidant } \\
\text { Activity (\%) }\end{array}$ & References \\
\hline $\mathrm{ZnO}$ & $\begin{array}{c}\text { Tecoma } \\
\text { castanifolia }\end{array}$ & $\begin{array}{c}70-75 \\
\text { spherical }\end{array}$ & $\begin{array}{c}\text { UV/Vis spectroscopy, TEM, } \\
\text { XRD, FTIR }\end{array}$ & DPPH & - & 56.11 & [198] \\
\hline $\mathrm{ZnO}$ & $\begin{array}{l}\text { Knoxia } \\
\text { sumatrensis }\end{array}$ & $\begin{array}{l}50-80 \\
\text { rod }\end{array}$ & $\begin{array}{l}\text { UV/Vis spectroscopy, XRD, } \\
\text { FTIR, FESEM }\end{array}$ & $\begin{array}{c}\text { DPPH, } \\
\text { ABTS }^{\bullet+}, \\
\mathrm{H}_{2} \mathrm{O}_{2} \\
\end{array}$ & $\begin{array}{l}95.80 \\
92.29 \\
98.92 \\
\end{array}$ & $\begin{array}{c}- \\
50.70 \\
- \\
\end{array}$ & [199] \\
\hline $\mathrm{CuO}$ & $\begin{array}{l}\text { Cissus } \\
\text { vitiginea }\end{array}$ & $\begin{array}{c}\sim 32.3 \\
\text { spherical }\end{array}$ & XRD, EDS, TEM & DPPH & 45.29 & 86.78 & [200] \\
\hline $\mathrm{TiO}_{2}$ & Cola nitida & $\begin{array}{l}\text { 25-191, } \\
\text { spherical }\end{array}$ & $\begin{array}{l}\text { UV/Vis, FTIR, TEM, EDX, } \\
\text { XRD, FESEM }\end{array}$ & $\begin{array}{l}\mathrm{DPPH}, \\
\mathrm{H}_{2} \mathrm{O}_{2}\end{array}$ & - & $\begin{array}{l}62.06 \\
99.23\end{array}$ & [201] \\
\hline
\end{tabular}

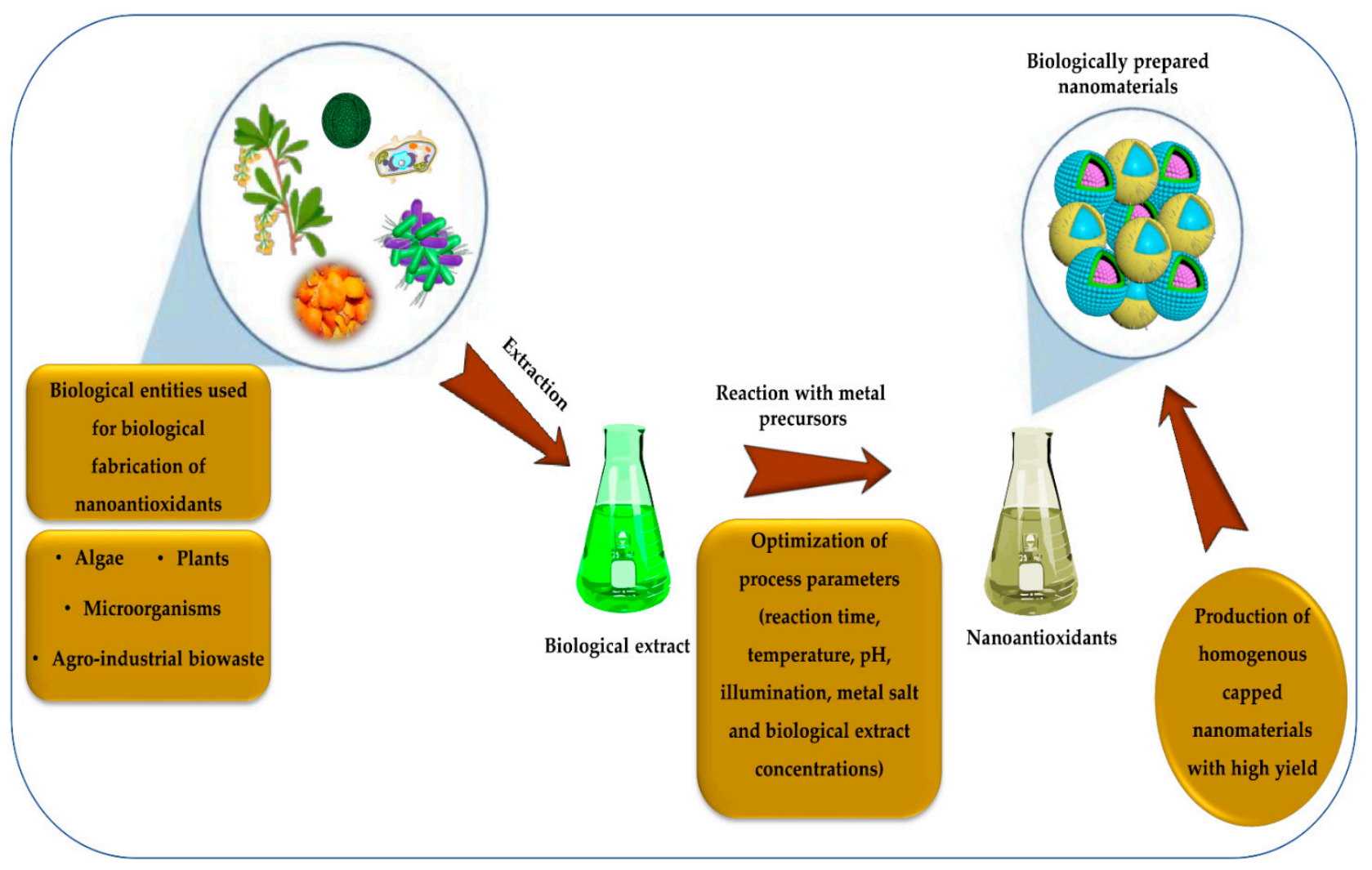

Figure 8. A schematic representation showing the biological fabrication of nanoantioxidants using different biological entities.

Rounded-shaped $\mathrm{CeO}_{2} \mathrm{NPs}$ with an average diameter of $21 \mathrm{~nm}$ were synthesized using the extract of Stachys japonica [202]. In vitro studies showed that the S. japonica-derived $\mathrm{CeO}_{2}$ NPs exhibited an antiradical activity against DPPH-radicals and $\mathrm{ABTS}^{+}$with $\mathrm{IC}_{50}$ values of $109.5 \pm 0.26 \mu \mathrm{g} / \mathrm{mL}$ and $12.16 \pm 0.12 \mu \mathrm{g} / \mathrm{mL}$, respectively. $S$. japonica-CeO $\mathrm{C}_{2} \mathrm{NPs}$ were biocompatible and efficiently reduced the cellular oxidative stress in mouse fibroblast NIH3T3 cells in terms of cytotoxicity, ROS generation, and prevention of mitochondrial membrane potential (MMP) loss, and nucleus impairment. Neurodegenerative disorders such as Alzheimer's and Parkinson's diseases occur as a result of neural cell death and/or weakening of neural cell-to-cell signaling [203]. In a recent study, Aloe vera leaf extract acted as a reducing and stabilizing agent for the biological synthesis of 2-3 nm-sized $\mathrm{CeO}_{2}$ NPs [204]. Pretreatment of mouse neuroblastoma cells with $A$. vera-derived $\mathrm{CeO}_{2} \mathrm{NPs}$ resulted in inhibition of oxidative stress in terms of cell viability, generation of intracellular ROS, loss of MMP, neural connectivity, and cell cycle arrest. 
Nonetheless, certain drawbacks of green nanoantioxidant fabrication impose further investigations. The most significant disadvantages of the green synthesis of nanoantioxidants are the difficulties in completely separating nanoantioxidants from biomass. On the other hand, the requirement for additional purification stages may have inevitable effects, particularly on potential pilot up-scale production [205]. The antioxidant properties of the biogenic nanomaterials are closely related to the chemical functionalities present on their surface, making standardization difficult. For the efficient synthesis of green nanoantioxidants, it is necessary to optimize the various process parameters that may influence the synthesis of desirable sizes, shapes, and monodispersed particles [206]. To gain a comprehensive understanding of the entire fabrication process, the precise identification of the bioactive molecules participating in the green synthesis of nanoantioxidants is required; however, the presence of numerous phytochemicals and biomolecules makes this a difficult task [205]. The application of synthetic approaches based primarily on the use of sustainable materials is quite interesting and necessitates more in-depth research to achieve commercial and industrial-scale production. Industrial upscaling of green synthesized nanoantioxidants can be accomplished by employing simple, low-cost protocols, and standardizing the synthesis parameters. Biologically fabricated nanoantioxidants have to be precisely fabricated, carefully monitored, and analyzed to overcome challenges related to crystallinity degree, morphological configuration, and conceptual size [207]. More in vivo research on biologically fabricated nanoantioxidants is critical for safe biomedical applications.

\section{Solid-Lipid-Based NPs, Nanostructured Lipid Carriers, and Liposome NPs as Efficient Nanoencapsulation Systems}

\subsection{Solid-Lipid-Based NPs and Nanostructured Lipid Carriers}

The structural configuration of solid lipid nanoparticles (SLNs) and nanostructured lipid carriers (NLCs), as well as their distinguishing features, make them preferable for delivering sensitive bioactive molecules while avoiding chemical degradation. SLNs were first introduced in 1991 as a revolutionary strategy to resolve the various drawbacks associated with other encapsulation methods [208]. SLNs are composed of lipids that remain solid at both the room and human body temperatures, making them extremely useful when it comes to achieving controlled drug release and for the development of new formulations [209]. Moreover, the size of SLNs ranges between 40 and $1000 \mathrm{~nm}$, allowing for a broader range of NPs and bioactive compounds to be encapsulated based on specific requirements [210]. SLNs possess various advantages compared to other colloidal systems, involving high stability, biodegradability, lack of toxicity, the possibility of upscale production, and the ability of lyophilization, and incorporation of hydrophilic and lipophilic drugs [211]. However, some limitations are associated with SLNs, such as a relatively high water content (i.e., $70 \%-99.9 \%$ ), which may represent a major issue during incorporation into a final product [212]. Furthermore, due to the tendency of lipid crystals to recrystallize over time, loading efficiency can decrease. Nanostructured lipid carriers (NLCs) are a new generation of lipid NPs that are made up of both solid and liquid lipids in ratios ranging from 70:30 to 99.9:0.1 [210]. When using liquid lipids, the melting point is reduced, which improves some of the intrinsic properties such as reduced drug release during storage and improved loading potential [213]. However, it is important to note that drug localization in the SLNs/NLCs is also affected by lipophilicity and the structure of the target molecule [214]. For the aforementioned reasons, NLCs are an interesting option for preserving antioxidant molecules while controlling their release rates. Several studies have shown that some antioxidants, such as lycopene [215], quercetin [216], curcumin [217], and astaxanthin [218] can be successfully loaded onto NLCs. Other studies revealed the successful encapsulation of resveratrol [219], idebenone [220], ferulic acid [221], and curcumin [222] on SLNs. Some of the most common techniques applied for the synthesis of SLNs and NLCs are presented in Figure 9 [209]. 


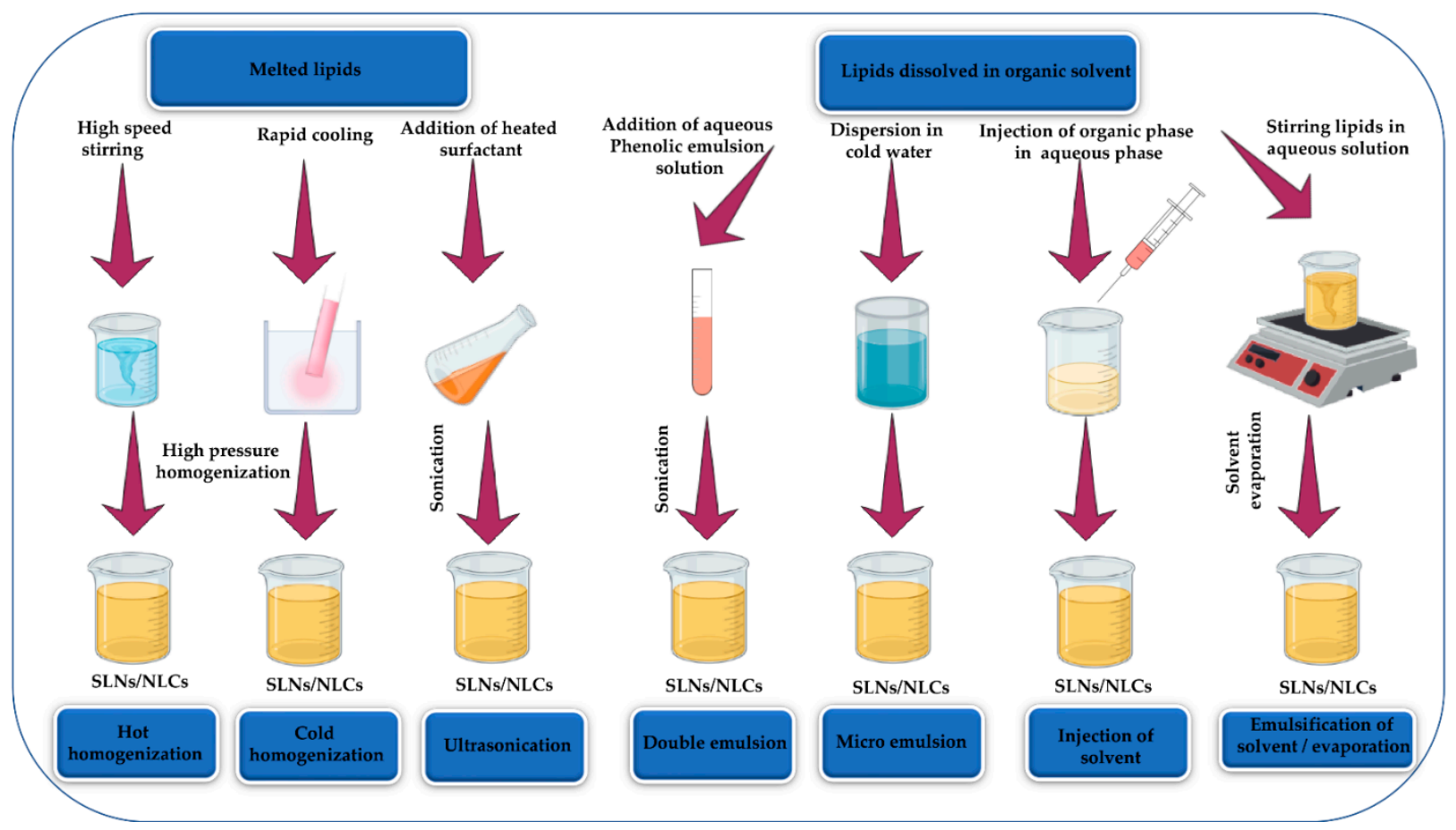

Figure 9. Scheme showing the most common techniques used for the preparation of SLNs and NLCs, involving (i) hot and cold homogenization, (ii) ultrasonication, (iii) double and micro emulsion, (iv) solvent injection, and (v) emulsification/evaporation methods.

\subsection{Liposomes and Their New Generations}

Liposomes were first introduced by Alec Bangham in 1961 [223] and since then they have become one of the most common carriers for encapsulation purposes, particularly in cosmetic and pharmaceutical applications. Liposomes are spherical vesicular structures made up of naturally occurring phospholipid bilayers, allowing lipophilic and hydrophilic drugs to be incorporated into the lipid layers and the aqueous core, respectively [224]. Liposomes are characterized by their decreased toxicity, biocompatibility, biodegradability, and non-immunogenicity because of their natural bilayer composition. Liposomes also have the ability to encapsulate hydrophilic, lipophilic, and amphiphilic molecules as well as having a versatile chemical structure [225]. The natural bilayer is composed of phosphatidylcholine, cholesterol, phosphatidylglycerol, dipalmitoylphosphatidylcholine, stearylamine, distearoylphosphatidylcholine, and dicetylphosphat [226]. Properties of liposomes are mainly dependent on their lipid structure, size, surface charge, and method of preparation. The rigidity and the charge of the liposomes are affected by the choice of the bilayer components [227]. Liposome NPs are classified into the following categories based on their size, involving small uni-lamellar vesicle $(20-100 \mathrm{~nm})$, large uni-lamellar vesicle $(>100 \mathrm{~nm})$, multi-lamellar vesicle (>500 nm), and multi-vesicular vesicle $(>1000 \mathrm{~nm})$ [228].

Liposomes as drug delivery systems have become a biomedical research hotspot because they offer specific-targeted delivery at target sites [229]. The innovative use of liposomes has significantly improved therapies by providing stability to therapeutic compounds, tackling the limitations related to cellular and tissue uptake, and enhancing their biodistribution and permeation at target sites in vivo [230]. Drugs loaded into liposomes are further protected from the surrounding physiological conditions, including enzymatic degradation, immunologic inactivation, and rapid plasma clearance, thus improving and extending their action. Liposomes have been reported as efficient nanoencapsulation systems because they can fuse with the cell membrane and deliver the exogenous drug molecules to target cells due to the similarity of the liposome lipid bilayer to the real cellular membrane [231]. However, the use of liposomes can be restricted due to their short life 
span, sensitivity to oxidation, tendency for aggregation, and poor response to external stimuli $[232,233]$. Furthermore, one of the major disadvantages of liposome formulation is its rapid clearance from systemic circulation. This rapid clearance is caused by the absorption of the phospholipid membrane that comprises the liposome structure by plasma proteins [234]. To overcome these limitations, liposome-polymer integration is regarded as an innovative strategy for improving in vitro and in vivo performance of liposomes [235]. Liposomes can be modified with polymers either by surface coating or grafting [236]. Liposome surface modification alters their shape, size, surface charge, and lipid chain ordering. Consequently, surface-modified liposomes can exhibit improved biological properties, such as increased stability, consistent targeting, and long-term circulation [237]. Examples of the several biopolymers that can be used for the modification of liposome surface involve chitosan, cellulose, pectin, polysaccharide gums, and proteins [238-241]. Moreover, coating the liposomal surface with hydrophilic polymers such as polyethylene glycol (PEGs) can slow the clearance of liposomes. PEGs are characterized by low immunogenicity and antigenicity, hence can act as a protective covering over the liposome phospholipid bilayer [234,242]. The improved stability of surface-modified liposomes is due to the electrostatic and/or steric repulsion between liposome vesicles. Various attempts have been carried out to develop new generations of liposome NPs such as transferosomes, ethosomes, niosomes, cubosomes, biosomes, novasomes, and vesosomes. The composition and advantages of each new generation of liposomes are shown in Table 3.

Table 3. Composition and characteristic features of each liposomal new generation.

\begin{tabular}{|c|c|c|c|}
\hline Type & Composition & Advantages & References \\
\hline Transfersomes & $\begin{array}{l}\text { Lipid chains and surfactants } \\
\text { "edge activators" }\end{array}$ & $\begin{array}{l}\text { High elasticity, flexibility, and } \\
\text { penetration potential }\end{array}$ & {$[243,244]$} \\
\hline Ethosomes & $\begin{array}{l}\text { Phospholipids, water, and high ethanol } \\
\text { concentrations }(20-45 \%)\end{array}$ & $\begin{array}{l}\text { High elasticity, permeability, distribution, } \\
\text { flexibility, steric stability, and low aggregation }\end{array}$ & [245] \\
\hline Niosomes & Non-ionic surfactant & $\begin{array}{l}\text { Ease of production, low production cost, high } \\
\text { chemical stability and storage }\end{array}$ & [246] \\
\hline Cubosomes & $\begin{array}{l}\text { Lipid cubic phase and coated by } \\
\text { apolymer-based outer coating }\end{array}$ & $\begin{array}{l}\text { High surface area, water solubility, better } \\
\text { stability, and encapsulation efficiency }\end{array}$ & [247] \\
\hline Biosomes & Bile salts & $\begin{array}{l}\text { Deep penetration, high stability, and } \\
\text { encapsulation efficiency }\end{array}$ & [248] \\
\hline Novasomes & $\begin{array}{l}\text { Numerous amphiphiles such as fatty } \\
\text { alcohols and acids with each other, or } \\
\text { with phospholipids }\end{array}$ & Precise targeting and efficient delivery & [249] \\
\hline Vesosomes & $\begin{array}{l}\text { Liposomal vesicles encapsulating } \\
\text { smaller liposomes of different sizes }\end{array}$ & High protection and encapsulation efficiency & [250] \\
\hline
\end{tabular}

\section{Toxicity Concerns of Nanoantioxidant Applications}

The discipline of nanotoxicology is concerned with determining the toxicity and safety of NMs [251]. The assessment models used for this purpose include 2D cultures at the cellular level, small animal experiments (mice and rats), and traditional model organisms (zebrafish). 2D cultures are basic and beneficial means for toxicity assessment. They have several merits, including low cost, short test period, and the ability to obtain quick results; thus, they can be used to conduct pro-phase experiments under controlled conditions. However, they have drawbacks, such as the inability to simulate the human body's complex tissue structure and microenvironment. Animal experiments are complicated because of the inevitable species differences as well as ethical concerns that may prevent their use by the scientific community. Recently, some emerging non-animal models have gradually emerged for toxicity assessment, including 3D co-cultures, organoids, as well as organon-chip technologies [252-254]. These emerging non-animal models can simulate the 
structure and key functions of human organs. More notably, when compared to 2D cultures, they can reproduce the interactions between cells and secreted substances in the microenvironment. Furthermore, they have other advantages, such as high throughput and less consumption [255].

Although nanoantioxidant-based therapies have shown promising results in laboratories, there are still some hurdles to overcome before their use in clinical applications. In vivo studies are a prerequisite for assessing the biological effects of nanoantioxidants. In vivo systems are distinguished by their complexity, which allows the elucidation of diverse biodistribution and metabolic mechanisms as well as excretion and immune responses [256]. For instance, several in vitro and in vivo animal studies indicated that different shapes and sizes of nanoceria have therapeutic efficacy; however, no clinical trials have certified their use in the treatment of human diseases [89]. This could be attributed to the deficiency of clinical guidelines and care protocols for the use of nanoceria. In this regard, more research is mandatory to thoroughly determine the possible accumulation and clearance of nanoceria in target tissues and vital organs and to define the best administration routes and optimum doses. Attention must be taken into account when using nanoceria because their pharmacokinetics and distribution differ significantly from their bulk counterparts. In male Wistar adult rats, toxicity studies were carried out to evaluate the histopathological changes after the administration of $\mathrm{CeO}_{2}$ NPs that were synthesized using pullulan [257]. When compared to negative control groups, in vivo experimental results revealed that $\mathrm{CeO}_{2}$ NPs had no significant effects at hematological and biochemical levels. Furthermore, the biosafety of $\mathrm{CeO}_{2} \mathrm{NPs}$ was evaluated by performing histopathological examinations on kidney and liver tissues using an optical microscope, which confirmed the absence of any significant pathological modifications. Findings were consistent with those reported by Srinivas et al. [258]. There were no negative effects on kidney and liver functions, hematology, or blood biochemistry of the tested rats after the exposure to $\mathrm{CeO}_{2} \mathrm{NPs}_{\text {in }}$ either study. Using the serum of Wistar rats, the pullulan-mediated $\mathrm{CeO}_{2} \mathrm{NPs}$ displayed a strong anti-radical activity as revealed by ferric reducing/antioxidant power (FRAP) assay. This was due to their ability to bind to oxygen under various oxidizing and reducing conditions. Future research should be directed towards elucidating the long-term fate of nanoceria and quantifying the lowest nanoceria therapeutic doses that can be administered without causing any toxic effects.

One of the major issues causing complications during the interpretation of SNP nanotoxicity is the presence of numerous influential parameters that must be controlled one by one. Nanotoxicity of SNP are influenced by two major factors: (i) physicochemical properties such as size, surface charge, surface area, aggregation severity, porosity, geometry, degradability, density, and dissolution, and (ii) treatment conditions such as dose concentration, tested medium, exposure time, cell type, and animal model [259]. The use of capping molecules to prevent the off-target release of SNPs is an innovative strategy. These capping molecules can be polymeric multi-layered supra-molecules, DNA constructs, or proteins [260]. Fabrication of these complexes facilitates the responses towards the changes of specific stimuli, such as redox chemistry, temperature, $\mathrm{pH}$, and enzymes [102]. The effect of the SNP size administrated intravenously on the biodistribution and pharmacokinetic behavior in mice was investigated [261]. Interestingly, small-sized SNPs (i.e., $50 \mathrm{~nm}$ ) exhibited no significant toxic effect, whereas large-sized SNPs (i.e., 100 and $200 \mathrm{~nm}$ ) caused liver inflammation in mice. All SNPs were excreted via urine and bile; however, particles accumulated in the liver and spleen remained for four weeks after the single first dose injection [262]. As a result, biosafety considerations, long-term accumulation in tissues and organs, nanotoxicity, and biodegradability of nano-sized silica particles necessitate further research [263]. Comprehensive research is required to precisely assess the genotoxicity levels and mechanisms, the impact of long-term exposure to SNPs, the effect of their physicochemical characteristics, their routes of exposure, and the role of the immune response [259]. Ecotoxicological studies for assessing the potential risk of SNP are critical for a safer application and handling. To control its potential hazards, safety designs, bio- 
logical monitoring, appropriate hazard evaluation, and suitable waste discharge should be implemented [264]. As a result of mass production, widespread application, and potential environmental release, occupational exposure to SNPs has become increasingly common and unavoidably resulting in different impacts on human health [265]. Several studies postulated that uncontrolled exposure to SNPs can result in negative impacts on multiple organs and systems, involving respiratory [266], cardiovascular [267], hepatic [268], renal [269], nervous [270], immune [271], and reproductive systems [272].

In one study, in vivo toxicity of $\mathrm{CeO}_{2} \mathrm{NPs}$ synthesized by a co-precipitation technique via the reaction of cerium nitrate (i.e., precursor) and xanthan gum (i.e., a hydrophilic polysaccharide with cellulose-like biopolymer and a green stabilizer) was investigated [273]. Intraperitoneal injection was applied to assure the uniform distribution of $\mathrm{CeO}_{2} \mathrm{NPs}$ in the tissues of albino laboratory male rats. The biochemical and histological studies revealed that the green synthesized $\mathrm{CeO}_{2} \mathrm{NPs}$ exhibited a dose-dependent biological activity. Serum samples were analyzed for some biochemical parameters, including aspartate transaminase, alanine aminotransferase, creatinine, and blood urea nitrogen. The effect of $\mathrm{CeO}_{2} \mathrm{NPs}$ on the activity of the two antioxidant enzymes (e.g., SOD and CAT), peroxidation of liver lipids, and liver histopathology were also studied. The intraperitoneal administration of $\mathrm{CeO}_{2} \mathrm{NPs}$ at a dose of $30 \mathrm{mg} / \mathrm{kg}$ had no significant changes on the biochemical parameters or antioxidant status, whereas the injection of $\mathrm{CeO}_{2} \mathrm{NPs}$ at a dose of $60 \mathrm{mg} / \mathrm{kg}$ dramatically reduced the activities of serum liver enzyme and enhanced the activities of serum CAT and SOD. However, for long-term biomedical applications, proper dose selection is mandatory. In another study, selenium NPs-enriched polysaccharide (Se-POP-21) synthesized by Pleurotus ostreatus were purified, analyzed using column chromatography, and evaluated for their antioxidant potential [274]. Se-POP-21 expressed a strong scavenging effect towards DPPH-radicals and ${ }^{\bullet} \mathrm{OH}$ and the scavenging rate was concentration-dependent. Interestingly, Se-POP-21 exhibited no remarkable effects on normal cells.

\section{Advantages of Nanoantioxidant Applications}

Progress in the design of nanomaterials with antioxidant activity over the last few years has given rise to promising therapeutic applications at different target sites [275]. The unique opportunities for clinical use of nanoantioxidants are attributed to the fact that their size is larger than the size of renal filtration (i.e., $10 \mathrm{~nm}$ ) and can therefore be retained in circulation for longer periods [276]. Nanoantioxidants can also be used at low doses but with high efficacy, minimizing any possible adverse health effects. Nanoantioxidants are characterized by high accessibility, reactivity, and responsiveness to task-specific functions in targeted tissues. Treatment with nanoantioxidants can be integrated with conventional therapy to provide a potential therapeutic option for patients with oxidative stress-mediated pathological disorders. In this context, excellent efficiency has been achieved by covalent linkage and encapsulation of natural antioxidants within nanospheres containing antioxidant-functionalized nanomaterials [277].

\section{Limitations of Nanoantioxidant Applications}

\subsection{Limitations of Nanoantioxidant Methods of Detection and Measurements}

Although nanoantioxidants possess distinct advantages over conventional antioxidants, they do have some limitations [278]. Prior to the clinical use of nanoantioxidants, several critical hurdles and challenges need to be addressed. Spectroscopic or fluorometric detection techniques of nanoantioxidants are influenced by interference, caused by overlaps between the absorption peaks of nanomaterials tested and those of the probes or reaction products. Noble metal-based nanomaterials reveal surface plasmon resonance (SPR) properties at visible wavelengths, which may cause the falsification of absorption peaks. The properties of SPR are usually influenced by the size, shape, and surface configuration of nanoantioxidants [279]. Interference of antioxidant determination assays is significantly related to the types of nanomaterials employed and their catalytic, absorption, fluorescence, and optical properties. Additionally, the suitability of the assay to determine 
the nanoantioxidant potential should be studied on a case-to-case basis to prevent any incorrect measurements. EPR is also referred to as electron spin resonance (ESR) or electron magnetic resonance (EMR) spectroscopy. The EPR spectrophotometer provides remarkable data for the identification, quantification, dynamics, and analysis of ROS and RNS. EPR spectrophotometer detects free radicals directly and accurately even at extremely low concentrations (i.e., $1 \mu \mathrm{M}$ ) [280]. It is distinguished by the ability to directly measure ROS in vivo. When dealing with short-lived ROS, the spin-trapping technique forms a spin adduct by adding radicals to a nitrone spin, which has a comparatively long half-life and can be detected using an EPR spectrophotometer. EPR combined with appropriate spin traps have emerged as powerful tools for measuring ${ }^{\bullet} \mathrm{OH}, \mathrm{O}_{2}{ }^{\bullet-}$, and ${ }^{\bullet} \mathrm{NO}$ in biological systems [280]. Pyrroline-based cyclic nitrones such as 5,5-dimethyl-pyrroline $\mathrm{N}$-oxide and 5-diethoxyphosphoryl-5-methyl pyrroline $\mathrm{N}$-oxide are the most frequently utilized spin traps [281]. Both types of spin traps react with the ${ }^{\bullet} \mathrm{OH}$ and $\mathrm{O}_{2}{ }^{\bullet-}$ radicals and form $-\mathrm{OH}$ and $-\mathrm{OOH}$ adducts, respectively. In comparison to other spectrophotometric techniques, EPR facilitates the interpretation of complex heterogeneous solutions [282]. However, the short lifetime of free radicals and the low-rate extent of radical generation in living tissues and organs make radical detection by EPR challenging. As a result, rapid-scan EPR has emerged as a powerful technique for sensitive detection of ROS with excessively short lifetimes (e.g., ${ }^{\bullet} \mathrm{OH}$ and $\mathrm{O}_{2}{ }^{\bullet-}$ ) at ambient temperatures, which were difficult to detect using EPR [283].

It is a contentious issue to improve existing protocols and assays for assessing the antioxidant potency of nanoantioxidants. Assays based on the spectrophotometric or spectrofluorimetric basis are subjected to light scattering exhibited by a variety of nanomaterials. In this context, inhibited autoxidation methods, which rely on measuring the autoxidation rate of a reference substrate in the presence and absence of nanoantioxidants, are among those methods that cause less interference. Inhibited autoxidation methods are preferable protocols because they assess the antioxidant activity in close-to-real settings. Monitoring the absence of reactants, most commonly $\mathrm{O}_{2}$ or the generation of oxidation products (e.g., hydroperoxides or conjugated dienes) can be used to assess inhibited autoxidation kinetics [284]. Oximetry methods measure oxygen $\left(\mathrm{O}_{2}\right)$ consumption and are carried out in closed systems and monitored by a fluorescence quenching probe [285], a polarographic probe [286], or a pressure transducer [287]. The trend of $\mathrm{O}_{2}$ uptake in oximetry methods typically follows a biphasic behavior, with an induction phase in which the antioxidant suppresses the autoxidation accompanied by a rapid rate of autoxidation. Oximetry methods can be implemented in homogeneous organic solutions, water-based solutions, and heterogeneous models such as liposomes or micelles. The potency of nanoantioxidants can be easily assessed using oximetry methods with a differential pressure transducer because this method is not affected either by the color of the colloidal solution or the incidence of the suspended NPs [288].

\subsection{Other Limitations of Nanoantioxidant Applications}

Nanomaterial agglomeration may also cause interference during antioxidant determination assays. The morphological structure, shape, surface charge, and type of nanomaterials affect the agglomeration tendency, which further affects the cellular uptake and ultimately affects the associated toxicity [289]. Some adjustments and strategies to avoid interference of conventional antioxidant assays and to provide more reliable measurements of the nanoantioxidant biological effects are described as follows [290]:

- Use of well-dispersed nanomaterials (not-agglomerated);

- Application of washing and separation steps (e.g., centrifugation, filtration, and precipitation);

- Use of appropriate conditions similar to those of biological systems;

- Application of concentrations below toxicity ranges.

Overall, a combination of more than one detection assay will provide a fully comprehensive and informative picture of the antioxidant capacity of nanomaterials. 
Nanoantioxidant doses and their frequency vary greatly based on the levels of RONS in different inflammatory diseases and even within the several phases of the same inflammatory disease. Application of appropriate doses of nanoantioxidants for the control of intracellular RONS should be directed towards therapeutic applications without exacerbating any adverse clinical manifestations. Ideally, nanoantioxidants should significantly contribute to the well-being of patients and reduce or prevent treatment-induced health side-effects to overcome potential risks. Enhancing biocompatibility and feasibility of nanoantioxidants are also issues of concern that need to be addressed prior to commercialization of nanoantioxidants. Scientists have spent the previous decade assessing and monitoring the impact of nanomaterials on biological systems and it has been suggested that the cytotoxic effects of nanomaterials are variable and can be reduced [52].

From a synthesis point of view, optimizing the synthesis parameters would contribute to the development of high-quality nanoantioxidants and well-defined and reproducible nanostructures with better physicochemical characteristics. Cost-effective commercial production is also a crucial step that should be considered for the potential use of nanoantioxidants in biomedical practices. Long-term chronic cytotoxic effects need to be thoroughly investigated and assessed for safe in vivo applications. The precise identification of nature, physicochemical properties, and the mechanism of action of functionalized nanoantioxidants is a prerequisite for achieving the maximum biological benefits [54]. Additionally, a comprehensive assessment of the toxicity of non-biodegradable nanoantioxidants is a vital issue for any future biomedical application. Hence, applications of sophisticated safety measurements for precise analysis, assessment, and toxicity evaluation are the basic requirements. To address some of the toxicity issues, nanoantioxidants derived from various biological sources, such as bacteria, fungi, algae, plants, and lichens have emerged as significant alternative options for improved biocompatibility, durability, efficacy, and stability. Biological sources are efficient producers of a wide range of biomolecules and secondary metabolites [291]. The amalgamation of these biologically active compounds mediates the manufacture of biogenic-derived nanomaterials with antioxidant potency.

\section{Future Insights of Nanoantioxidant Applications}

Nanoantioxidants have exhibited high potency for oxidative stress depletion with high cellular antioxidant potential, specificity, and targeted delivery. However, to achieve significant clinical benefits, a thorough understanding of the detailed antioxidative mechanisms of nanoantioxidants necessitates extensive cross-collaboration of experts from various fields, including materials science, chemistry, as well as physical and biomedical fields. In-depth mechanistic studies of oxidative stress in vivo will be helpful to revolutionize the nanoantioxidant therapeutic field. Identification of the oxidative species that are primarily responsible for the onset and progression of oxidative stress-related diseases is required. Most notably, the use of nanoantioxidants will be significantly dependent on their rational design, characterization, as well as tools and methods that can provide a thorough and detailed understanding of their antioxidant activities. The tailored design of nanoantioxidants can result in significant antioxidative potential in vivo and, as a result, improve clinical effectiveness. It is necessary to precisely identify the nature, physicochemical properties, and mechanisms of action of nanoantioxidant composites in terms of their biological and catalytic activities. Searching for the best and the most cost-effective routes for the preparation of nanoantioxidants is necessary while minimizing their cytotoxic effects. The use of advanced models to assess their cytotoxic effects will aid in the robust evaluation of emerging antioxidative monotherapies. Prior to practical applications of nanoantioxidants, more research is required related to their in-situ delivery and on-time release at target sites. Evaluation of the benefits and side effects of using nanoantioxidants is necessary before they can be used safely in vivo, particularly for long-term treatments. Moreover, novel and efficient therapeutic nanoantioxidant delivery methods are required. Understanding the nature of new nanostructures with antioxidant activity will thus pave the way for nanoantioxidant-mediated treatments in the future. 
To summarize, future studies shall be aimed at (i) analyzing the impact of prolonged exposure to minor concentrations of nanoantioxidants; (ii) assessing the potential risks of nanoantioxidants during fabrication, manipulation, and storage; (iii) simplifying the fabrication processes for the manufacture of highly potent nanoantioxidants; (iv) enhancing the reproducibility, biocompatibility, reliability, robustness, and stability of nanoantioxidants in biological microenvironments; and (v) designing microreactors that can effectively control the parameters of reaction synthesis.

\section{Conclusions}

Specific types of nanoantioxidants have emerged as pioneer types due to their antioxidant potency, demonstrating a superior potential to reduce oxidative stress with increased sensitivity, low cytotoxicity, and better-targeted delivery. Ceria-, silica-, PDA, polysaccharide-, protein-, and nanocomposite-based nanoantioxidants are among the most interesting and investigated types of nanoantioxidants due to their unique physicochemical properties, which can be tunned/adjusted to produce superior multifunctional nanoantioxidants. This can be accomplished by monitoring the preparation methods and optimizing the reaction parameters to obtain the desired types of nanoantioxidants with proper surface functionalization. Bioengineered nanomaterials have emerged as promising green nanoantioxidants and better alternatives due to their biocompatibility, biodegradability, low toxicity, and stability. Solid lipid NPs, nanostructured lipid carriers, and liposome NPs are efficient nanoencapsulation systems. The toxicity concerns of nanoantioxidant applications have been emphasized. The advantages, limitations, and future insights of nanoantioxidant applications have been proposed to achieve a win-win situation in the fight against oxidative stress-mediated disorders.

Author Contributions: Collection of data, B.O.; Writing—original draft preparation, B.O.; and Review and editing, K.-H.B. All authors have read and agreed to the published version of the manuscript.

Funding: This research was supported by the Basic Science Research Program through the National Research Foundation of Korea (NRF) funded by the Ministry of Education (NRF-2021R1F1A1060297).

Conflicts of Interest: The authors declare no conflict of interest.

\section{References}

1. Zheng, F.; Gonçalves, F.M.; Abiko, Y.; Li, H.; Kumagai, Y.; Aschner, M. Redox toxicology of environmental chemicals causing oxidative stress. Redox Biol. 2020, 34, 101475-101491. [CrossRef]

2. Giam, B.; Kaye, D.M.; Rajapakse, N.W. Role of renal oxidative stress in the pathogenesis of the cardiorenal syndrome. Heart Lung Circ. 2016, 25, 874-880. [CrossRef]

3. Chen, T.; Luo, W.; Wu, G.; Wu, L.; Huang, S.; Li, J.; Wang, J.; Hu, X.; Huang, W.; Liang, G. A novel MyD88 inhibitor LM9 prevents atherosclerosis by regulating inflammatory responses and oxidative stress in macrophages. Toxicol. Appl. Pharmacol. 2019, 370, 44-55. [CrossRef] [PubMed]

4. Yuan, T.; Yang, T.; Chen, H.; Fu, D.; Hu, Y.; Wang, J.; Yuan, Q.; Yu, H.; Xu, W.; Xie, X. New insights into oxidative stress and inflammation during diabetes mellitus-accelerated atherosclerosis. Redox Biol. 2019, 20, 247-260. [CrossRef]

5. Doridot, L.; Jeljeli, M.; Chêne, C.; Batteux, F. Implication of oxidative stress in the pathogenesis of systemic sclerosis via inflammation, autoimmunity and fibrosis. Redox Biol. 2019, 25, 101122. [CrossRef]

6. Marseglia, L.; D'Angelo, G.; Granese, R.; Falsaperla, R.; Reiter, R.J.; Corsello, G.; Gitto, E. Role of oxidative stress in neonatal respiratory distress syndrome. Free Radic. Biol. Med. 2019, 142, 132-137. [CrossRef] [PubMed]

7. Huang, C.-Y.; Hu, R.-C.; Li, J.; Chen, B.-B.; Dai, A.-G. $\alpha 1$-Antitrypsin alleviates inflammation and oxidative stress by suppressing autophagy in asthma. Cytokine 2021, 141, 155454. [CrossRef]

8. Fang, Y.; Lu, L.; Liang, Y.; Peng, D.; Aschner, M.; Jiang, Y. Signal transduction associated with lead-induced neurological disorders: A Review. Food Chem. Toxicol. 2021, 150, 112063. [CrossRef]

9. Dastmalchi, N.; Baradaran, B.; Latifi-Navid, S.; Safaralizadeh, R.; Khojasteh, S.M.B.; Amini, M.; Roshani, E.; Lotfinejad, P. Antioxidants with two faces toward cancer. Life Sci. 2020, 258, 118186. [CrossRef] [PubMed]

10. Lv, X.; Huang, J.; Wang, H. MiR-30a-3p ameliorates oxidative stress in rheumatoid arthritis synovial fibroblasts via activation of Nrf2-ARE signaling pathway. Immunol. Lett. 2021, 232, 1-8. [CrossRef]

11. Sies, H. Oxidative stress: Introductory remarks. In Oxidative Stress; Sies, H., Ed.; Academic Press: London, UK, 1985.

12. Harman, D. Free radical theory of aging suggests that free radicals produced during normal metabolic process later react with and damage important molecules. J. Gerontol. 1956, 11, 298-300. [CrossRef] [PubMed] 
13. Flieger, J.; Flieger, W.; Baj, J. Antioxidants: Classification, natural sources, activity/capacity measurements, and usefulness for the synthesis of nanoparticles. Materials 2021, 14, 4135. [CrossRef]

14. Weinberg, D.R.; Gagliardi, C.J.; Hull, J.F.; Murphy, C.F.; Kent, C.A.; Westlake, B.C.; Paul, A.; Ess, D.H.; Granville, D.; Meyer, T.J. Proton-coupled electron transfer. Chem Rev. 2012, 107, 5004-5064. [CrossRef]

15. Liang, N.; Kitts, D.D. Antioxidant property of coffee components: Assessment of methods that define mechanism of action. Molecules 2014, 19, 19180-19208. [CrossRef]

16. Garcia, C.; Blesso, C.N. Antioxidant properties of anthocyanins and their mechanism of action in atherosclerosis. Free Radic. Biol. Med. 2021, 172, 152-166. [CrossRef]

17. Zheng, Y.Z.; Deng, G.; Liang, Q.; Chen, D.F.; Guo, R.; Lai, R.C. Antioxidant activity of quercetin and its glucosides from propolis: A theoretical study. Sci. Rep. 2017, 7, 7543-7754. [CrossRef] [PubMed]

18. Lu, L.; Qiang, M.; Li, F.; Zhang, H.; Zhang, S. Theoretical investigation on the antioxidative activity of anthocyanidins: A DFT/B3LYP study. Dyes Pigment. 2014, 103, 175-182. [CrossRef]

19. Munteanu, I.G.; Apetrei, C. Analytical methods used in determining antioxidant activity: A review. Int. J. Mol. Sci. 2021, 22, 3380. [CrossRef] [PubMed]

20. Ivanova, A.; Gerasimova, E.; Gazizullina, E. Study of antioxidant properties of agents from the perspective of their action mechanisms. Molecules 2020, 25, 4251. [CrossRef]

21. Di Meo, F.; Lemaur, V.; Cornil, J.; Lazzaroni, R.; Duroux, J.-L.; Olivier, Y.; Trouillas, P. Free radical scavenging by natural polyphenols: Atom versus electron transfer. J. Phys. Chem. A 2013, 117, 2082-2092. [CrossRef]

22. Marchi, R.C.; Campos, I.A.S.; Santana, V.T.; Carlos, R.M. Chemical implications and considerations on techniques used to assess the in vitro antioxidant activity of coordination compounds. Coord. Chem. Rev. 2022, 451, 214275. [CrossRef]

23. Lee, C.Y.; Sharma, A.; Semenya, J.; Anamoah, C.; Chapman, K.N.; Barone, V. Computational study of ortho-substituent effects on antioxidant activities of phenolic dendritic antioxidants. Antioxidants 2020, 9, 189. [CrossRef]

24. Litwinienko, G.; Ingold, K.U. Abnormal solvent effects on hydrogen atom abstractions. 1. The reactions of phenols with 2, 2-diphenyl-1-picrylhydrazyl (dpph ${ }^{\bullet}$ ) in alcohols. J. Org. Chem. 2003, 68, 3433-3438. [CrossRef]

25. Litwinienko, G.; Ingold, K.U. Abnormal solvent effects on hydrogen atom abstraction. 2. Resolution of the curcumin antioxidant controversy. The role of sequential proton loss electron transfer. J. Org. Chem. 2004, 69, 5888-5896. [CrossRef]

26. Litwinienko, G.; Ingold, K.U. Abnormal solvent effects on hydrogen atom abstraction. 3. Novel kinetics in sequential proton loss electron transfer chemistry. J. Org. Chem. 2005, 70, 8982-8990. [CrossRef]

27. Álvarez-Diduk, R.; Galano, A.; Tan, D.X.; Reiter, R.J. The key role of the sequential proton loss electron transfer mechanism on the free radical scavenging activity of some melatonin-related compounds. Theor. Chem. Acc. 2016, 135, 38-43. [CrossRef]

28. Galano, A.; Raúl Alvarez-Idaboy, J. Computational strategies for predicting free radical scavengers' protection against oxidative stress: Where are we and what might follow? Int. J. Quantum Chem. 2019, 119, e25665. [CrossRef]

29. Amić, D.; Stepanić, V.; Lučić, B.; Marković, Z.; Dimitrić Marković, J.M. PM6 study of free radical scavenging mechanisms of flavonoids: Why does O-H bond dissociation enthalpy effectively represent free radical scavenging activity? J. Mol. Model. 2013, 19, 2593-2603. [CrossRef] [PubMed]

30. Fifen, J.J.; Dhaouadi, Z.; Nsangou, M.; Holtomo, O.; Jaidane, N. "Proton-coupled electron transfer in the reaction of 3,4dihydroxyphenylpyruvic acid with reactive species in various media. Int. J. Chem. Phys. 2015, 2015, 13. [CrossRef]

31. MacAleese, L.; Hermelin, S.; El Hage, K.; Chouzenoux, P.; Kulesza, A.; Antoine, R.; Bonacina, L.; Meuwly, M.; Wolf, J.P.; Dugourd, P. Sequential proton coupled electron transfer (PCET): Dynamics observed over 8 orders of magnitude in time. J. Am. Chem. Soc. 2016, 138, 4401-4407. [CrossRef] [PubMed]

32. Nosaka, Y.; Nosaka, A.Y. Generation and detection of reactive oxygen species in photocatalysis. Chem. Rev. 2017, 117, 11302-11336. [CrossRef]

33. Weidinger, A.; Kozlov, A.V. Biological activities of reactive oxygen and nitrogen species: Oxidative stress versus signal transduction. Biomolecules 2015, 5, 472-484. [CrossRef] [PubMed]

34. Neha, K.; Haider, M.R.; Pathak, A.; Yar, M.S. Medicinal prospects of antioxidants: A review. Eur. J. Med. Chem. 2019, 178, 687-704. [CrossRef]

35. Lo Conte, M.; Carroll, K.S. The redox biochemistry of protein sulfenylation and sulfinylation. J. Biol. Chem. 2013, 288, 26480-26488. [CrossRef]

36. van Lith, R.; Ameer, G.A. Antioxidant polymers as biomaterial. In Oxidative Stress and Biomaterials; Dziubla, T., Butterfield, D.A., Eds.; Elsevier Inc.: San Diego, CA, USA, 2016; pp. 251-296.

37. Liu, Y.; Shi, J. Antioxidative nanomaterials and biomedical applications. Nano Today 2019, 27, 146-177. [CrossRef]

38. Azab, A.E.; Adwas, A.A.; Elsayed, A.S.I.; Adwas, A.A.; Elsayed, A.S.I.; Azab, A.E.; Quwaydir, F.A. Oxidative stress and antioxidant mechanisms in human body. J. Appl. Biotechnol. Bioeng. 2019, 6, 43-47. [CrossRef]

39. Drzeżdżon, J.; Jacewicz, D.; Chmurzyński, L. The impact of environmental contamination on the generation of reactive oxygen and nitrogen species-Consequences for plants and humans. Environ. Int. 2018, 119, 133-151. [CrossRef]

40. Sharpe, E.; Andreescu, D.; Andreescu, S. Artificial nanoparticle antioxidants. In Oxidative Stress: Diagnostics, Prevention, and Therapy; Andreescu, S., Hepel, M., Eds.; Oxford University Press Inc.: New York, NY, USA, 2012; pp. 235-253.

41. Medhe, S.; Bansal, P.; Srivastava, M.M. Enhanced antioxidant activity of gold nanoparticle embedded 3, 6-dihydroxyflavone: A combinational study. Appl. Nanosci. 2014, 4, 153-161. [CrossRef] 
42. Das, M.; Chatterjee, S. Green synthesis of metal/metal oxide nanoparticles toward biomedical applications: Boon or bane. In Green Synthesis, Characterization and Applications of Nanoparticles; Shukla, A.K., Iravani, S., Eds.; Elsevier Health Sciences: London, UK, 2019; pp. 265-301.

43. Huang, K.-J.; Wu, S.-R.; Shieh, D.-B. Zero-valent iron nanoparticles inhibited head and neck cancer cells growth: A pilot evaluation and mechanistic characterization. Free Radic. Biol. Med. 2017, 108, S39. [CrossRef]

44. Brindhadevi, K.; Samuel, M.S.; Verma, T.N.; Vasantharaj, S.; Sathiyavimal, S.; Saravanan, M.; Pugazhendhi, A.; Duc, P.A. Zinc oxide nanoparticles (ZnONPs)-induced antioxidants and photocatalytic degradation activity from hybrid grape pulp extract (HGPE). Biocatal. Agric. Biotechnol. 2020, 28, 101730-101737. [CrossRef]

45. Kokalari, I.; Gassino, R.; Giovannozzi, A.M.; Croin, L.; Gazzano, E.; Bergamaschi, E.; Rossi, A.M.; Perrone, G.; Riganti, C.; Ponti, J. Pro-and anti-oxidant properties of near-infrared (NIR) light responsive carbon nanoparticles. Free Radic. Biol. Med. 2019, 134, 165-176. [CrossRef]

46. Mansour Lakourj, M.; Norouzian, R.S.; Esfandyar, M.; Ghasemi Mir, S. Conducting nanocomposites of polypyrrole-co-polyindole doped with carboxylated CNT: Synthesis approach and anticorrosion/antibacterial/antioxidation property. Mater. Sci. Eng. B Solid-State Mater. Adv. Technol. 2020, 261, 114673-114688. [CrossRef]

47. Shah, S.T.; Yehya, A.W.; Saad, O.; Simarani, K.; Chowdhury, Z.; Alhadi, A.A.; Al-Ani, L.A. Surface functionalization of iron oxide nanoparticles with gallic acid as potential antioxidant and antimicrobial agents. Nanomaterials 2017, 7, 306. [CrossRef] [PubMed]

48. Shi, J.; Kantoff, P.W.; Wooster, R.; Farokhzad, O.C. Cancer nanomedicine: Progress, challenges and opportunities. Nat. Rev. Cancer 2017, 17, 20-38. [CrossRef]

49. Ferreira, C.A.; Ni, D.; Rosenkrans, Z.T.; Cai, W. Scavenging of reactive oxygen and nitrogen species with nanomaterials. Nano Res. 2018, 11, 4955-4984. [CrossRef] [PubMed]

50. Vaiserman, A.; Koliada, A.; Zayachkivska, A.; Lushchak, O. Nanodelivery of Natural Antioxidants: An Anti-aging Perspective. Front. Bioeng. Biotechnol. 2020, 7, 447-466. [CrossRef]

51. Lushchak, O.; Zayachkivska, A.; Vaiserman, A. Metallic nanoantioxidants as potential therapeutics for type 2 diabetes: A hypothetical background and translational perspectives. Oxid. Med. Cell. Longev. 2018, 2018, 9. [CrossRef] [PubMed]

52. Eftekhari, A.; Dizaj, S.M.; Chodari, L.; Sunar, S.; Hasanzadeh, A.; Ahmadian, E.; Hasanzadeh, M. The promising future of nano-antioxidant therapy against environmental pollutants induced-toxicities. Biomed. Pharmacother. 2018, 103, 1018-1027. [CrossRef]

53. Martinelli, C.; Pucci, C.; Battaglini, M.; Marino, A.; Ciofani, G. Antioxidants and nanotechnology: Promises and limits of potentially disruptive approaches in the treatment of central nervous system diseases. Adv. Healthc. Mater. 2019, 9, 19015891901617. [CrossRef]

54. Khalil, I.; Yehye, W.A.; Etxeberria, A.E.; Alhadi, A.A.; Dezfooli, S.M.; Julkapli, N.B.M.; Basirun, W.J.; Seyfoddin, A. Nanoantioxidants: Recent trends in antioxidant delivery applications. Antioxidants 2020, 9, 24. [CrossRef]

55. Kumar, H.; Bhardwaj, K.; Nepovimova, E.; Kuča, K.; Dhanjal, D.S.; Bhardwaj, S.; Bhatia, S.K.; Verma, R.; Kumar, D. Antioxidant functionalized nanoparticles: A combat against oxidative stress. Nanomaterials 2020, 10, 1334. [CrossRef]

56. Halliwell, B. How to characterize a biological antioxidant. Free Radic. Res. Commun. 1990, 9, 1-32. [CrossRef] [PubMed]

57. Galano, A. Free radicals induced oxidative stress at a molecular level: The current status, challenges and perspectives of computational chemistry-based protocols. J. Mex. Chem. Soc. 2017, 59, 231-262. [CrossRef]

58. Hunyadi, A. The mechanism(s) of action of antioxidants: From scavenging reactive oxygen/nitrogen species to redox signaling and the generation of bioactive secondary metabolites. Med. Res. Rev. 2019, 39, 2505-2533. [CrossRef] [PubMed]

59. Omran, B.A. Fundamentals of Nanotechnology and Nanobiotechnology. In Nanobiotechnology: A Multidisciplinary Field of Science; Springer: Cham, Switzerland, 2020; pp. 1-36.

60. Chenthamara, D.; Subramaniam, S.; Ramakrishnan, S.G.; Krishnaswamy, S.; Essa, M.M.; Lin, F.; Qoronfleh, M.W. Therapeutic efficacy of nanoparticles and routes of administration. Biomater. Res. 2019, 23, 20-49. [CrossRef]

61. Valgimigli, L.; Amorati, R. Antioxidant activity of nanomaterials. J. Mater. Chem. B 2018, 6, 2036-2051. [CrossRef]

62. Xu, Y.; Musumeci, V.; Aymonier, C. Chemistry in supercritical fluids for the synthesis of metal nanomaterials. React. Chem. Eng. 2019, 4, 2030-2054. [CrossRef]

63. Zielińska, A.; Carreiró, F.; Oliveira, A.M.; Neves, A.; Pires, B.; Venkatesh, D.N.; Durazzo, A.; Lucarini, M.; Eder, P.; Silva, A.M. Polymeric nanoparticles: Production, characterization, toxicology and ecotoxicology. Molecules 2020, 25, 3731. [CrossRef]

64. Chen, G.; Roy, I.; Yang, C.; Prasad, P.N. Nanochemistry and nanomedicine for nanoparticle-based diagnostics and therapy. Chem. Rev. 2016, 116, 2826-2885. [CrossRef]

65. Yang, G.; Xu, L.; Chao, Y.; Xu, J.; Sun, X.; Wu, Y.; Peng, R.; Liu, Z. Hollow $\mathrm{MnO}_{2}$ as a tumor-microenvironment-responsive biodegradable nano-platform for combination therapy favoring antitumor immune responses. Nat. Commun. 2017, 8, 902-915. [CrossRef]

66. Kim, J.; Kim, H.Y.; Song, S.Y.; Go, S.; Sohn, H.S.; Baik, S.; Soh, M.; Kim, K.; Kim, D.; Kim, H.-C. Synergistic oxygen generation and reactive oxygen species scavenging by manganese ferrite/ceria co-decorated nanoparticles for rheumatoid arthritis treatment. ACS Nano 2019, 13, 3206-3217. [CrossRef] [PubMed]

67. Xiao, J.; Chen, S.; Yi, J.; Zhang, H.F.; Ameer, G.A. A cooperative copper metal-organic framework-hydrogel system improves wound healing in diabetes. Adv. Funct. Mater. 2016, 27, 1604872-1604882. [CrossRef] [PubMed] 
68. Arriagada, F.; Günther, G.; Morales, J. Nanoantioxidant-based silica particles as flavonoid carrier for drug delivery applications. Pharmaceutics 2020, 12, 302. [CrossRef]

69. Keles, E.; Song, Y.; Du, D.; Dong, W.-J.; Lin, Y. Recent progress in nanomaterials for gene delivery applications. Biomater. Sci. 2016, 4, 1291-1309. [CrossRef] [PubMed]

70. Banavar, S.; Deshpande, A.; Sur, S.; Andreescu, S. Ceria nanoparticle theranostics: Harnessing antioxidant properties in biomedicine and beyond. J. Phys. Mater. 2021, 4, 042003-42026. [CrossRef]

71. Moskvin, M.; Huntošová, V.; Herynek, V.; Matouš, P.; Michalcová, A.; Lobaz, V.; Zasońska, B.; Šlouf, M.; Seliga, R.; Horák, D. In vitro cellular activity of maghemite/cerium oxide magnetic nanoparticles with antioxidant properties. Colloids Surf. B Biointerfaces 2021, 204, 111824-111833. [CrossRef]

72. Kulkarni, M.B.; Goel, S. Microfluidic devices for synthesizing nanomaterials-A review. Nano Express 2020, 1, 32004-32033. [CrossRef]

73. Chandar, N.K.; Jayavel, R. Synthesis and characterization of C14TAB passivated cerium oxide nanoparticles prepared by co-precipitation route. Phys. E Low-Dimens. Syst. Nanostructures 2014, 58, 48-51. [CrossRef]

74. Derakhshandeh, P.G.; Soleimannejad, J. Sonochemical synthesis of a new nano-sized cerium (III) supramolecular compound; Precursor for nanoceria. Ultrason. Sonochem. 2016, 31, 122-128. [CrossRef]

75. Akbari, A.; Khammar, M.; Taherzadeh, D.; Rajabian, A.; Zak, A.K.; Darroudi, M. Zinc-doped cerium oxide nanoparticles: Sol-gel synthesis, characterization, and investigation of their in vitro cytotoxicity effects. J. Mol. Struct. 2017, 1149, 771-776. [CrossRef]

76. Soren, S.; Jena, S.R.; Samanta, L.; Parhi, P. Antioxidant potential and toxicity study of the cerium oxide nanoparticles synthesized by microwave-mediated synthesis. Appl. Biochem. Biotechnol. 2015, 177, 148-161. [CrossRef] [PubMed]

77. Khadar, Y.A.S.; Balamurugan, A.; Devarajan, V.P.; Subramanian, R.; Kumar, S.D. Synthesis, characterization and antibacterial activity of cobalt doped cerium oxide $\left(\mathrm{CeO}_{2}\right.$ : Co) nanoparticles by using hydrothermal method. J. Mater. Res. Technol. 2019, 8, 267-274. [CrossRef]

78. Mishra, S.; Priyadarshinee, M.; Debnath, A.K.; Muthe, K.P.; Mallick, B.C.; Das, N.; Parhi, P. Rapid microwave assisted hydrothermal synthesis cerium vanadate nanoparticle and its photocatalytic and antibacterial studies. J. Phys. Chem. Solids 2020, 137, 109211-109220. [CrossRef]

79. Sundararajan, V.; Venkatasubbu, G.D.; Sheik Mohideen, S. Investigation of therapeutic potential of cerium oxide nanoparticles in Alzheimer's disease using transgenic Drosophila. 3 Biotech 2021, 11, 159-170. [CrossRef]

80. Gliga, A.R.; Edoff, K.; Caputo, F.; Källman, T.; Blom, H.; Karlsson, H.L.; Ghibelli, L.; Traversa, E.; Ceccatelli, S.; Fadeel, B. Cerium oxide nanoparticles inhibit differentiation of neural stem cells. Sci. Rep. 2017, 7, 1-20. [CrossRef]

81. Pagliari, F.; Mandoli, C.; Forte, G.; Magnani, E.; Pagliari, S.; Nardone, G.; Licoccia, S.; Minieri, M.; Di Nardo, P.; Traversa, E. Cerium oxide nanoparticles protect cardiac progenitor cells from oxidative stress. ACS Nano 2012, 6, 3767-3775. [CrossRef]

82. Giri, S.; Karakoti, A.; Graham, R.P.; Maguire, J.L.; Reilly, C.M.; Seal, S.; Rattan, R.; Shridhar, V. Nanoceria: A rare-earth nanoparticle as a novel anti-angiogenic therapeutic agent in ovarian cancer. PLoS ONE 2013, 8, e54578. [CrossRef]

83. Zarkovic, N. Roles and functions of ROS and RNS in cellular physiology and pathology. Cells 2020, 9, 767. [CrossRef]

84. Shields, H.J.; Traa, A.; Van Raamsdonk, J.M. Beneficial and detrimental effects of reactive oxygen species on lifespan: A comprehensive review of comparative and experimental studies. Front. Cell Dev. Biol. 2021, 9, 628157. [CrossRef]

85. Thakur, N.; Manna, P.; Das, J. Synthesis and biomedical applications of nanoceria, a redox active nanoparticle. J. Nano Biotechnol. 2019, 17, 84. [CrossRef]

86. Perez, J.M.; Asati, A.; Nath, S.; Kaittanis, C. Synthesis of biocompatible dextran-coated nanoceria with pH-dependent antioxidant properties. Small 2008, 4, 552-556. [CrossRef] [PubMed]

87. Qi, L.; Fresnais, J.; Muller, P.; Theodoly, O.; Berret, J.-F.; Chapel, J.-P. Interfacial activity of phosphonated-PEG functionalized cerium oxide nanoparticles. Langmuir 2012, 28, 11448-11456. [CrossRef] [PubMed]

88. Wang, Q.; Perez, J.M.; Webster, T.J. Inhibited growth of Pseudomonas aeruginosa by dextran-and polyacrylic acid-coated ceria nanoparticles. Int. J. Nanomed. 2013, 8, 3395-3399.

89. Sadidi, H.; Hooshmand, S.; Ahmadabadi, A.; Hoseini, S.J.; Baino, F.; Vatanpour, M.; Kargozar, S. Cerium oxide nanoparticles (Nanoceria): Hopes in soft tissue engineering. Molecules 2020, 25, 4559. [CrossRef]

90. Kim, S.J.; Chung, B.H. Antioxidant activity of levan coated cerium oxide nanoparticles. Carbohydr. Polym. 2016, 150, 400-407. [CrossRef]

91. Weaver, J.D.; Stabler, C.L. Antioxidant cerium oxide nanoparticle hydrogels for cellular encapsulation. Acta Biomater. 2015, 16, 136-144. [CrossRef] [PubMed]

92. Mortazavi, Z.; Charbgoo, F.; Darroudi, M. Impact of physicochemical properties of cerium oxide nanoparticles on their toxicity effects. Ceram. Int. 2017, 43, 14572-14581. [CrossRef]

93. Fa, M.; Yang, D.; Gao, L.; Zhao, R.; Luo, Y.; Yao, X. The effect of AuNP modification on the antioxidant activity of CeO 2 nanomaterials with different morphologies. Appl. Surf. Sci. 2018, 457, 352-359. [CrossRef]

94. Vernekar, A.A.; Sinha, D.; Srivastava, S.; Paramasivam, P.U.; D'Silva, P.; Mugesh, G. An antioxidant nanozyme that uncovers the cytoprotective potential of vanadia nanowires. Nat. Commun. 2014, 5. [CrossRef]

95. Ragg, R.; Natalio, F.; Tahir, M.N.; Janssen, H.; Kashyap, A.; Strand, D.; Strand, S.; Tremel, W. Molybdenum trioxide nanoparticles with intrinsic sulfite oxidase activity. ACS Nano 2014, 8, 5182-5189. [CrossRef] 
96. Olvera Salazar, A.; García Hernández, M.; López Camacho, P.Y.; López Marure, A.; Reyes de la Torre, A.I.; de Jesús Morales Ramírez, A.; Hernández Santiago, F.; Aguilera Vázquez, L. Influence of $\mathrm{Eu}^{3+}$ doping content on antioxidant properties of $\mathrm{Lu}_{2} \mathrm{O}_{3}$ sol-gel derived nanoparticles. Mater. Sci. Eng. C 2016, 69, 850-855. [CrossRef]

97. Javed, R.; Ahmed, M.; ul Haq, I.; Nisa, S.; Zia, M. PVP and PEG doped CuO nanoparticles are more biologically active: Antibacterial, antioxidant, antidiabetic and cytotoxic perspective. Mater. Sci. Eng. C 2017, 79, 108-115. [CrossRef]

98. Javed, R.; Usman, M.; Tabassum, S.; Zia, M. Effect of capping agents: Structural, optical and biological properties of ZnO nanoparticles. Appl. Surf. Sci. 2016, 386, 319-326. [CrossRef]

99. Juarez-Moreno, K.; Ayala, M.; Vazquez-Duhalt, R. Antioxidant capacity of poly (ethylene glycol) (PEG) as protection mechanism against hydrogen peroxide inactivation of peroxidases. Appl. Biochem. Biotechnol. 2015, 177, 1364-1373. [CrossRef]

100. Vance, M.E.; Kuiken, T.; Vejerano, E.P.; McGinnis, S.P.; Hochella Jr, M.F.; Rejeski, D.; Hull, M.S. Nanotechnology in the real world: Redeveloping the nanomaterial consumer products inventory. Beilstein J. Nanotechnol. 2015, 6, 1769-1780. [CrossRef] [PubMed]

101. Bayda, S.; Hadla, M.; Palazzolo, S.; Riello, P.; Corona, G.; Toffoli, G.; Rizzolio, F. Inorganic nanoparticles for cancer therapy: A transition from lab to clinic. Curr. Med. Chem. 2018, 25, 4269-4303. [CrossRef] [PubMed]

102. Bakhshian Nik, A.; Zare, H.; Razavi, S.; Mohammadi, H.; Torab Ahmadi, P.; Yazdani, N.; Bayandori, M.; Rabiee, N.; Izadi Mobarakeh, J. Smart drug delivery: Capping strategies for mesoporous silica nanoparticles. Microporous Mesoporous Mater. 2020, 299, 110115-110129. [CrossRef]

103. Manzano, M.; Vallet-Regí, M. Mesoporous silica nanoparticles for drug delivery. Adv. Funct. Mater. 2020, 30, $1902634-1902647$. [CrossRef]

104. Wilczewska, A.Z.; Niemirowicz, K.; Markiewicz, K.H.; Car, H. Nanoparticles as drug delivery systems. Pharmacol. Rep. 2012, 64, 1020-1037. [CrossRef]

105. Gimenez, C.; de la Torre, C.; Gorbe, M.; Aznar, E.; Sancenon, F.; Murguía, J.R.; Martinez-Manez, R.; Marcos, M.D.; Amoros, P. Gated mesoporous silica nanoparticles for the controlled delivery of drugs in cancer cells. Langmuir 2015, 31, 3753-3762. [CrossRef]

106. Yao, X.; Niu, X.; Ma, K.; Huang, P.; Grothe, J.; Kaskel, S.; Zhu, Y. Graphene quantum dots-capped magnetic mesoporous silica nanoparticles as a multifunctional platform for controlled drug delivery, magnetic hyperthermia, and photothermal therapy. Small 2017, 13, 1602225-1602236. [CrossRef]

107. Zhang, R.; Hua, M.; Liu, H.; Li, J. How to design nanoporous silica nanoparticles in regulating drug delivery: Surface modification and porous control. Mater. Sci. Eng. B 2021, 263, 114835-114849. [CrossRef]

108. Deligiannakis, Y.; Sotiriou, G.A.; Pratsinis, S.E. Antioxidant and antiradical $\mathrm{SiO}_{2}$ nanoparticles covalently functionalized with gallic acid. ACS Appl. Mater. Interfaces 2012, 4, 6609-6617. [CrossRef] [PubMed]

109. Sahiner, N.; Sagbas, S.; Aktas, N. Preparation and characterization of monodisperse, mesoporous natural poly (tannic acid)-silica nanoparticle composites with antioxidant properties. Microporous Mesoporous Mater. 2016, 226, 316-324. [CrossRef]

110. Alvarez Echazú, M.I.; Olivetti, C.E.; Peralta, I.; Alonso, M.R.; Anesini, C.; Perez, C.J.; Alvarez, G.S.; Desimone, M.F. Development of $\mathrm{pH}$-responsive biopolymer-silica composites loaded with Larrea divaricata Cav. extract with antioxidant activity. Colloids Surf. B Biointerfaces 2018, 169, 82-91. [CrossRef]

111. Das, S.; Batuta, S.; Alam, M.N.; Fouzder, C.; Kundu, R.; Mandal, D.; Begum, N.A. Antioxidant flavone analog functionalized fluorescent silica nanoparticles: Synthesis and exploration of their possible use as biomolecule sensor. Colloids Surf. B Biointerfaces 2017, 157, 286-296. [CrossRef]

112. Firuzi, O.; Lacanna, A.; Petrucci, R.; Marrosu, G.; Saso, L. Evaluation of the antioxidant activity of flavonoids by "ferric reducing antioxidant power" assay and cyclic voltammetry. Biochim. Biophys. Acta 2005, 1721, 174-184. [CrossRef]

113. Lee, G.H.; Lee, S.J.; Jeong, S.W.; Kim, H.C.; Park, G.Y.; Lee, S.G.; Choi, J.H. Antioxidative and anti-inflammatory activities of quercetin-loaded silica nanoparticles. Colloids Surf. B Biointerfaces 2016, 143, 511-517. [CrossRef]

114. Kumar, S.; Sarita; Nehra, M.; Dilbaghi, N.; Tankeshwar, K.; Kim, K.H. Recent advances and remaining challenges for polymeric nanocomposites in healthcare applications. Prog. Polym. Sci. 2018, 80, 1-38. [CrossRef]

115. Omanović-Mikličanin, E.; Badnjević, A.; Kazlagić, A.; Hajlovac, M. Nanocomposites: A brief review. Health Technol. 2020, 10, 51-59. [CrossRef]

116. Yan, L.; Gonca, S.; Zhu, G.; Zhang, W.; Chen, X. Layered double hydroxide nanostructures and nanocomposites for biomedical applications. J. Mater. Chem. B 2019, 7, 5583-5601. [CrossRef]

117. Safdari, M.; Al-Haik, M.S. Synergistic electrical and thermal transport properties of hybrid polymeric nanocomposites based on carbon nanotubes and graphite nanoplatelets. Carbon 2013, 64, 111-121. [CrossRef]

118. Lee, R.-J.; Tamm, T.; Temmer, R.; Aabloo, A.; Kiefer, R. Two formation mechanisms and renewable antioxidant properties of suspensible chitosan-PPy and chitosan-PPy-BTDA composites. Synth. Met. 2013, 164, 6-11. [CrossRef]

119. Huang, Y.; Liu, Z.; Liu, C.; Ju, E.; Zhang, Y.; Ren, J.; Qu, X. Self-assembly of multi-nanozymes to mimic an intracellular antioxidant defense system. Angew. Chem. 2016, 128, 6758-6762. [CrossRef]

120. Liu, X.; Li, D.; Liang, Y.; Lin, Y.; Liu, Z.; Niu, H.; Xu, Y. Establishment of anti-oxidation platform based on few-layer molybdenum disulfide nanosheet-coated titanium dioxide nanobelt nanocomposite. J. Colloid Interface Sci. 2021, 601, 167-176. [CrossRef]

121. Sachdev, A.; Gopinath, P. Monitoring the intracellular distribution and ROS scavenging potential of carbon dot-cerium oxide nanocomposites in fibroblast cells. ChemNanoMat 2016, 2, 226-235. [CrossRef] 
122. Tejwan, N.; Saini, A.K.; Sharma, A.; Singh, T.A.; Kumar, N.; Das, J. Metal-doped and hybrid carbon dots: A comprehensive review on their synthesis and biomedical applications. J. Control. Release 2021, 330, 132-150. [CrossRef]

123. Xiao, Y.; Du, J. Superparamagnetic nanoparticles for biomedical applications. J. Mater. Chem. B 2020, 8, 354-367. [CrossRef] [PubMed]

124. Xuan, S.; Hao, L.; Jiang, W.; Gong, X.; Hu, Y.; Chen, Z. A facile method to fabricate carbon-encapsulated $\mathrm{Fe}_{3} \mathrm{O}_{4}$ core $/$ shell composites. Nanotechnology 2007, 18, 35602-35608. [CrossRef]

125. Bharathi, D.; Ranjithkumar, R.; Vasantharaj, S.; Chandarshekar, B.; Bhuvaneshwari, V. Synthesis and characterization of chitosan/iron oxide nanocomposite for biomedical applications. Int. J. Biol. Macromol. 2019, 132, 880-887. [CrossRef]

126. Rajeswari, R.; Gurumallesh Prabu, H. Palladium-Decorated reduced graphene oxide/zinc oxide nanocomposite for enhanced antimicrobial, antioxidant and cytotoxicity activities. Process. Biochem. 2020, 93, 36-47. [CrossRef]

127. Shrimal, P.; Jadeja, G.; Patel, S. A review on novel methodologies for drug nanoparticle preparation: Microfluidic approach. Chem. Eng. Res. Des. 2020, 153, 728-756. [CrossRef]

128. Niculescu, A.G.; Chircov, C.; Bîrcă, A.C.; Grumezescu, A.M. Nanomaterials synthesis through microfluidic methods: An updated overview. Nanomaterials 2021, 11, 864. [CrossRef]

129. Cui, X.; Yin, Y.; Ma, Z.; Yin, Y.; Guan, Y.; Rong, S.; Gao, J.; Niu, Y.; Li, M. Polydopamine used as hollow capsule and core-shell structures for multiple applications. Nano 2015, 10, 1530003-1530026. [CrossRef]

130. Lee, H.; Dellatore, S.M.; Miller, W.M.; Messersmith, P.B. Mussel-inspired surface chemistry for multifunctional coatings. Science 2007, 318, 426-430. [CrossRef]

131. Waite, J.H.; Qin, X. Polyphosphoprotein from the adhesive pads of Mytilus edulis. Biochemistry 2001, 40, 2887-2893. [CrossRef]

132. Harrington, M.J.; Masic, A.; Holten-Andersen, N.; Waite, J.H.; Fratzl, P. Iron-clad fibers: A metal-based biological strategy for hard flexible coatings. Science 2010, 328, 216-220. [CrossRef] [PubMed]

133. Zheng, W.; Fan, H.; Wang, L.; Jin, Z. Oxidative self-polymerization of dopamine in an acidic environment. Langmuir 2015, 31, 11671-11677. [CrossRef] [PubMed]

134. Wang, Z.; Duan, Y.; Duan, Y. Application of polydopamine in tumor targeted drug delivery system and its drug release behavior. J. Control. Release 2018, 290, 56-74. [CrossRef] [PubMed]

135. Malinovskaya, Y.; Melnikov, P.; Baklaushev, V.; Gabashvili, A.; Osipova, N.; Mantrov, S.; Ermolenko, Y.; Maksimenko, O.; Gorshkova, M.; Balabanyan, V. Delivery of doxorubicin-loaded PLGA nanoparticles into U87 human glioblastoma cells. Int. J. Pharm. 2017, 524, 77-90. [CrossRef]

136. Fu, Y.; Zhang, J.; Wang, Y.; Li, J.; Bao, J.; Xu, X.; Zhang, C.; Li, Y.; Wu, H.; Gu, Z. Reduced polydopamine nanoparticles incorporated oxidized dextran/chitosan hybrid hydrogels with enhanced antioxidative and antibacterial properties for accelerated wound healing. Carbohydr. Polym. 2021, 257, 117598-117608. [CrossRef] [PubMed]

137. Battaglini, M.; Marino, A.; Carmignani, A.; Tapeinos, C.; Cauda, V.; Ancona, A.; Garino, N.; Vighetto, V.; La Rosa, G.; Sinibaldi, E.; et al. Polydopamine nanoparticles as an organic and biodegradable multitasking tool for neuroprotection and remote neuronal stimulation. ACS Appl. Mater. Interfaces 2020, 12, 35782-35798. [CrossRef]

138. Hemmati, S.; Zangeneh, M.M.; Zangeneh, A. $\mathrm{CuCl}_{2}$ anchored on polydopamine coated-magnetic nanoparticles $\left(\mathrm{Fe}_{3} \mathrm{O}_{4} @ \mathrm{PDA} / \mathrm{Cu}\right.$ (II)): Preparation, characterization and evaluation of its cytotoxicity, antioxidant, antibacterial, and antifungal properties. Polyhedron 2020, 177, 114327-114336. [CrossRef]

139. Lepetsos, P.; Papavassiliou, A.G. ROS/oxidative stress signaling in osteoarthritis. Biochim. Biophys. Acta Mol. Basis Dis. 2016, 1862, 576-591. [CrossRef] [PubMed]

140. Wang, X.; Zhao, H.; Liu, Z.; Wang, Y.; Lin, D.; Chen, L.; Dai, J.; Lin, K.; Shen, S.G. Polydopamine nanoparticles as dual-task platform for osteoarthritis therapy: A scavenger for reactive oxygen species and regulator for cellular powerhouses. Chem. Eng. J. 2021, 417, 129284-129300. [CrossRef]

141. Hernansanz-Agustín, P.; Enríquez, J.A. Generation of reactive oxygen species by mitochondria. Antioxidants 2021, $10,415$. [CrossRef]

142. Gericke, M.; Schulze, P.; Heinze, T. Nanoparticles Based on Hydrophobic Polysaccharide Derivatives—Formation Principles, characterization techniques, and biomedical applications. Macromol. Biosci. 2020, 20, 1900415-1900454. [CrossRef]

143. Ulbrich, K.; Hola, K.; Subr, V.; Bakandritsos, A.; Tucek, J.; Zboril, R. Targeted drug delivery with polymers and magnetic nanoparticles: Covalent and noncovalent approaches, release control, and clinical studies. Chem. Rev. 2016, 116, 5338-5431. [CrossRef]

144. Patra, J.K.; Das, G.; Fraceto, L.F.; Vangelie, E.; Campos, R.; Rodriguez, P.; Susana, L.; Torres, A.; Armando, L.; Torres, D.; et al. Nano based drug delivery systems: Recent developments and future prospects. J. Nanobiotechnol. 2018, 16, 71-104. [CrossRef]

145. Matos, B.N.; Reis, T.A.; Gratieri, T.; Gelfuso, G.M. Chitosan nanoparticles for targeting and sustaining minoxidil sulphate delivery to hair follicles. Int. J. Biol. Macromol. 2015, 75, 225-229. [CrossRef]

146. Rudzinski, W.E.; Palacios, A.; Ahmed, A.; Lane, M.A.; Aminabhavi, T.M. Targeted delivery of small interfering RNA to colon cancer cells using chitosan and PEGylated chitosan nanoparticles. Carbohydr. Polym. 2016, 147, 323-332. [CrossRef]

147. Cevher, E.; Salomon, S.K.; Somavarapu, S.; Brocchini, S.; Alpar, H.O. Development of chitosan-pullulan composite nanoparticles for nasal delivery of vaccines: In vivo studies. J. Microencapsul. 2015, 32, 769-783. [CrossRef]

148. Kirschning, A.; Dibbert, N.; Dräger, G. Chemical functionalization of polysaccharides—Towards biocompatible hydrogels for biomedical applications. Chem. A Eur. J. 2018, 24, 1231-1240. [CrossRef] 
149. Mandal, S.; Khandalavala, K.; Pham, R.; Bruck, P.; Varghese, M.; Kochvar, A.; Monaco, A.; Prathipati, P.K.; Destache, C.; Shibata, A. Cellulose acetate phthalate and antiretroviral nanoparticle fabrications for HIV pre-exposure prophylaxis. Polymers $2017,9,423$. [CrossRef] [PubMed]

150. Breitenbach, B.B.; Schmid, I.; Wich, P.R. Amphiphilic polysaccharide block copolymers for $\mathrm{pH}$-responsive micellar nanoparticles. Biomacromolecules 2017, 18, 2839-2848. [CrossRef] [PubMed]

151. Sauraj; Kumar, S.U.; Kumar, V.; Priyadarshi, V.K.R.; Gopinath, P.; Negi, Y.S. pH-responsive prodrug nanoparticles based on xylan-curcumin conjugate for the efficient delivery of curcumin in cancer therapy. Carbohydr. Polym. 2018, 188, 252-259. [CrossRef] [PubMed]

152. Sood, A.; Gupta, A.; Agrawal, G. Recent advances in polysaccharides-based biomaterials for drug delivery and tissue engineering applications. Carbohydr. Polym. Technol. Appl. 2021, 2, 100067-100091. [CrossRef]

153. Muhammad, G.; Hussain, M.A.; Amin, M.; Hussain, S.Z.; Hussain, I.; Bukhari, S.N.A.; Naeem-ul-Hassan, M. Glucuronoxylanmediated silver nanoparticles: Green synthesis, antimicrobial and wound healing applications. RSC Adv. 2017, 7, 42900-42908. [CrossRef]

154. Ganie, S.A.; Rather, L.J.; Li, Q. A review on anticancer applications of pullulan and pullulan derivative nanoparticles. Carbohydr. Polym. Technol. Appl. 2021, 2, 100115-100132. [CrossRef]

155. Aluani, D.; Tzankova, V.; Kondeva-Burdina, M.; Yordanov, Y.; Nikolova, E.; Odzhakov, F.; Apostolov, A.; Markova, T.; Yoncheva, K. Evaluation of biocompatibility and antioxidant efficiency of chitosan-alginate nanoparticles loaded with quercetin. Int. J. Biol. Macromol. 2017, 103, 771-782. [CrossRef]

156. Luo, Y.; Wang, Q. Recent development of chitosan-based polyelectrolyte complexes with natural polysaccharides for drug delivery. Int. J. Biol. Macromol. 2014, 64, 353-367. [CrossRef]

157. Frank, L.A.; Onzi, G.R.; Morawski, A.S.; Pohlmann, A.R.; Guterres, S.S.; Contri, R.V. Chitosan as a coating material for nanoparticles intended for biomedical applications. React. Funct. Polym. 2020, 147, 104459-104473. [CrossRef]

158. Kumar, S.P.; Birundha, K.; Kaveri, K.; Devi, K.T.R. Antioxidant studies of chitosan nanoparticles containing naringenin and their cytotoxicity effects in lung cancer cells. Int. J. Biol. Macromol. 2015, 78, 87-95. [CrossRef] [PubMed]

159. Kaur, R.; Rajput, R.; Nag, P.; Kumar, S.; Singh, M. Synthesis, characterization and evaluation of antioxidant properties of catechin hydrate nanoparticles. J. Drug Deliv. Sci. Technol. 2017, 39, 398-407. [CrossRef]

160. Nallamuthu, I.; Devi, A.; Khanum, F. Chlorogenic acid loaded chitosan nanoparticles with sustained release property, retained antioxidant activity and enhanced bioavailability. Asian J. Pharm. Sci. 2015, 10, 203-211. [CrossRef]

161. Szekalska, M.; Puciłowska, A.; Szymańska, E.; Ciosek, P.; Winnicka, K. Alginate: Current use and future perspectives in pharmaceutical and biomedical applications. Int. J. Polym. Sci. 2016, 2016, 17. [CrossRef]

162. Jin, S.; Li, K.; Xia, C.; Li, J. Sodium alginate-assisted route to antimicrobial biopolymer film combined with aminoclay for enhanced mechanical behaviors. Ind. Crop. Prod. 2019, 135, 271-282. [CrossRef]

163. John, T.; Nwude, F.; Singh, S.; Odunayo, O.; Benjakul, S.; Rujiralai, T. Synthesis of gold nanoparticles/polyaniline boronic acid/sodium alginate aqueous nanocomposite based on chemical oxidative polymerization for biological applications. Int. J. Biol. Macromol. 2021, 179, 196-205. [CrossRef]

164. Lohcharoenkal, W.; Wang, L.; Chen, Y.C.; Rojanasakul, Y. Protein nanoparticles as drug delivery carriers for cancer therapy. Biomed. Res. Int. 2014, 2014, 12. [CrossRef]

165. Sandra, F.; Khaliq, N.U.; Sunna, A.; Care, A. Developing protein-based nanoparticles as versatile delivery systems for cancer therapy and imaging. Nanomaterials 2019, 9, 1329. [CrossRef]

166. Oliveira, A.M.; Guimarães, K.L.; Cerize, N.; Tunussi, A.S.; Poço, J.G. Nano spray drying as an innovative technology for encapsulating hydrophilic active pharmaceutical ingredients (API). J. Nanomed. Nanotechnol 2013, 4, 1000186-1000192. [CrossRef]

167. Rather, H.A.; Thakore, R.; Singh, R.; Jhala, D.; Singh, S.; Vasita, R. Antioxidative study of cerium oxide nanoparticle functionalised PCL-Gelatin electrospun fibers for wound healing application. Bioact. Mater. 2018, 3, 201-211. [CrossRef] [PubMed]

168. Omran, B.A.; Whitehead, K.A.; Baek, K.-H. One-pot bioinspired synthesis of fluorescent metal chalcogenide and carbon quantum dots: Applications and potential biotoxicity. Colloids Surf. B Biointerfaces 2021, 200, 111578-111597. [CrossRef] [PubMed]

169. De Marco, B.A.; Rechelo, B.S.; Tótoli, E.G.; Kogawa, A.C.; Salgado, H.R.N. Evolution of green chemistry and its multidimensional impacts: A review. Saudi Pharm. J. 2019, 27, 1-8. [CrossRef]

170. Anastas, P.T. Green chemistry and the role of analytical methodology development. Crit. Rev. Anal. Chem. 1999, 29, 167-175. [CrossRef]

171. O'Neil, N.J.; Scott, S.; Relph, R.; Ponnusamy, E. Approaches to incorporating green chemistry and safety into laboratory culture. J. Chem. Educ. 2020, 98, 84-91. [CrossRef]

172. Omran, B.A. Biosynthesized nanomaterials via processing of different plant parts (phytonanotechnology) and biovalorization of agro-industrial wastes to nano-sized valuable products. In Nanobiotechnology: A Multidisciplinary Field of Science; Springer: Cham, Switzerland, 2020; pp. 145-184.

173. Nagaich, U.; Gulati, N.; Chauhan, S. Antioxidant and antibacterial potential of silver nanoparticles: Biogenic synthesis utilizing apple extract. J. Pharm. 2016, 2016, 8. [CrossRef]

174. Fafal, T.; Taştan, P.; Tüzün, B.S.; Ozyazici, M.; Kivcak, B. Synthesis, characterization and studies on antioxidant activity of silver nanoparticles using Asphodelus aestivus Brot. aerial part extract. S. Afr. J. Bot. 2017, 112, 346-353. [CrossRef] 
175. Sudha, A.; Jeyakanthan, J.; Srinivasan, P. Green synthesis of silver nanoparticles using Lippia nodiflora aerial extract and evaluation of their antioxidant, antibacterial and cytotoxic effects. Resour. Technol. 2017, 3, 506-515. [CrossRef]

176. AlSalhi, M.S.; Elangovan, K.; Ranjitsingh, A.J.A.; Murali, P.; Devanesan, S. Synthesis of silver nanoparticles using plant derived 4-N-methyl benzoic acid and evaluation of antimicrobial, antioxidant and antitumor activity. Saudi J. Biol. Sci. 2019, 26, 970-978. [CrossRef]

177. Govindappa, M.; Hemashekhar, B.; Arthikala, M.; Rai, V.R.; Ramachandra, Y.L. Results in Physics anti-inflammatory and antityrosinase activity of green synthesized silver nanoparticles using Calophyllum tomentosum leaves extract. Results Phys. 2018, 9, 400-408. [CrossRef]

178. Das, D.; Ghosh, R.; Mandal, P. Biogenic synthesis of silver nanoparticles using S1 genotype of Morus alba leaf extract: Characterization, antimicrobial and antioxidant potential assessment. SN Appl. Sci. 2019, 1, 498-514. [CrossRef]

179. Yadav, R.; Saini, H.; Kumar, D.; Pasi, S.; Agrawal, V. Bioengineering of Piper longum L. extract mediated silver nanoparticles and their potential biomedical applications. Mater. Sci. Eng. C 2019, 104, 109984-110001. [CrossRef]

180. Gulbagca, F.; Ozdemir, S.; Gulcan, M.; Sen, F. Synthesis and characterization of Rosa canina-mediated biogenic silver nanoparticles for anti-oxidant, antibacterial, antifungal, and DNA cleavage activities. Heliyon 2019, 5, e02980. [CrossRef]

181. Sharma, C.; Ansari, S.; Ansari, M.S.; Satsangee, S.P.; Srivastava, M.M. Single-step green route synthesis of Au/Ag bimetallic nanoparticles using clove buds extract: Enhancement in antioxidant bio-efficacy and catalytic activity. Mater. Sci. Eng. C 2020, 116, 111153-111166. [CrossRef] [PubMed]

182. Yarrappagaari, S.; Gutha, R.; Narayanaswamy, L.; Thopireddy, L.; Benne, L.; Mohiyuddin, S.S.; Vijayakumar, V.; Saddala, R.R. Eco-friendly synthesis of silver nanoparticles from the whole plant of Cleome viscosa and evaluation of their characterization, antibacterial, antioxidant and antidiabetic properties. Saudi J. Biol. Sci. 2020, 27, 3601-3614. [CrossRef] [PubMed]

183. Uma Maheshwari Nallal, V.; Prabha, K.; VethaPotheher, I.; Ravindran, B.; Baazeem, A.; Woong Chang, S.; Aderonke Otunola, G.; Razia, M. Sunlight-driven rapid and facile synthesis of silver nanoparticles using Allium ampeloprasum extract with enhanced antioxidant and antifungal activity. Saudi J. Biol. Sci. 2021, 28, 3660-3668. [CrossRef]

184. Küp, F.Ö.; Çoşkunçay, S.; Duman, F. Biosynthesis of silver nanoparticles using leaf extract of Aesculus hippocastanum (horse chestnut): Evaluation of their antibacterial, antioxidant and drug release system activities. Mater. Sci. Eng. C 2020, 107, 110207-110218. [CrossRef]

185. Riaz Rajoka, M.S.; Mehwish, H.M.; Zhang, H.; Ashraf, M.; Fang, H.; Zeng, X.; Wu, Y.; Khurshid, M.; Zhao, L.; He, Z. Antibacterial and antioxidant activity of exopolysaccharide mediated silver nanoparticle synthesized by Lactobacillus brevis isolated from Chinese koumiss. Colloids Surf. B Biointerfaces 2020, 186, 110734-110745. [CrossRef] [PubMed]

186. Yousaf, H.; Mehmood, A.; Ahmad, K.S.; Raffi, M. Green synthesis of silver nanoparticles and their applications as an alternative antibacterial and antioxidant agent. Mater. Sci. Eng. C 2020, 112, 110901-110908. [CrossRef]

187. Kong, Y.; Ahmad, B.; Al-sadoon, M.K.; Fahad, M. Novel green synthesis, chemical characterization, toxicity, colorectal carcinoma, antioxidant, anti-diabetic, and anticholinergic properties of silver nanoparticles: A chemopharmacological study. Arab. J. Chem. 2021, 14, 103193-103203. [CrossRef]

188. Oueslati, M.H.; Tahar, L.B.; Harrath, A.H. Catalytic, antioxidant and anticancer activities of gold nanoparticles synthesized by kaempferol glucoside from Lotus leguminosae. Arab. J. Chem. 2020, 13, 3112-3122. [CrossRef]

189. Muniyappan, N.; Pandeeswaran, M.; Amalraj, A. Green synthesis of gold nanoparticles using Curcuma pseudomontana isolated curcumin: Its characterization, antimicrobial, antioxidant and anti-inflammatory activities. Environ. Chem. Ecotoxicol. 2021, 3, 117-124. [CrossRef]

190. Priya Velammal, S.; Devi, T.A.; Amaladhas, T.P. Antioxidant, antimicrobial and cytotoxic activities of silver and gold nanoparticles synthesized using Plumbago zeylanica bark. J. Nanostruct. Chem. 2016, 6, 247-260. [CrossRef]

191. Selvi, A.M.; Palanisamy, S.; Jeyanthi, S.; Vinosha, M.; Mohandoss, S.; Tabarsa, M.; You, S.G.; Kannapiran, E.; Prabhu, N.M. Synthesis of Tragia involucrata mediated platinum nanoparticles for comprehensive therapeutic applications: Antioxidant, antibacterial and mitochondria-associated apoptosis in HeLa cells. Process. Biochem. 2020, 98, 21-33. [CrossRef]

192. Zangeneh, M.M.; Ghaneialvar, H.; Akbaribazm, M.; Ghanimatdan, M.; Abbasi, N.; Goorani, S.; Pirabbasi, E.; Zangeneh, A. Novel synthesis of Falcaria vulgaris leaf extract conjugated copper nanoparticles with potent cytotoxicity, antioxidant, antifungal, antibacterial, and cutaneous wound healing activities under in vitro and in vivo condition. J. Photochem. Photobiol. B Biol. 2019, 197, 111556-111569. [CrossRef]

193. Venugopalan, R.; Pitchai, S.; Devarayan, K.; Swaminathan, V.C. Biogenic synthesis of copper nanoparticles using Borreria hispida (Linn.) extract and its antioxidant activity. Mater. Today Proc. 2020, 33, 4023-4025. [CrossRef]

194. Merugu, R.; Gothalwal, R.; Kaushik Deshpande, P.; De Mandal, S.; Padala, G.; Chitturi, K.L. Synthesis of Ag/Cu and Cu/Zn bimetallic nanoparticles using toddy palm: Investigations of their antitumor, antioxidant and antibacterial activities. Mater. Today Proc. 2020, 99-105. [CrossRef]

195. Unuofin, J.O.; Oladipo, A.O.; Msagati, T.A.M.; Lebelo, S.L.; Meddows-Taylor, S.; More, G.K. Novel silver-platinum bimetallic nanoalloy synthesized from Vernonia mespilifolia extract: Antioxidant, antimicrobial, and cytotoxic activities. Arab. J. Chem. 2020, 13, 6639-6648. [CrossRef]

196. Velsankar, K.; Sudhahar, S.; Maheshwaran, G.; Krishna Kumar, M. Effect of biosynthesis of ZnO nanoparticles via Cucurbita seed extract on Culex tritaeniorhynchus mosquito larvae with its biological applications. J. Photochem. Photobiol. B Biol. 2019, $200,111650$. [CrossRef] 
197. Sharmila, G.; Muthukumaran, C.; Sangeetha, E.; Saraswathi, H.; Soundarya, S.; Kumar, N.M. Green fabrication, characterization of Pisonia alba leaf extract derived $\mathrm{MgO}$ nanoparticles and its biological applications. Nano-Struct. Nano-Objects 2019, 20, 100380-100385. [CrossRef]

198. Sharmila, G.; Thirumarimurugan, M.; Muthukumaran, C. Green synthesis of ZnO nanoparticles using Tecoma castanifolia leaf extract: Characterization and evaluation of its antioxidant, bactericidal and anticancer activities. Microchem. J. 2019, 145, 578-587. [CrossRef]

199. Loganathan, S.; Shivakumar, M.S.; Karthi, S.; Nathan, S.S.; Selvam, K. Metal oxide nanoparticle synthesis (ZnO-NPs) of Knoxia sumatrensis (Retz.) DC. Aqueous leaf extract and It's evaluation of their antioxidant, anti-proliferative and larvicidal activities. Toxicol. Rep. 2021, 8, 64-72. [CrossRef] [PubMed]

200. Thakar, M.A.; Saurabh Jha, S.; Phasinam, K.; Manne, R.; Qureshi, Y.; Hari Babu, V.V. X ray diffraction (XRD) analysis and evaluation of antioxidant activity of copper oxide nanoparticles synthesized from leaf extract of Cissus vitiginea. Mater. Today Proc. 2021. [CrossRef]

201. Akinola, P.O.; Lateef, A.; Asafa, T.B.; Beukes, L.S.; Hakeem, A.S.; Irshad, H.M. Multifunctional titanium dioxide nanoparticles biofabricated via phytosynthetic route using extracts of Cola nitida: Antimicrobial, dye degradation, antioxidant and anticoagulant activities. Heliyon 2020, 6, e04610. [CrossRef] [PubMed]

202. Saravanakumar, K.; Sathiyaseelan, A.; Mariadoss, A.V.A.; Wang, M.H. Antioxidant and antidiabetic properties of biocompatible ceria oxide $\left(\mathrm{CeO}_{2}\right)$ nanoparticles in mouse fibroblast NIH3T3 and insulin resistant HepG2 cells. Ceram. Int. 2021, 47, 8618-8626. [CrossRef]

203. Bordoni, M.; Scarian, E.; Rey, F.; Gagliardi, S.; Carelli, S.; Pansarasa, O.; Cereda, C. Biomaterials in neurodegenerative disorders: A promising therapeutic approach. Int. J. Mol. Sci. 2020, 21, 3243. [CrossRef]

204. Dutta, D.; Mukherjee, R.; Patra, M.; Banik, M.; Dasgupta, R.; Mukherjee, M.; Basu, T. Green synthesized cerium oxide nanoparticle: A prospective drug against oxidative harm. Colloids Surf. B Biointerfaces 2016, 147, 45-53. [CrossRef]

205. Karmous, I.; Pandey, A.; Haj, K.B.; Chaoui, A. Efficiency of the green synthesized nanoparticles as new tools in cancer therapy: Insights on plant-based bioengineered nanoparticles, biophysical properties, and anticancer roles. Biol. Trace Elem. Res. 2020, 196, 330-342. [CrossRef]

206. Sharma, D.; Shandilya, P.; Saini, N.K.; Singh, P.; Thakur, V.K.; Saini, R.V.; Mittal, D.; Chandan, G.; Saini, V.; Saini, A.K. Insights into the synthesis and mechanism of green synthesized antimicrobial nanoparticles, answer to the multidrug resistance. Mater. Today Chem. 2021, 19, 100391. [CrossRef]

207. Paiva-Santos, A.C.; Herdade, A.M.; Guerra, C.; Peixoto, D.; Pereira-Silva, M.; Zeinali, M.; Mascarenhas-Melo, F.; Paranhos, A.; Veiga, F. Plant-mediated green synthesis of metal-based nanoparticles for dermopharmaceutical and cosmetic applications. Int. J. Pharm. 2021, 597, 120311. [CrossRef]

208. Müller, R.H.; Mäder, K.; Gohla, S. Solid lipid nanoparticles (SLN) for controlled drug delivery-a review of the state of the art. Eur. J. Pharm. Biopharm. 2000, 50, 161-177. [CrossRef]

209. Borges, A.; de Freitas, V.; Mateus, N.; Fernandes, I.; Oliveira, J. Solid lipid nanoparticles as carriers of natural phenolic compounds. Antioxidants 2020, 9, 998. [CrossRef]

210. Nasirizadeh, S.; Malaekeh-Nikouei, B. Solid lipid nanoparticles and nanostructured lipid carriers in oral cancer drug delivery. J. Drug Deliv. Sci. Technol. 2020, 55, 101458. [CrossRef]

211. Pink, D.L.; Loruthai, O.; Ziolek, R.M.; Wasutrasawat, P.; Terry, A.E.; Lawrence, M.J.; Lorenz, C.D. On the structure of solid lipid nanoparticles. Small 2019, 15, 1903156. [CrossRef]

212. Zhai, Y.; Zhai, G. Advances in lipid-based colloid systems as drug carrier for topic delivery. J. Control. Release 2014, 193, 90-99. [CrossRef]

213. D'Souza, A.; Shegokar, R. Nanostructured lipid carriers (NLCs) for drug delivery: Role of liquid lipid (oil). Curr. Drug Deliv. 2021, 18, 249-270. [CrossRef] [PubMed]

214. Muller, H.R.; Shegokar, R.; Keck, M.C. 20 years of lipid nanoparticles (SLN \& NLC): Present state of development \& industrial applications. Curr. Drug Discov. Technol. 2011, 8, 207-227. [CrossRef] [PubMed]

215. Okonogi, S.; Riangjanapatee, P. Physicochemical characterization of lycopene-loaded nanostructured lipid carrier formulations for topical administration. Int. J. Pharm. 2015, 478, 726-735. [CrossRef]

216. Huang, J.; Wang, Q.; Li, T.; Xia, N.; Xia, Q. Nanostructured lipid carrier (NLC) as a strategy for encapsulation of quercetin and linseed oil: Preparation and in vitro characterization studies. J. Food Eng. 2017, 215, 1-12. [CrossRef]

217. Karimi, N.; Ghanbarzadeh, B.; Hamishehkar, H.; Mehramuz, B.; Kafil, H.S. Antioxidant, antimicrobial and physicochemical properties of turmeric extract-loaded nanostructured lipid carrier (NLC). Colloid Interface Sci. Commun. 2018, 22, 18-24. [CrossRef]

218. Rodriguez-Ruiz, V.; Salatti-Dorado, J.Á.; Barzegari, A.; Nicolas-Boluda, A.; Houaoui, A.; Caballo, C.; Caballero-Casero, N.; Sicilia, D.; Venegas, J.B.; Pauthe, E.; et al. Astaxanthin-loaded nanostructured lipid carriers for preservation of antioxidant activity. Molecules 2018, 23, 2601. [CrossRef] [PubMed]

219. Poonia, N.; Narang, J.K.; Lather, V.; Beg, S.; Sharma, T.; Singh, B.; Pandita, D. Resveratrol loaded functionalized nanostructured lipid carriers for breast cancer targeting: Systematic development, characterization and pharmacokinetic evaluation. Colloids Surf. B Biointerfaces 2019, 181, 756-766. [CrossRef] [PubMed]

220. Montenegro, L.; Messina, C.M.; Manuguerra, S.; Santagati, L.M.; Pasquinucci, L.; Turnaturi, R.; Parenti, C.; Arena, R.; Santulli, A. In vitro antioxidant activity and in vivo topical efficacy of lipid nanoparticles co-loadingm idebenone and tocopheryl acetate. Appl. Sci. 2019, 9, 845. [CrossRef] 
221. Gupta, K.M.; Das, S.; Chow, P.S.; Macbeath, C. Encapsulation of ferulic acid in lipid nanoparticles as antioxidant for skin: Mechanistic understanding through experiment and molecular simulation. ACS Appl. Nano Mater. 2020, 3, 5351-5361. [CrossRef]

222. Gupta, T.; Singh, J.; Kaur, S.; Sandhu, S.; Singh, G.; Kaur, I.P. Enhancing bioavailability and stability of curcumin using solid lipid nanoparticles (CLEN): A covenant for its effectiveness. Front. Bioeng. Biotechnol. 2020, 8, 879-893. [CrossRef] [PubMed]

223. Bangham, A.D.; Standish, M.M.; Watkins, J.C. Diffusion of univalent ions across the lamellae of swollen phospholipids. J. Mol. Biol. 1965, 13, 238-252. [CrossRef]

224. Simão, A.M.S.; Bolean, M.; Cury, T.A.C.; Stabeli, R.G.; Itri, R.; Ciancaglini, P. Liposomal systems as carriers for bioactive compounds. Biophys. Rev. 2015, 7, 391-397. [CrossRef]

225. Sercombe, L.; Veerati, T.; Moheimani, F.; Wu, S.Y.; Sood, A.K.; Hua, S. Advances and challenges of liposome assisted drug delivery. Front. Pharmacol. 2015, 6, 286-299. [CrossRef]

226. Đorđević, V.; Balanč, B.; Belščak-Cvitanović, A.; Lević, S.; Trifković, K.; Kalušević, A.; Kostić, I.; Komes, D.; Bugarski, B.; Nedović, V. Trends in encapsulation technologies for delivery of food bioactive compounds. Food Eng. Rev. 2015, 7, 452-490. [CrossRef]

227. Akbarzadeh, A.; Rezaei-Sadabady, R.; Davaran, S.; Joo, S.W.; Zarghami, N.; Hanifehpour, Y.; Samiei, M.; Kouhi, M.; Nejati-Koshki, K. Liposome: Classification, preparation, and applications. Nanoscale Res. Lett. 2013, 8, 102-111. [CrossRef]

228. Maja, L.; Željko, K.; Mateja, P. Sustainable technologies for liposome preparation. J. Supercrit. Fluids 2020, 165, $104984-105001$. [CrossRef]

229. Wicki, A.; Witzigmann, D.; Balasubramanian, V.; Huwyler, J. Nanomedicine in cancer therapy: Challenges, opportunities, and clinical applications. J. Control. Release 2015, 200, 138-157. [CrossRef] [PubMed]

230. Guimarães, D.; Cavaco-Paulo, A.; Nogueira, E. Design of liposomes as drug delivery system for therapeutic applications. Int. J. Pharm. 2021, 601, 120571-120586. [CrossRef] [PubMed]

231. Hou, K.; Bao, M.; Xin, C.; Wang, L.; Zhang, H.; Zhao, H.; Wang, Z. Green synthesis of gold nanoparticles coated doxorubicin liposomes using procyanidins for light-controlled drug release. Adv. Powder Technol. 2020, 31, 3640-3649. [CrossRef]

232. Liu, W.; Ye, A.; Han, F.; Han, J. Advances and challenges in liposome digestion: Surface interaction, biological fate, and GIT modeling. Adv. Colloid Interface Sci. 2019, 263, 52-67. [CrossRef]

233. Zahednezhad, F.; Saadat, M.; Valizadeh, H.; Zakeri-Milani, P.; Baradaran, B. Liposome and immune system interplay: Challenges and potentials. J. Control. Release 2019, 305, 194-209. [CrossRef]

234. Dave, V.; Gupta, A.; Singh, P.; Gupta, C.; Sadhu, V.; Reddy, K.R. Synthesis and characterization of celecoxib loaded PEGylated liposome nanoparticles for biomedical applications. Nano-Struct. Nano-Objects 2019, 18, 100288. [CrossRef]

235. Tan, C.; Wang, J.; Sun, B. Biopolymer-liposome hybrid systems for controlled delivery of bioactive compounds: Recent advances. Biotechnol. Adv. 2021, 107727. [CrossRef]

236. Tahara, K.; Nishio, M.; Takeuchi, H. Evaluation of liposomal behavior in the gastrointestinal tract after oral administration using real-time in vivo imaging. Drug Dev. Ind. Pharm. 2018, 44, 608-614. [CrossRef]

237. Nguyen, T.X.; Huang, L.; Gauthier, M.; Yang, G.; Wang, Q. Recent advances in liposome surface modification for oral drug delivery. Nanomedicine 2016, 11, 1169-1185. [CrossRef] [PubMed]

238. Li, R.; Deng, L.; Cai, Z.; Zhang, S.; Wang, K.; Li, L.; Ding, S.; Zhou, C. Liposomes coated with thiolated chitosan as drug carriers of curcumin. Mater. Sci. Eng. C 2017, 80, 156-164. [CrossRef]

239. Niaz, T.; Shabbir, S.; Noor, T.; Rahman, A.; Bokhari, H.; Imran, M. Potential of polymer stabilized nano-liposomes to enhance antimicrobial activity of nisin Z against foodborne pathogens. LWT 2018, 96, 98-110. [CrossRef]

240. Zheng, F.; Li, R.; He, Q.; Koral, K.; Tao, J.; Fan, L.; Xiang, R.; Ma, J.; Wang, N.; Yin, Y. The electrostimulation and scar inhibition effect of chitosan/oxidized hydroxyethyl cellulose/reduced graphene oxide/asiaticoside liposome-based hydrogel on peripheral nerve regeneration in vitro. Mater. Sci. Eng. C 2020, 109, 110560-110573. [CrossRef] [PubMed]

241. Pan, L.; Zhang, X.; Fan, X.; Li, H.; Xu, B.; Li, X. Whey protein isolate coated liposomes as novel carrier systems for astaxanthin. Eur. J. Lipid Sci. Technol. 2020, 122, 1900325-1900335. [CrossRef]

242. Yamazoe, E.; Fang, J.-Y.; Tahara, K. Oral mucus-penetrating PEGylated liposomes to improve drug absorption: Differences in the interaction mechanisms of a mucoadhesive liposome. Int. J. Pharm. 2021, 593, 120148. [CrossRef] [PubMed]

243. Chen, J.; Lu, W.-L.; Gu, W.; Lu, S.-S.; Chen, Z.-P.; Cai, B.-C. Skin permeation behavior of elastic liposomes: Role of formulation ingredients. Expert Opin. Drug Deliv. 2013, 10, 845-856. [CrossRef]

244. Rai, S.; Pandey, V.; Rai, G. Transfersomes as versatile and flexible nano-vesicular carriers in skin cancer therapy: The state of the art. Nano Rev. Exp. 2017, 8, 1325708-1325726. [CrossRef]

245. Zylberberg, C.; Matosevic, S. Pharmaceutical liposomal drug delivery: A review of new delivery systems and a look at the regulatory landscape. Drug Deliv. 2016, 23, 3319-3329. [CrossRef] [PubMed]

246. Chen, S.; Hanning, S.; Falconer, J.; Locke, M.; Wen, J. Recent advances in non-ionic surfactant vesicles (niosomes): Fabrication, characterization, pharmaceutical and cosmetic applications. Eur. J. Pharm. Biopharm. 2019, 144, 18-39. [CrossRef]

247. Barriga, H.M.G.; Holme, M.N.; Stevens, M.M. Cubosomes: The next generation of smart lipid nanoparticles? Angew. Chem. Int. Ed. 2019, 58, 2958-2978. [CrossRef] [PubMed]

248. Al-Mahallawi, A.M.; Abdelbary, A.A.; Aburahma, M.H. Investigating the potential of employing bilosomes as a novel vesicular carrier for transdermal delivery of tenoxicam. Int. J. Pharm. 2015, 485, 329-340. [CrossRef]

249. Van Tran, V.; Moon, J.Y.; Lee, Y.C. Liposomes for delivery of antioxidants in cosmeceuticals: Challenges and development strategies. J. Control. Release 2019, 300, 114-140. [CrossRef] 
250. Paleos, C.M.; Tsiourvas, D.; Sideratou, Z.; Pantos, A. Formation of artificial multicompartment vesosome and dendrosome as prospected drug and gene delivery carriers. J. Control. Release 2013, 170, 141-152. [CrossRef]

251. Zhang, C.; Wang, X.; Du, J.; Gu, Z.; Zhao, Y. Reactive Oxygen Species-Regulating Strategies Based on Nanomaterials for Disease Treatment. Adv. Sci. 2021, 8, 2002797-2002831. [CrossRef] [PubMed]

252. Nabi, S.U.; Ali, S.I.; Rather, M.A.; Sheikh, W.M.; Altaf, M.; Singh, H.; Mumtaz, P.T.; Mishra, N.C.; Nazir, S.U.; Bashir, S.M. Organoids: A new approach in toxicity testing of nanotherapeutics. J. Appl. Toxicol. 2021. [CrossRef]

253. Andrysiak, K.; Stepniewski, J.; Dulak, J. Human-induced pluripotent stem cell-derived cardiomyocytes, 3D cardiac structures, and heart-on-a-chip as tools for drug research. Pflügers Arch. J. Physiol. 2021, 473, 1061-1085. [CrossRef]

254. Saydé, T.; El Hamoui, O.; Alies, B.; Gaudin, K.; Lespes, G.; Battu, S. Biomaterials for three-dimensional cell culture: From applications in oncology to nanotechnology. Nanomaterials 2021, 11, 481. [CrossRef] [PubMed]

255. Fritsche, E.; Haarmann-Stemmann, T.; Kapr, J.; Galanjuk, S.; Hartmann, J.; Mertens, P.R.; Kämpfer, A.A.M.; Schins, R.P.F.; Tigges, J.; Koch, K. Stem cells for next level toxicity testing in the 21st century. Small 2021, 17, 2006252. [CrossRef]

256. Vardakas, P.; Skaperda, Z.; Tekos, F.; Trompeta, A.F.; Tsatsakis, A.; Charitidis, C.A.; Kouretas, D. An integrated approach for assessing the in vitro and in vivo redox-related effects of nanomaterials. Environ. Res. 2021, 197, 111083. [CrossRef] [PubMed]

257. Khorrami, M.B.; Sadeghnia, H.R.; Pasdar, A.; Ghayour-Mobarhan, M.; Riahi-Zanjani, B.; Hashemzadeh, A.; Zare, M.; Darroudi, M. Antioxidant and toxicity studies of biosynthesized cerium oxide nanoparticles in rats. Int. J. Nanomed. 2019, 14, 2915-2926. [CrossRef]

258. Srinivas, A.; Rao, P.J.; Selvam, G.; Murthy, P.B.; Reddy, P.N. Acute inhalation toxicity of cerium oxide nanoparticles in rats. Toxicol. Lett. 2011, 205, 105-115. [CrossRef]

259. Yazdimamaghani, M.; Moos, P.J.; Dobrovolskaia, M.A.; Ghandehari, H. Genotoxicity of amorphous silica nanoparticles: Status and prospects. Nanomed. Nanotechnol. Biol. Med. 2019, 16, 106-125. [CrossRef]

260. Chen, F.; Hong, H.; Zhang, Y.; Valdovinos, H.F.; Shi, S.; Kwon, G.S.; Theuer, C.P.; Barnhart, T.E.; Cai, W. In vivo tumor targeting and image-guided drug delivery with antibody-conjugated, radiolabeled mesoporous silica nanoparticles. ACS Nano 2013, 7, 9027-9039. [CrossRef] [PubMed]

261. Cho, M.; Cho, W.-S.; Choi, M.; Kim, S.J.; Han, B.S.; Kim, S.H.; Kim, H.O.; Sheen, Y.Y.; Jeong, J. The impact of size on tissue distribution and elimination by single intravenous injection of silica nanoparticles. Toxicol. Lett. 2009, 189, 177-183. [CrossRef] [PubMed]

262. Asefa, T.; Tao, Z. Biocompatibility of mesoporous silica nanoparticles. Chem. Res. Toxicol. 2012, 25, 2265-2284. [CrossRef]

263. Liu, T.-P.; Wu, S.-H.; Chen, Y.-P.; Chou, C.-M.; Chen, C.-T. Biosafety evaluations of well-dispersed mesoporous silica nanoparticles: Towards in vivo-relevant conditions. Nanoscale 2015, 7, 6471-6480. [CrossRef]

264. Guo, C.; Liu, Y.; Li, Y. Adverse effects of amorphous silica nanoparticles: Focus on human cardiovascular health. J. Hazard. Mater. 2021, 406, 124626-124646. [CrossRef]

265. Som, C.; Nowack, B.; Krug, H.F.; Wick, P. Toward the development of decision supporting tools that can be used for safe production and use of nanomaterials. Acc. Chem. Res. 2013, 46, 863-872. [CrossRef] [PubMed]

266. Zhao, X.; Wei, S.; Li, Z.; Lin, C.; Zhu, Z.; Sun, D.; Bai, R.; Qian, J.; Gao, X.; Chen, G. Autophagic flux blockage in alveolar epithelial cells is essential in silica nanoparticle-induced pulmonary fibrosis. Cell Death Dis. 2019, 10, 127-143. [CrossRef]

267. Li, Y.; Ma, R.; Liu, X.; Qi, Y.; Abulikemu, A.; Zhao, X.; Duan, H.; Zhou, X.; Guo, C.; Sun, Z. Endoplasmic reticulum stress-dependent oxidative stress mediated vascular injury induced by silica nanoparticles in vivo and in vitro. NanoImpact 2019, 14, 100169. [CrossRef]

268. Zhang, X.; Luan, J.; Chen, W.; Fan, J.; Nan, Y.; Wang, Y.; Liang, Y.; Meng, G.; Ju, D. Mesoporous silica nanoparticles induced hepatotoxicity via NLRP3 inflammasome activation and caspase-1-dependent pyroptosis. Nanoscale 2018, 10, 9141-9152. [CrossRef] [PubMed]

269. Chen, X.; Zhouhua, W.; Jie, Z.; Xinlu, F.; Jinqiang, L.; Yuwen, Q.; Zhiying, H. Renal interstitial fibrosis induced by high-dose mesoporous silica nanoparticles via the NF- KB signaling pathway. Int. J. Nanomed. 2015, 10, 1-22. [CrossRef] [PubMed]

270. You, R.; Ho, Y.-S.; Hung, C.H.-L.; Liu, Y.; Huang, C.-X.; Chan, H.-N.; Ho, S.-L.; Lui, S.-Y.; Li, H.-W.; Chang, R.C.-C. Silica nanoparticles induce neurodegeneration-like changes in behavior, neuropathology, and affect synapse through MAPK activation. Part. Fibre Toxicol. 2018, 15, 28-46. [CrossRef]

271. Chen, L.; Liu, J.; Zhang, Y.; Zhang, G.; Kang, Y.; Chen, A.; Feng, X.; Shao, L. The toxicity of silica nanoparticles to the immune system. Nanomedicine 2018, 13, 1939-1962. [CrossRef]

272. Zhang, L.; Wei, J.; Duan, J.; Guo, C.; Zhang, J.; Ren, L.; Liu, J.; Li, Y.; Sun, Z.; Zhou, X. Silica nanoparticles exacerbates reproductive toxicity development in high-fat diet-treated Wistar rats. J. Hazard. Mater. 2020, 384, 121361. [CrossRef]

273. Rahdar, A.; Aliahmad, M.; Hajinezhad, M.R.; Samani, M. Xanthan gum-stabilized nano-ceria: Green chemistry based synthesis, characterization, study of biochemical alterations induced by intraperitoneal doses of nanoparticles in rat. J. Mol. Struct. 2018, 1173, 166-172. [CrossRef]

274. Zhang, Z.; Zhang, Y.; Liu, H.; Wang, J.; Wang, D.; Deng, Z.; Li, T.; He, Y.; Yang, Y.; Zhong, S. A water-soluble selenium-enriched polysaccharide produced by Pleurotus ostreatus: Purification, characterization, antioxidant and antitumor activities in vitro. Int. J. Biol. Macromol. 2021, 168, 356-370. [CrossRef] [PubMed]

275. Sandhir, R.; Yadav, A.; Sunkaria, A.; Singhal, N. Nano-antioxidants: An emerging strategy for intervention against neurodegenerative conditions. Neurochem. Int. 2015, 89, 209-226. [CrossRef] 
276. Morry, J.; Ngamcherdtrakul, W.; Yantasee, W. Oxidative stress in cancer and fibrosis: Opportunity for therapeutic intervention with antioxidant compounds, enzymes, and nanoparticles. Redox Biol. 2017, 11, 240-253. [CrossRef]

277. Li, C.; Li, L.; Chen, S.; Zhang, J.; Lu, W. Antioxidant Nanotherapies for the Treatment of Inflammatory Diseases. Front. Bioeng. Biotechnol. 2020, 8, 200. [CrossRef]

278. Rout, G.K.; Shin, H.; Gouda, S.; Sahoo, S.; Das, G.; Fraceto, L.F.; Patra, J.K. Current advances in nanocarriers for biomedical research and their applications. Artif. Cells Nanomed. Biotechnol. 2018, 46, S1053-S1062. [CrossRef] [PubMed]

279. Tamang, J.S.; Borbora, H.; Sutar, A.; Dhar, R.S.; Chatterjee, S. Influence of design parameters on multilayered nanoplasmonic structures in modified Kretschmann-Raether configurations. Plasmonics 2020, 15, 1133-1140. [CrossRef]

280. Suzen, S.; Gurer-Orhan, H.; Saso, L. Detection of reactive oxygen and nitrogen species by electron paramagnetic resonance (EPR) technique. Molecules 2017, 22, 181. [CrossRef]

281. Kim, S.-U.; Liu, Y.; Nash, K.M.; Zweier, J.L.; Rockenbauer, A.; Villamena, F.A. Fast reactivity of a cyclic nitrone- calix [4] pyrrole conjugate with superoxide radical anion: Theoretical and experimental studies. J. Am. Chem. Soc. 2010, 132, 17157-17173. [CrossRef] [PubMed]

282. Shulaev, V.; Oliver, D.J. Metabolic and proteomic markers for oxidative stress. New tools for reactive oxygen species research. Plant. Physiol. 2006, 141, 367-372. [CrossRef] [PubMed]

283. Mitchell, D.G.; Rosen, G.M.; Tseitlin, M.; Symmes, B.; Eaton, S.S.; Eaton, G.R. Use of rapid-scan EPR to improve detection sensitivity for spin-trapped radicals. Biophys. J. 2013, 105, 338-342. [CrossRef]

284. Hanthorn, J.J.; Haidasz, E.; Gebhardt, P.; Pratt, D.A. A versatile fluorescence approach to kinetic studies of hydrocarbon autoxidations and their inhibition by radical-trapping antioxidants. Chem. Commun. 2012, 48, 10141-10143. [CrossRef]

285. Hay, K.X.; Waisundara, V.Y.; Timmins, M.; Ou, B.; Pappalardo, K.; McHale, N.; Huang, D. High-throughput quantitation of peroxyl radical scavenging capacity in bulk oils. J. Agric. Food Chem. 2006, 54, 5299-5305. [CrossRef]

286. Jodko-Piórecka, K.; Litwinienko, G. Antioxidant activity of dopamine and L-DOPA in lipid micelles and their cooperation with an analogue of $\alpha$-tocopherol. Free Radic. Biol. Med. 2015, 83, 1-11. [CrossRef]

287. Mengele, E.A.; Plashchina, I.G.; Kasaikina, O.T. Kinetics of lecithin oxidation in liposomal aqueous solutions. Colloid J. 2011, 73, 815-821. [CrossRef]

288. Pacioni, N.L.; Filippenko, V.; Presseau, N.; Scaiano, J.C. Oxidation of copper nanoparticles in water: Mechanistic insights revealed by oxygen uptake and spectroscopic methods. Dalt. Trans. 2013, 42, 5832-5838. [CrossRef] [PubMed]

289. Morais, T.; Soares, M.E.; Duarte, J.A.; Soares, L.; Maia, S.; Gomes, P.; Pereira, E.; Fraga, S.; Carmo, H.; de Lourdes Bastos, M. Effect of surface coating on the biodistribution profile of gold nanoparticles in the rat. Eur. J. Pharm. Biopharm. 2012, 80, 185-193. [CrossRef] [PubMed]

290. Tournebize, J.; Sapin-minet, A.; Bartosz, G.; Leroy, P. Pitfalls of assays devoted to evaluation of oxidative stress induced by inorganic nanoparticles. Talanta 2013, 116, 753-763. [CrossRef]

291. Huguet-Casquero, A.; Gainza, E.; Pedraz, J.L. Towards green nanoscience: From extraction to nanoformulation. Biotechnol. Adv. 2021, 46, 107657. [CrossRef] 